Universidade de São Paulo

Escola de Engenharia de São Carlos

\title{
Influência das frequências de ride no conforto e dirigibilidade veiculares na faixa linear de uso do veículo
}

Francisco Ganzarolli 
Universidade de São Paulo

Escola de Engenharia de São Carlos

Departamento de Engenharia Mecânica

\title{
Influência das frequências de ride no conforto e dirigibilidade veiculares na faixa linear de uso do veículo
}

\author{
Autor: Francisco Ganzarolli \\ Orientador: Prof. Dr. Álvaro Costa Neto
}

Dissertação apresentada a Escola de Engenharia de São Carlos da Universidade de São Paulo, como parte dos requisitos para a obtenção do título de Mestre em Engenharia Mecânica.

\begin{tabular}{llrrr|}
\hline ESTE EXEMPLAR & É & A & VERSÃO \\
CORRIGIDA, A VERSÃO & ORIGINAL & SE \\
ENCONTRA & DISPONÍVEL & JUNTO & AO \\
DEPARTAMENTO & DE & ENGENHARIA \\
\hline
\end{tabular}

São Carlos 
AUTORIZO A REPRODUÇÃO E DIVULGAÇÃO TOTAL OU PARCIAL DESTE TRABALHO, POR QUALQUER MEIO CONVENCIONAL OU ELETRÔNICO, PARA FINS DE ESTUDO E PESQUISA, DESDE QUE CITADA A FONTE.

Ficha catalográfica preparada pela Seção de Tratamento da Informação do Serviço de Biblioteca - EESC/USP

Ganzarolli, Francisco

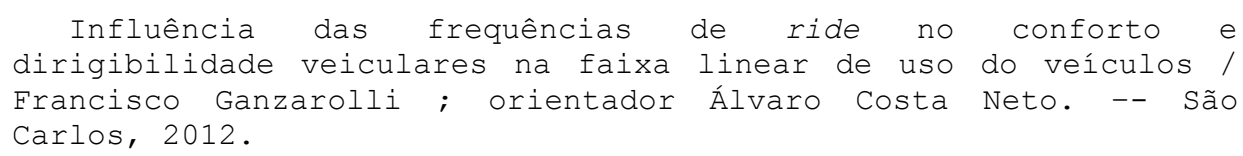

1. Dinâmica veicular 2. Conforto. 3. Estabilidade. 4. 5. Frequências. 6. Ride. 7. Handling. 8. Dirigibilidade. 9. Molas. 10. Amortecedores. 11. Suspensão. 12. Batentes. 13. Atributos veiculares. I. Título. 


\section{FOLHA DE JULGAMENTO}

Candidato: Engenheiro FRANCISCO GANZAROLLI.

Título da dissertação: "Influência das freqüências de ride no conforto e dirigibilidade veiculares na faixa linear de uso do veículo".

Data da defesa: 03/07/2012

Comissão Julgadora:

Prof. Dr. Álvaro Costa Neto (Orientador)

(Escola de Engenharia de São Carlos/EESC)

Prof. Dr. Cláudio Gomes Fernandes

(Universidade Paulista/UNIP)

Prof $^{\mathrm{a}}$. Dr ${ }^{\mathrm{a}}$. Maira Martins da Silva

(Escola de Engenharia de São Carlos/EESC)
Resultado:

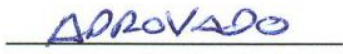

APROVADO

APROVADO

Coordenador do Programa de Pós-Graduação em Engenheira Mecânica:

Prof. Associado Marcelo Areias Trindade

Presidente da Comissão de Pós-Graduação:

Prof. Titular Denis Vinicius Coury 


\section{Agradecimentos}

A Ford Motor Company Ltda pelos trabalhos em Dinâmica veicular

A General Motors do Brasil pelos trabalhos em Dinâmica veicular

Ao Prof. Ricardo de Andrade Bock pela amizade

Ao Prof. Dr. Claudio Gomes Fernandes pela amizade e conhecimento matemático

Ao Prof. Dr. Álvaro Costa Neto pela amizade e orientação nesta dissertação

A minha família pelo apoio.

A Deus, acima de tudo e todos. 
"Si vis pacem, para bellum" Publius Flavius Vegetius Renatus 


\section{Resumo}

GANZAROLLI, F. (2012). Influência das freqüências de ride no conforto e dirigibilidade veiculares na faixa linear de uso do veículo. São Carlos (2012), Dissertação (mestrado) Escola de Engenharia de São Carlos, Universidade de São Paulo.

O tema do conforto na automobilística é bastante extenso e possuidor de muitas interpretações. A ideia central deste trabalho é definir e direcionar alguns métricos para que, durante as fases de conceituação e desenvolvimento de um veículo, seja possível ter um direcional de definição de componentes e atributos veiculares de modo a facilitar o direcionamento dos atributos no programa veicular, e assim atingir suas necessidades. Como exemplo empregado, é empregado um veículo de plataforma tipo B em desenvolvimento por uma montadora, o qual teve as molas de suspensão definidas e rigidezes laterais de eixos com base em material técnico interno equivalente aos estudos apresentados neste trabalho. É adotada uma abordagem inicialmente empírica conforme os primeiros estudos de suspensões independentes realizados neste continente, depois o trabalho é complementado com exigências de normas especificas para vibrações (ISO2361, ISO5008, BS6055) de modo a caracterizar energia vibracional e a interpretação pelo ser humano. Porém como hoje em dia as suspensões automotivas são muito mais complexas, existem componentes específicos para as várias condições de solicitação, deste modo a análise é limitada a situações de ride (conforto) primário e handling (dirigibilidade) em situações de sublimite na faixa linear (cerca de $0,5 \mathrm{~g}$ ). Como conclusão dos estudos, é possível ter em um veículo atributos de estabilidade sem necessariamente prejudicar o conforto, pois sendo definidos corretamente os componentes elásticos da dinâmica vertical para situações estacionárias e de ride primário, é definido seu equilíbrio estacionário e assim não é necessário comprometimento dos atributos de outros componentes para compensar alguma deficiência existente.

Palavras chave: Conforto, estabilidade, Dinâmica veicular, frequências, ride, handling, dirigibilidade, molas, amortecedores, suspensão, batentes, atributos veiculares, 


\begin{abstract}
GANZAROLLI, F. (2012). Influence of ride frequencies in vehicle comfort and stability at linear range of driving. São Carlos (2012), Dissertation (master degree) - Engineering School of SãoCarlos, SãoPaulo University.
\end{abstract}

The range of assumptions for ride comfort is considered very wide in the automotive world and they can assume lots of possible interpretations. The central idea in this work is define and manage some metrics that, during the concept and development phases of a vehicular program, be possible to follow a better direction for the attributes development and so reach the program targets. As the example in this work, a B platform typical vehicle is used and it is under development in a carmaker, its suspension springs and axle roll stiffness were setup with technical information similar to the ones presented in this work. The initial approach is empiric as occurred with the first independent suspension system studies in this continent and in the sequence, the work is complemented with standards for vibrational issues (ISO2361, ISO5008, BS6055), after this, finally how the vibrational energy is defined and perceived by human beings. The automotive suspensions of current days are very complex and there are lots of specific components to do a specific work, so the analysis are limited to primary ride and sub limit handling (up to $0,5 \mathrm{~g}$ ). As conclusion, its possible setup a car that is comfortable and stable in the same time, since the elastic components for the vertical dynamics and steady state conditions are correctly set, so its correct balance is reached and no other components attributes are compromised to compensate any deficiency.

Key-words: Comfort, stability, Vehicle dynamics, frequencies, ride, handling, drivability, springs, shock absorbers, suspension, jounce bumpers, vehicle attributes. 


\section{Índice de figuras}

Figura 1 - Imagem do paradigma comumente aceito para os atributos de dinâmica veicular (autor) .... 2

Figura 2 - Modelo do direcional que melhor retrata os atributos discutidos (autor) 2

Figura 3 - Observação sobre consumidores e veículos (autor) 3

Figura 4 - Fotos tiradas de veículos em teste em estradas brasileiras (Quatro Rodas, maio 1974, p54). 4

Figura 5 - Conceito de válvula "regressiva" em amortecedores (Penske, divulgação) ........................... 5

Figura 6 - Exemplos de curvas de amortecimento em válvula regressiva (Racecar Engineering, 2009, $\mathrm{p} 48)$ 6

Figura 7 - Imagem sobre a área de interesse deste trabalho (autor) ….................................................. 7

Figura 8 - Exemplo das prioridades de diversas áreas quanto ao produto carro (autor) .......................... 7

Figura 9 - Sistema de eixos normalizados SAE (SAE-J670) ............................................................ 9

Figura 10 - Conceito do veículo "K² rig" baseado em um Cadillac limousine ..................................... 11

Figura 11 - Representação da definição de centro de mola e centro de rigidez (MILLIKEN, 2002,

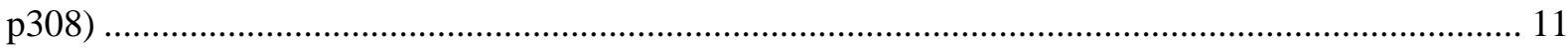

Figura 12 - Sistema de eixos normalizados para pneus da SAE (MILLIKEN, 1995, p.62) ................. 17

Figura 13 - Modelo da bicicleta para 2 graus de liberdade (MILLIKEN, 1995, p127) ........................ 18

Figura 14 - Exemplo de sistema massa mola amortecedor (MILLIKEN, 1995, p.235) ....................... 19

Figura 15 - Exemplo em gráfico de transmissibilidade do piso para o motorista (autor) ...................... 21

Figura 16 - Comportamento qualitativo das molas (Dixon, 1999, p133)........................................... 23

Figura 17 - Loop qualitativo para conforto e estabilidade (Dixon, 1999, p133) ................................... 24

Figura 18 - Interações da dinâmica veicular (BLUNDEL, 2004, p.3) ................................................. 25

Figura 19 - Representação do exemplo de cinemática planar (Ranejat, 1998, P46) ............................ 27

Figura 20 - Representação do modelo de veículo e ângulos de escorregamentos dos pneus

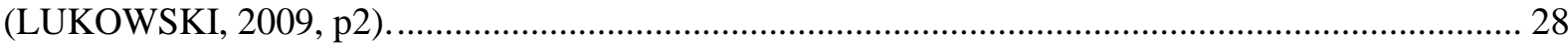

Figura 21 - Curva de escorregamento do pneu conforme autores (LUKOWSKI, 2008, p4) ............... 29

Figura 22 - Sistema mecânico representando o corpo humano sujeito a vibração vertical (Balbinot,

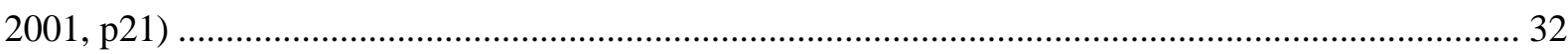

Figura 23 - Representação de típica curva de escorregamento de pneus (Milliken, 1995, p25) ............ 37

Figura 24 - Rigidezes de mola e batente de suspensão (autor)............................................................ 37

Figura 25 - Gráfico de força lateral em função da cambagem de um pneu (MILLIKEN, 1995, p49).. 38

Figura 26 - Exemplo de curva de cambagem e uma suspensão tipo McPherson (autor)...................... 39

Figura 27 - Conceito cinemático de eixo instantâneo (MILLKEN, 1995, p613) ................................... 39

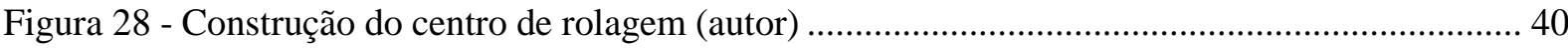

Figura 29 - Meio diagrama de circulo de atrito (Milliken, 1995, p58) ……......................................... 41

Figura 30 - Exemplo de protótipo de "pneu" executado com molas ...................................................... 42

Figura 31 - Representação de quarto de carro de suspensão e pneu ....................................................... 42 
Figura 32 - Influências dos eventos de ride/handling nas suspensões (autor) ...................................... 43

Figura 33 - Estados do movimento em uma curva (autor) .................................................................... 44

Figura 34 - Representação do modelo da bicicleta (Milliken, 1995, p131) ........................................... 45

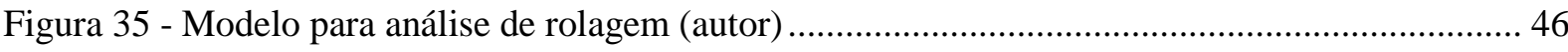

Figura 36 - Veículo apresentando maior ângulo de rolagem na dianteira........................................... 47

Figura 37 - Veículo apresentando maior ângulo de rolagem na traseira .............................................. 47

Figura 38 - Modelo da bicicleta considerando influência do CG......................................................... 48

Figura 39 - Característica de subesterço pra o exemplo do modelo de bicicleta (Milliken, 1995, p139)

Figura 40 - Geometria base para transferência de carga lateral (Milliken, 1995, p681) ....................... 52

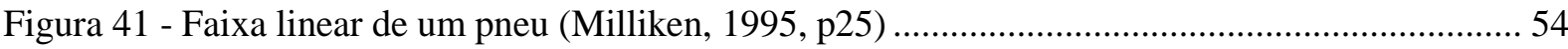

Figura 42 - Sistema massa-mola-amortecedor ((Milliken, 1995, p235) ……....................................... 56

Figura 43 - Resposta transiente para tipos de amortecimento (Milliken, 1995, p238)......................... 57

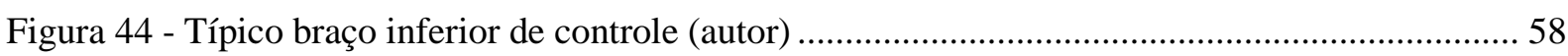

Figura 45 - Aumento do torque de esforço na direção em função do ângulo de esterço ....................... 59

Figura 46 - Resposta de rotação (veículo) em função da frequência do esterço .................................... 59

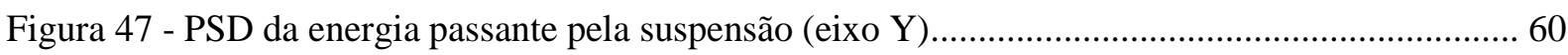

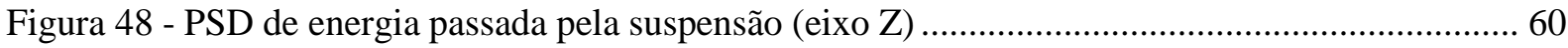

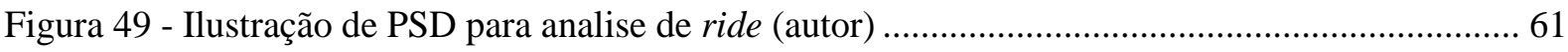

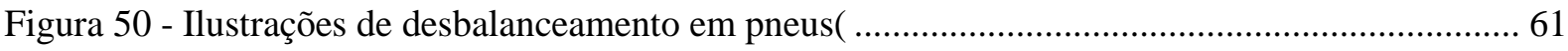

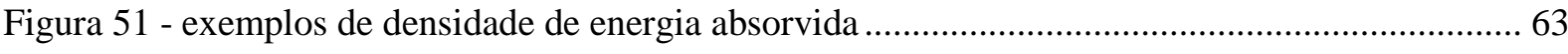

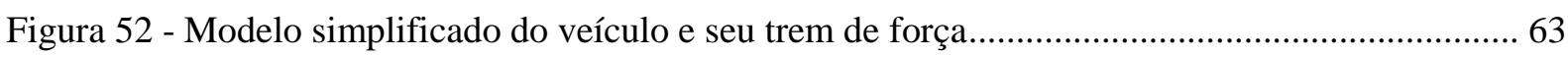

Figura 53 - Ilustração do DMS empregado na F1 para melhoria de aderência (site Formula1, julho

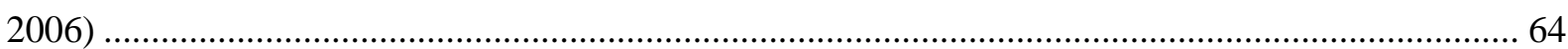

Figura 54 - Diferentes interpretações dos tipos de vibração em veículos ............................................. 66

Figura 55 - Orientação normalizada conforme ISO2631-1, 1997 ....................................................... 69

Figura 56 - Exemplo da comparação dos limites da norma ISO com valores medidos (Hansson, et

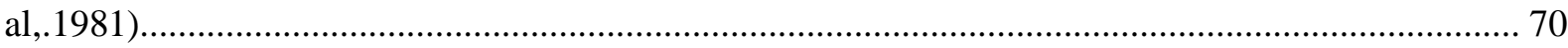

Figura 57 - Limites para conforto e fadiga em terço de oitava para eixo Z (ISO2631) ........................ 71

Figura 58 - Limites para conforto e fadiga em terço de oitava para eixo X e Y ISO2631) ................... 71

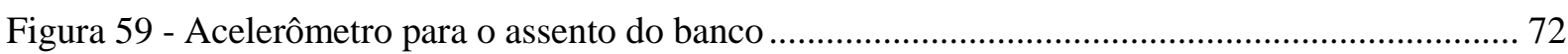

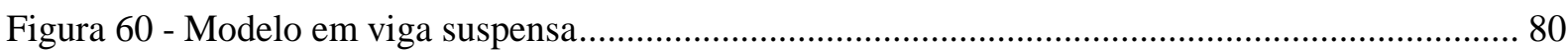

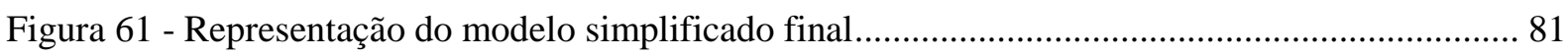

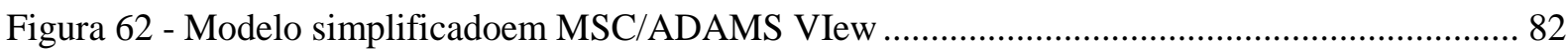

Figura 63 - Detalhes do modelo simplificado(vista lateral) ……......................................................... 83

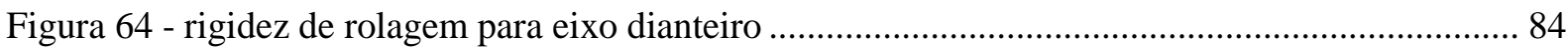

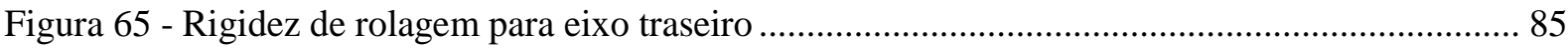


Figura 66 - Ilustração para instalação de acelerômetro de banco

Figura 67 - PSD resultante de aquisição de energia de ride primário..................................................... 90

Figura 68 - Ilustração das oscilações das suspensões e suas descrições ................................................ 91

Figura 69 - Imagem de pistas empregadas (ride primário) ..................................................................... 92

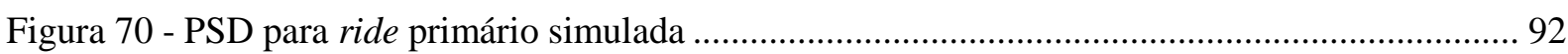

Figura 71 - Ilustração da oscilação resultante para ride ....................................................................... 94

Figura 72 - Representação de modelo simplificado para análise de vibrações e trem de força ............ 97

Figura 73 - PSD gerada a partir de valores de aceleração no bando do motorista ................................. 97

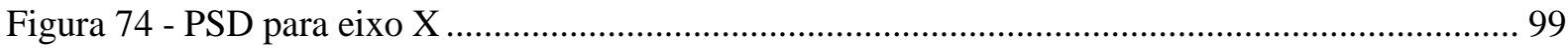

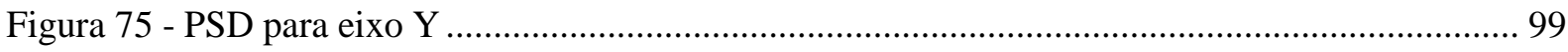

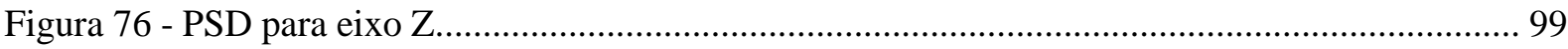

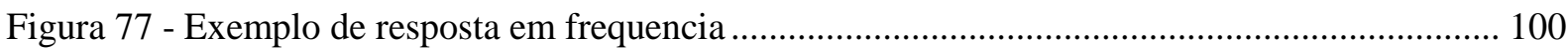

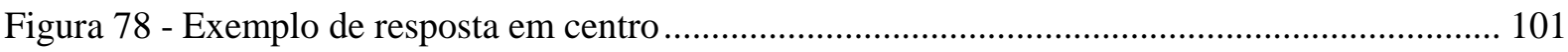

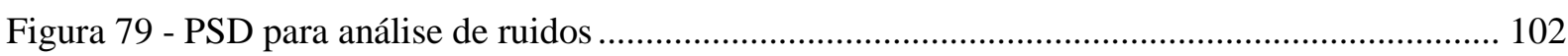

Figura 80 - Quantia de energia em faixa de ride secundário......................................................... 103

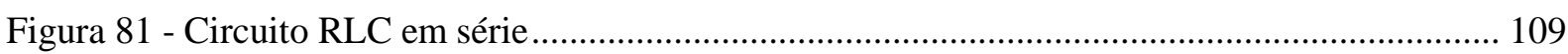

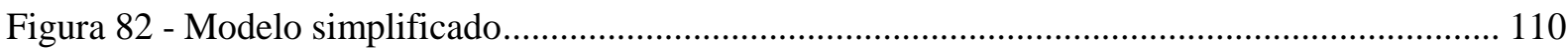

Figura 83 - Efeito do DMS num modelo simplificado de motor ...................................................... 111

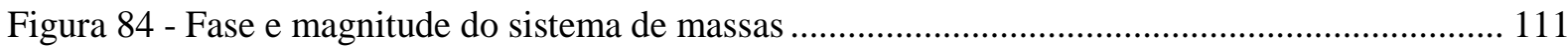

Figura 85 - Instalação de DMS em bico de carro de Formula1........................................................... 112

Figura 86 - Um dos primeiros sistemas de amortecedores a ser empregado em veículo ..................... 113

Figura 87 - Exemplo de modelo de quarto de carro ........................................................................... 114

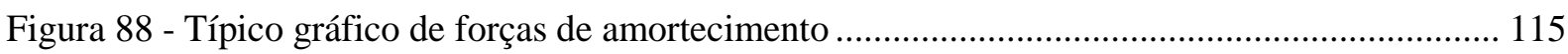

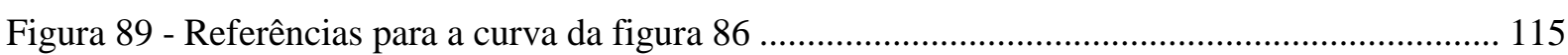

Figura 90 - Referência de manobras e entradas para a suspensão veicular........................................ 116

Figura 91 - Exemplo de PSD das harmônicas em uma suspensão ...................................................... 117 


\section{Índice de tabelas}

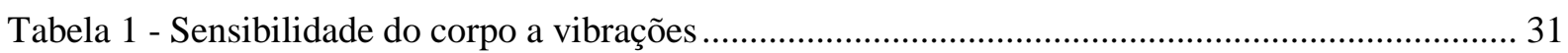

Tabela 2 - Referências para faixas de acelerações no corpo humano ................................................... 72

Tabela 3 - Comparativo das frequências de ride avaliadas(eixo dianteiro)........................................... 85

Tabela 4 - Comparativo das frequências de ride avaliadas(eixo traseiro) ............................................. 85

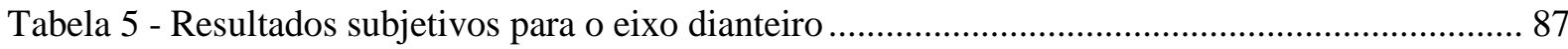

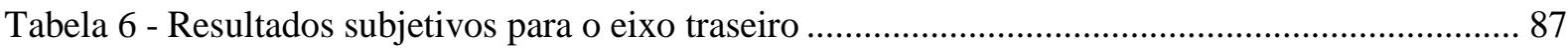

Tabela 7 - Referencia subjetiva para comparação com aquisição.......................................................... 89

Tabela 8 - Valores de referência para percepção de ride ....................................................................... 91

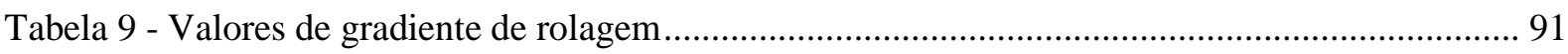

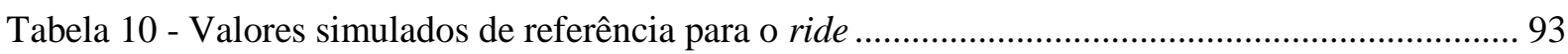

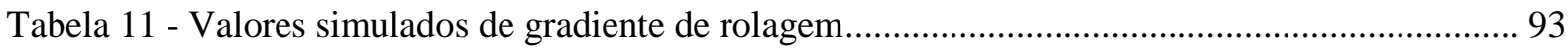




\section{Lista de símbolos}

A - Suspensão dianteira (no centro da roda)

Ay - Aceleração lateral (g)

B - Suspensão traseira (no centro da roda)

$\mathrm{C}$ - centro de mola, coeficiente de amortecimento

C - Capacitância do capacitor

$\mathrm{F}_{\text {roll }}$ - Frequência natural à rolagem do veículo

$\mathrm{G}-\mathrm{CG}$ da massa suspensa

H - Distância do CG ao eixo de rolagem

I - Corrente da fonte de força

$\mathrm{I}_{\mathrm{zz}}-$ Momento de inercia no eixo $\mathrm{z}$ do veículo

$\mathrm{I}_{\mathrm{B}}-$ Momento de inércia da barra

$I_{b}$ - Relação de instalação da barra estabilizadora

$L$ - Braço de alavanca da barra estabilizadora

L - Indutância do indutor

$\mathrm{K}_{\mathrm{R} 1}$ - valor típico de rigidez de mola para conforto

$\mathrm{K}_{\mathrm{R} 2}$ - valor típico de rigidez de mola para estabilidade

$\mathrm{K}_{\text {res }}-$ Rigidez resultante

$\mathrm{K}_{1 \mathrm{r}}-$ Rigidez vertical do pneu

$\mathrm{K}_{2 \mathrm{r}}$ - Rigidez da mola da suspensão

$\mathrm{K}_{\mathrm{F}}-$ Rigidez de rolagem do eixo dianteiro

$\mathrm{K}_{\mathrm{R}}$ - Rigidez de rolagem do eixo traseiro

$\mathrm{K}_{\mathrm{roll}}$ - Constante elástica quanto em movimento de rolagem

$\mathrm{K}_{\varnothing}$ - Rigidez de rolagem do veículo

$K_{w}-$ Rigidez efetiva aproximada na roda

$K_{b}$ - Rigidez da barra estabilizadora

$\mathrm{M}_{\mathrm{d} \rightarrow \mathrm{t}}$ - Proporção entre deslocamentos dos eixos traseiro e dianteiro

$\mathrm{P}$ - Centro de oscilação dianteiro (arfagem)

Q - Centro de oscilação traseiro (oscilação de carroceria)

$\mathrm{Q}_{\mathrm{R}}$ - nota subjetiva para qualificação de conforto

$\mathrm{Q}_{\mathrm{H}}$ - nota subjetiva para qualificação de estabilidade

$\mathrm{R}$ - Resistência do resistor

$\mathrm{RMS}_{\text {diant }}$ - Valor RMS do deslocamento no eixo dianteiro 
$\mathrm{RMS}_{\text {tras }}$ - Valor RMS do deslocamento no eixo traseiro

$\mathrm{T}$ - Duração da medição realizada (em segundos), espaço de probabilidade

$T-$ Bitola

V- Tensão da fonte de força

$V$ - Velocidade translacional do corpo

W - Peso do veículo

$\mathrm{W}_{\mathrm{UF}}-$ Massa não suspensa dianteira, na altura

$\mathrm{W}_{\mathrm{UR}}-$ Massa não suspensa traseira, na altura

$\mathrm{W}_{\mathrm{S}}$ - Peso da massa suspensa, na altura $\mathrm{h}_{\mathrm{S}}$ e perpendicular a distância $\mathrm{h}_{2}$ da NRA

$\mathrm{W}$ - Peso total do veículo na altura h e distancia vertical H do NRA

$\mathrm{Z}_{\mathrm{RF}}, \mathrm{Z}_{\mathrm{RR}}$ - Alturas dos centros de rolagem dianteiro e traseiro

a - Distância do eixo dianteiro ao CG

ay - Aceleração lateral

b - Distância do eixo traseiro ao CG

$\mathrm{c}$ - coeficiente de amortecimento

$e-$ Vetor posição

$f, f_{n}$ - frequência natural

$\mathrm{g}$ - aceleração da gravidade

$k$ - Raio de giração da massa suspensa pelo CG

$\mathrm{k}$ - constante elástica da mola

$k_{\theta B}-$ Rigidez torcional barra estabilizadora

$k_{\emptyset B}$ - Contribuição da rigidez da barra estabilizadora à rigidez total do veículo

$k_{I B}-$ Rigidez torcional da barra estabilizadora

1 - Entreeixos do veículo

$\mathrm{m}$ - massa do corpo

$\mathrm{t}$ - tempo

$t_{\mathrm{F}}$ - Bitola dianteira

$t_{R}$ - Bitola traseira

$u$ - componente da velocidade translacional

$v$-componente da velocidade translacional

$\mathrm{x}$ - deslocamento

$\mathrm{Z}_{\mathrm{RF}}-$ Distância do roll center dianteiro ao solo

$\mathrm{Z}_{\mathrm{RR}}$ - Distância do roll center traseiro ao solo

$\alpha$ - aceleração

$\alpha_{1}$ - Ângulo de escorregamento

$\alpha_{F}-$ Ângulo de escorregamento dianteiro 
$\alpha_{R}$ - Ângulo de escorregamento traseiro

$\alpha_{w}$ - aceleração compensada em função do tempo em $\left[\mathrm{m} / \mathrm{s}^{2}\right]$

$\theta$ - Inclinação do eixo de rolagem neutro (radianos)

$\theta_{\text {roll }}$ - Inercia do veículo à rolagem

$\varnothing$ - Ângulo de rolagem

$\varnothing$ - Rotação infinitesimal

$\xi$ - Constante de amortecimento

$\mu$ - Uma medida no espaço de probabilidade

$\vartheta$ - Tensão em um circuito RLC

$\omega$ - Velocidade angular 


\section{Índice geral}

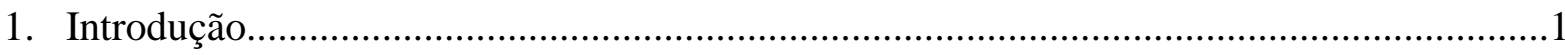

1.1. Motivação: O problema do compromisso entre conforto e estabilidade.......................1

1.2. Análise: Mercados emergentes e de primeiro mundo - Perfil de usuário........................3

1.3. Análise: Conceitos de estabilidade e conforto............................................................

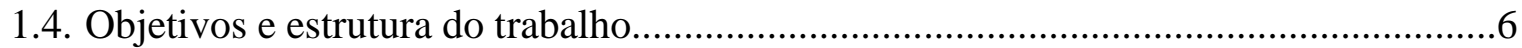

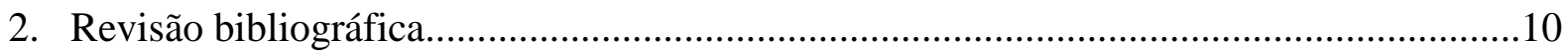

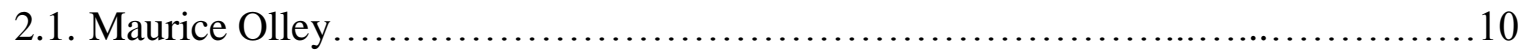

2.2. Homer S. Roswell e James J. Guest.............................................................................11

2.3. William F. Milliken.................................................... 15

2.3.1. Estudos relacionados ao conforto, o ride .........................................................16

2.3.2. Estudos relacionados à estabilidade, o handling...........................................17

2.3.2.1.Comportamento dos pneus..................................................................... 17

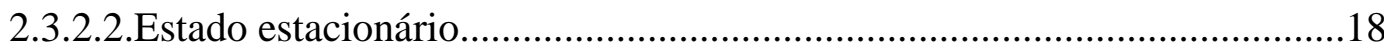

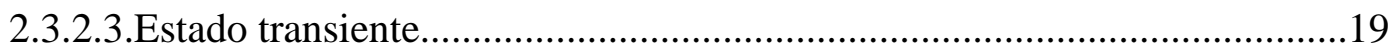

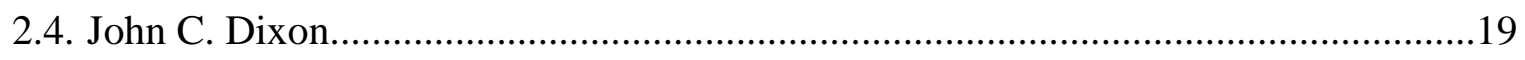

2.4.1. Análise de ride em função do tempo............................................................20

2.4.2. Análise de ride em função da freqüência........................................................20

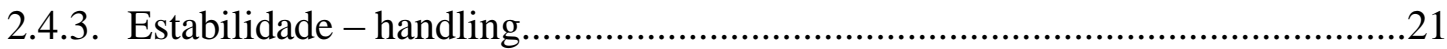

2.4.4. Compromisso entre conforto e estabilidade...................................................22

2.5. Michael Blundell and Damian Harty.......................................... 25

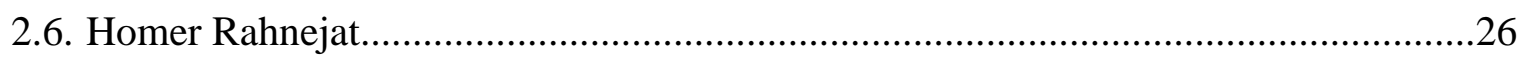

2.7. Teoria linear básica de estabilidade e dirigibilidade do automóvel.............................28

2.8. Caracterização dos níveis de vibração..........................................................................30

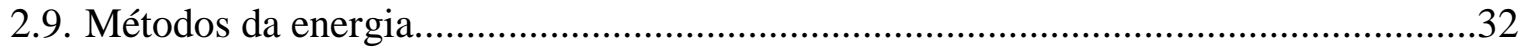

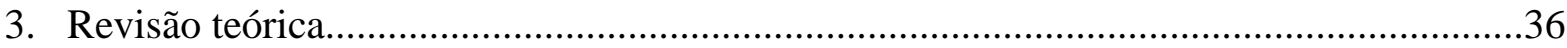

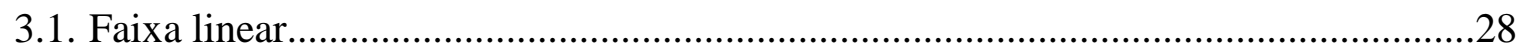

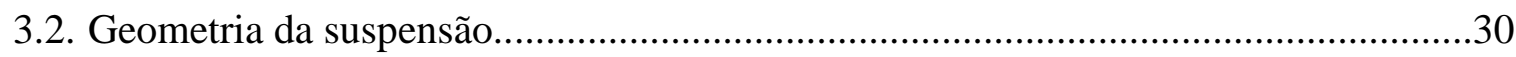

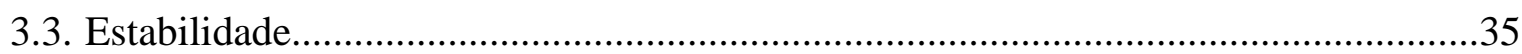

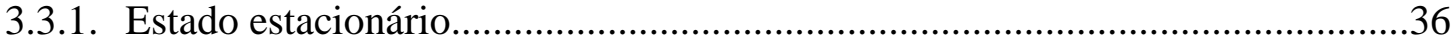

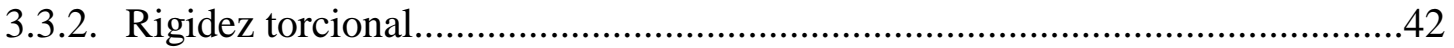




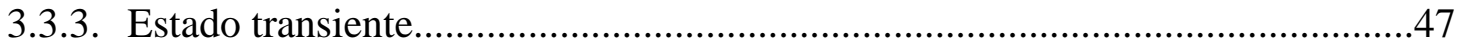

3.3.4. Precisão e estabilidade direcional.................................................................50

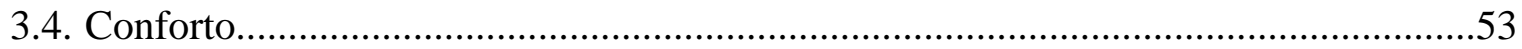

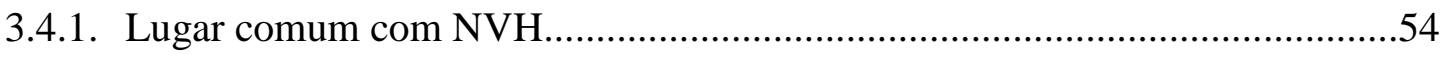

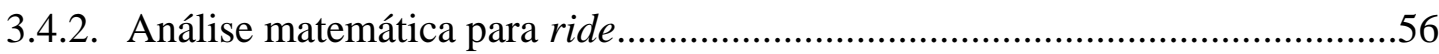

3.5. Métodos de energia, as equações de lagrange...........................................................73

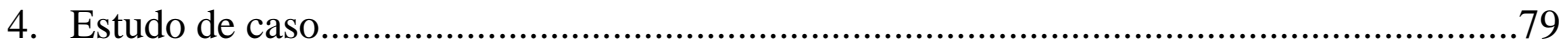

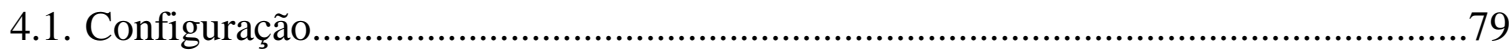

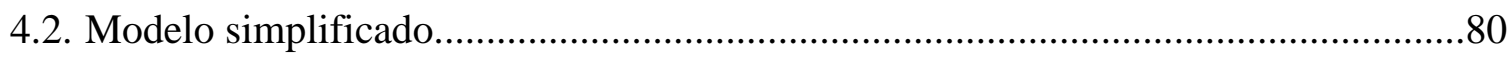

4.3. Conceitos iniciais e avaliações subjetivas.............................................................. 86

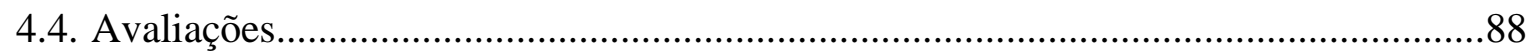

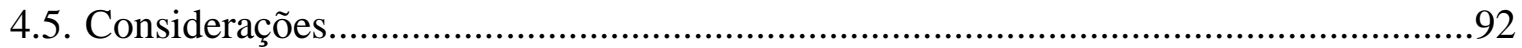

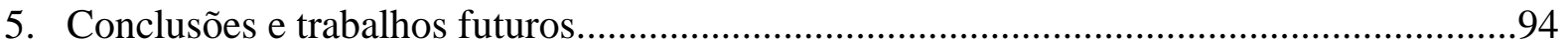

5.1. Comentários iniciais devidos ao escopo da dissertação.............................................94

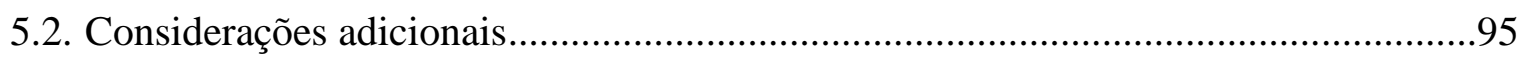

5.2.1. Vibrações e asperezas do trem de força...........................................................96

5.2.2. Buchas do sistema de suspensão...................................................................98

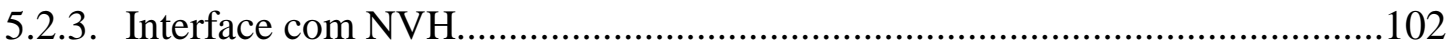

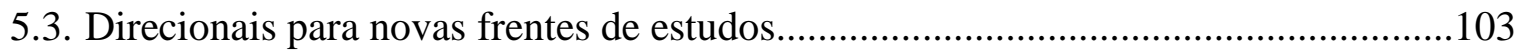

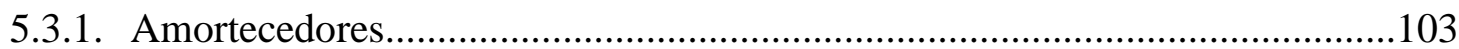

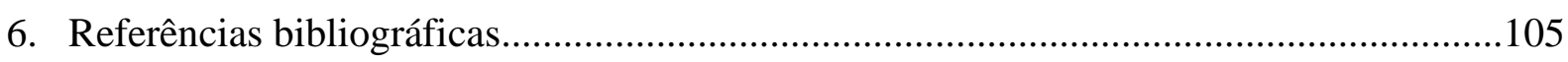

Apêndices

Apêndice A - Vibrações do trem de força e a Dinâmica veicular..............................109

Apêndice B - Amortecedores da suspensão..............................................................113 


\section{Capítulo 1 - Introdução}

\section{1 - Motivação: O problema do compromisso entre conforto e estabilidade}

Apesar dos atributos veiculares relativos a conforto e dirigibilidade serem tratados de modo antagônico, eles possuem vários pontos em comum que podem ser desenvolvidos para manter um bom compromisso de desempenho em dirigibilidade e conforto adequado para os ocupantes. É bastante comum sacrificar-se estabilidade para atingir um melhor nível de conforto para os ocupantes. Considerando-se o uso do veículo em rua, existem muitas situações em manobras que nunca se aproximam dos limites seguros de estabilidade, porém são poucas as situações que exigem um conjunto corretamente desenvolvido e são nessas situações que os cuidados com estabilidade se fazem necessários.

Considerando o conjunto de ideias e atributos, que estão sob a chamada dinâmica veicular, estão vários que podem ser comumente definidos como conforto e estabilidade. $\mathrm{O}$ ponto primordial e central do que se têm estudado nos últimos séculos, desde que surgiram os primeiros veículos, acabam sendo os usuários, ou seja, a percepção humana. E devido ao fato de cada ser humano ser um ser único, cada um de nós vivencia a experiência de conduzir um veículo de um modo diferente.

Tomando como referencia alguns direcionais quanto a definição de técnica de usuários de automóveis da Ford Motor Company, e direcionais de Richard Parry-Jones pode-se considerar a existência de quatro níveis básicos de usuários/avaliadores veiculares:

. Nível 1 - Usuário genérico, sendo o conhecimento sobre o que ocorre com o veículo expressado como bom ou ruim.

. Nível 2 - Usuário crítico, que possui percepção de não somente se o veículo é bom ou não, mas expressa em um nível de subsistema algum comportamento que venha a apresentar.

. Nível 3 - Especialista, sabe expressar qualidade assim como direcionar ações específicas no veículo de modo a demonstrar todos os atributos, comportamentos que caracterizam o veículo. 
. Nível 4 - Especialista, porém também possui conhecimento para quantificar em forma de métricos, valores objetivos o comportamento do veículo.

A maioria absoluta de motoristas pode ser classificada como no nível 1, deste modo muitas lendas surgem quanto ao comportamento dinâmico de um veículo. O paradigma que mais se perpetuou é a linha de pensamentos que defende a afirmação "conforto e estabilidade são atributos que caminham em direções opostas", ou seja, quando se tem um veículo confortável ele não possui estabilidade, sendo que para se priorizar uma direção a outra será sacrificada (figura 1). Fazendo uma análise considerando diretamente os conceitos da dinâmica veicular, seus atributos e o correto modo de acessá-los e balanceá-los, o paradigma não é verdadeiro.

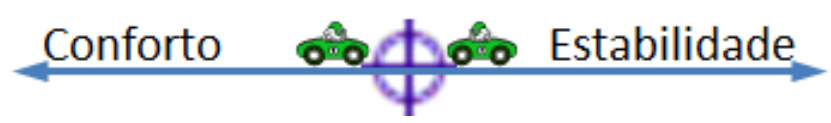

Figura 1 - Imagem do paradigma comumente aceito para os atributos de dinâmica veicular (autor)

A função das suspensões do veículo é controlar a movimentação da carroceria (melhor chamada de massas suspensas) e prover estabilidade para várias situações de piso do leito carroçável em que o veículo seja exposto e também filtrar ou eliminar qualquer vibração que seja indesejada tanto referente aos ocupantes do veículo quanto ao próprio veículo (Figura 2).

Vale lembrar que a palavra que define melhor tudo o que será exposto neste trabalho é conhecimento. $\mathrm{O}$ conhecimento dos fenômenos naturais que significam o ato de dirigir e do carro respondendo ao comando do motorista.

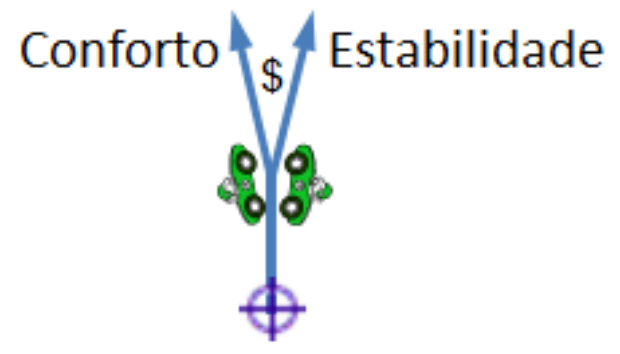

Figura 2 - Modelo do direcional que melhor retrata os atributos discutidos (autor) 


\section{2 - Análise: Mercados emergentes e de primeiro mundo - perfil de usuários}

Devido à natureza do ser humano, muitas diferenças, variedades de gostos, visão e conhecimento existem. É necessário ponderar sobre as diferenças socioculturais humanas, pois elas podem agir como inibidores ou catalisadores de muitos paradigmas e comportamentos que podem refletir diretamente em percepção de atributos automotivos e consequentemente nos da dinâmica veicular.

Considerando nosso planeta, a Terra, e todas as mudanças que a raça humana tem sofrido nos últimos séculos, a formação de cada polo geopolítico global acaba apresentando um determinado tipo de influência em seus habitantes e também nos direcionais que norteiam projeto e fabricação de seus carros para uso em rua. Novamente tendo em mente a dinâmica veicular, e sendo um pouco generalista pode-se apresentar o seguinte quadro que engloba os países de primeiro mundo e os países emergentes (figura 3). A imagem deve ser interpretada como uma forma de demonstrar como é o crescimento da demanda de refinamentos técnicos por parte dos consumidores à medida que eles têm acesso à informação e à cultura geral e automotiva.

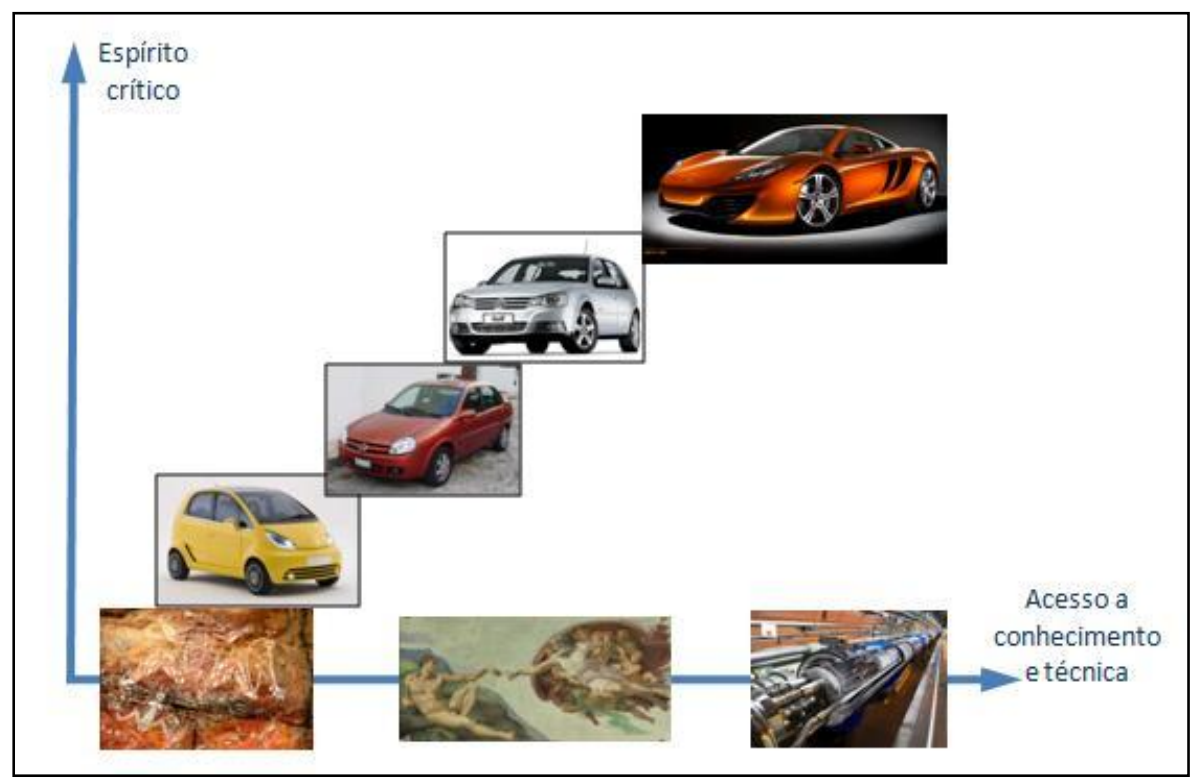

Figura 3 - Observação sobre consumidores e veículos (autor)

Em adição, o aspecto econômico e integralista das montadoras que resultou no conceito de plataformas globais, faz com que a necessidade técnica do veículo seja maior para atender os diversos tipos de mercado. Deste modo, os países emergentes apresentam 
solicitações dinâmicas muito maiores que os do primeiro mundo, porém, o conhecimento para a resolução dos problemas de conforto e estabilidade está no primeiro mundo.

Novamente empregando um exemplo não usual para ilustrar a busca técnica do conforto e da estabilidade, pode ser citada a Mercedes Benz AG, que utiliza características e perfis topográficos das vias de países emergentes para desenvolvimento de seus projetos (figura 4).

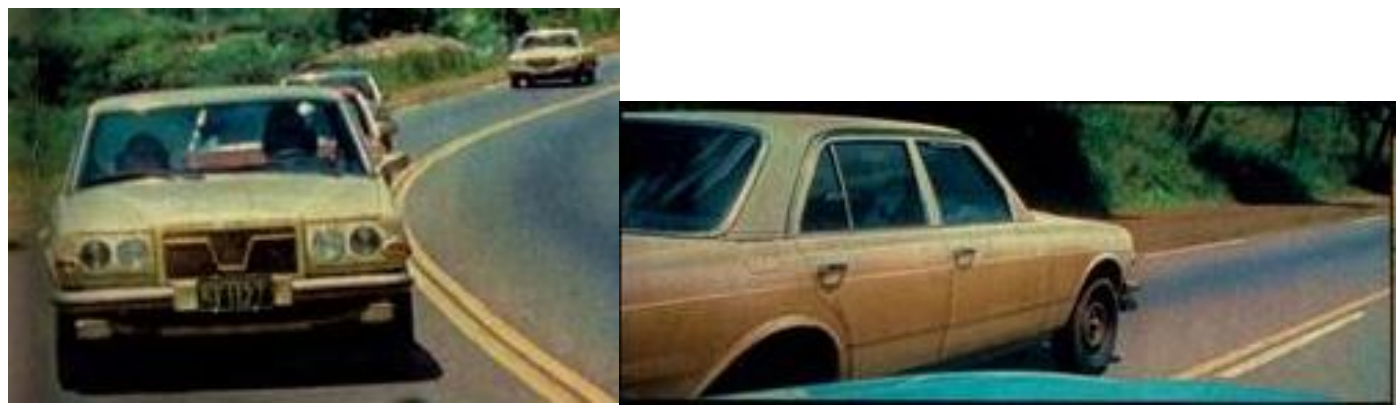

Figura 4 - Fotos tiradas de veículos em teste em estradas brasileiras (Quatro Rodas, maio 1974, p54)

\section{3 - Análise: Conceitos de estabilidade e conforto}

Considerando o conforto, é necessário definir que tipo de entrada de vibrações está ocorrendo no veículo, a percepção dessas vibrações poder ser desde movimentação de carroceria devido a oscilações de pista (baixa frequência) até asperezas induzidas por qualidade da textura do piso (altas frequências), assim dependendo do tipo de excitação e de sua amplitude, seu isolamento pode ser feito com maior ou menor facilidade.

Considerando a estabilidade, as faixas de frequências das excitações que são de interesse são comparativamente baixas, pois as manobras que signifiquem necessidade de estabilidade geram acelerações e movimentações que resultam em perturbações cujas frequências de trabalho são baixas. Assim, conceitualmente, a suspensão veicular possui como função primordial gerenciar do mesmo modo os atributos que são considerados discrepantes.

A ideia de um carro tido como "estado da arte" para um tipo de atributo é meramente ilustrativa para que se possam fazer comparativos e classificações. O melhor carro é aquele 
que cumpre a sua função e pode apresentar "personalidade", pois assim, além de funcional pode ser reconhecido. Em outras palavras, para a pergunta “qual é o melhor carro?” a resposta é "depende".

Como referência, um exemplo incomum que pode se utilizado para abstrair o conceito e torná-lo mais inteligível está na categoria de Formula-1. Já é de praxe há vários anos nela um crescente investimento de mentes e recursos para que os veículos passem a apresentar melhores características de "conforto", não um conforto subjetivo de tranquilidade que os usuários normais possuem e que vem do uso dos veículos de rua, mas sim da necessidade dos veículos formula de serem maximizados para conseguirem diminuir o tempo de volta durante as corridas. Esse "conforto" é explicado no que se refere à necessidade de controlar a movimentação das rodas de modo a mantê-las o máximo de tempo possível em contato com o solo e evitar qualquer movimentação indesejada de carroceria que prejudicaria na condução do veículo. Assim, quando o veículo passa por ondulações de pista, "zebras" ele não deve transmitir o perfil do evento, as suspensões devem realizar seu movimento e deste modo manter a estabilidade da carroceria, isso podendo também considerar o fato de cada um dos eventos possuírem uma determinada frequência de excitação e todas elas serem conceitualmente semelhantes às que são indesejadas também para o usuário comum.

Neste exemplo, o dispositivo empregado para o efeito de melhoria de conforto desejada é a chamada válvula de amortecedor regressiva (figura 5) que permite a geração de curvas de amortecimento ditas regressivas (figura 6).

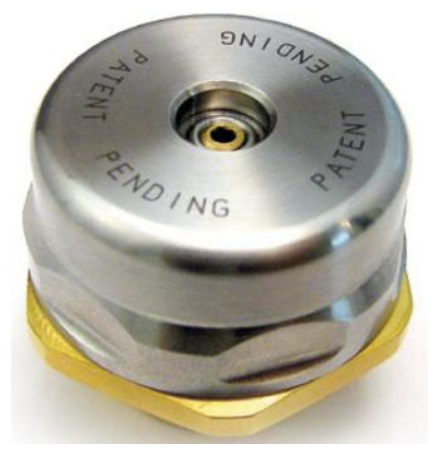

Figura 5 - Conceito de válvula "regressiva" em amortecedores (Penske, divulgação) 


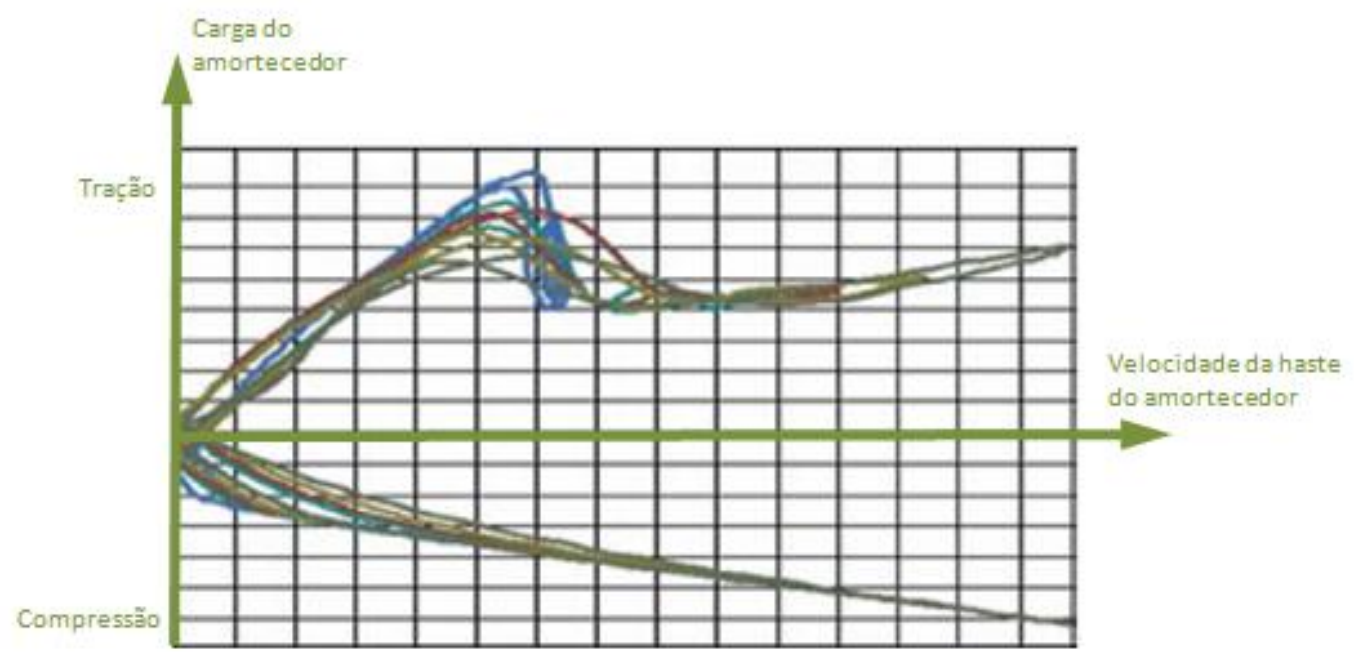

Figura 6 - Exemplos de curvas de amortecimento em válvula regressiva (Racecar Engineering, 2009, p48)

\section{4 - Objetivos e estrutura do trabalho}

De um modo geral, os estudos devem auxiliar a atribuir a importância e a função corretas a cada componente de suspensão e como eles devem trabalhar em conjunto para atenderem as necessidades de boas práticas de engenharia e dos consumidores. Esta dissertação deverá abordar características de massa, rigidez e amortecimento empregados em suspensões de modo a compreender a influência desses componentes nos atributos veiculares. Podendo ser sintetizados na equação 1.1 , onde a massa $(m)$ possui sensibilidade quanto a acelerações $(\ddot{x})$, o amortecimento $(c)$ à velocidade $(\dot{x})$ e a rigidez elástica $(k)$ ao deslocamento $(x)$.

$$
F(t)=k \cdot x+c \cdot \dot{x}+m \cdot \ddot{x}
$$

Com este trabalho, espera-se ganhar maior experiência no entendimento dos fatores que influenciam no adequado direcional para acerto de suspensões para veículos, de modo a manter características de segurança, diversão e conforto, acrescentando ainda a possibilidade de se introduzir um DNA de marca para tornar mais detalhada e identificável a experiência de se dirigir veículos automotores de determinado fabricante.

O assunto esteve em pauta durante vários estudos conduzidos em campos de provas onde se buscava um melhor compromisso de conforto, sem abrir mão das características de 
estabilidade/dirigibilidade dos veículos e também manter a identidade da marca. Como resultados desses estudos existem vários direcionais e conclusões que deverão ser analisadas e adotadas como referência para os futuros programas a serem conceituados e conduzidos.

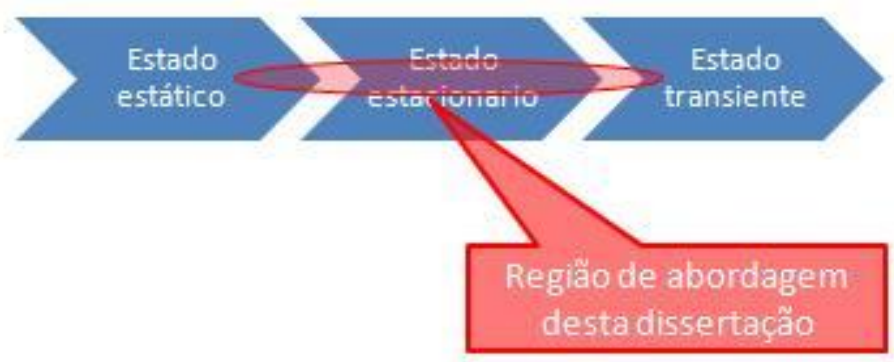

Figura 7 - Imagem sobre a área de interesse deste trabalho (autor)

Parte-se inicialmente das definições das ideias que cercam os termos conforto e estabilidade, como elas estão relacionadas e como se relacionam com o consumidor do veículo, o elemento humano. Em seguida será apresentada uma visão geral de como é usualmente direcionado pelas montadoras o conceito das suspensões no tocante aos atributos, os direcionais adotados e exemplos, também lembrados de como esses paradigmas são direcionados nas montadoras. Sendo que devido às melhores práticas que cada uma segue, pode-se falar de um "DNA" existente. Independente de haver outros fatores de igual ou maior influência nessas decisões, a análise aqui discorrida é técnica devido à natureza dessa dissertação. Assim pode-se definir um caminho que possui uma sequencia lógica, porém com várias idas e vindas até se alcançar o objetivo desejado (figura 7). Nesta mesma figura esta assinalada, no citado caminho, a parte em que este trabalho discorre.

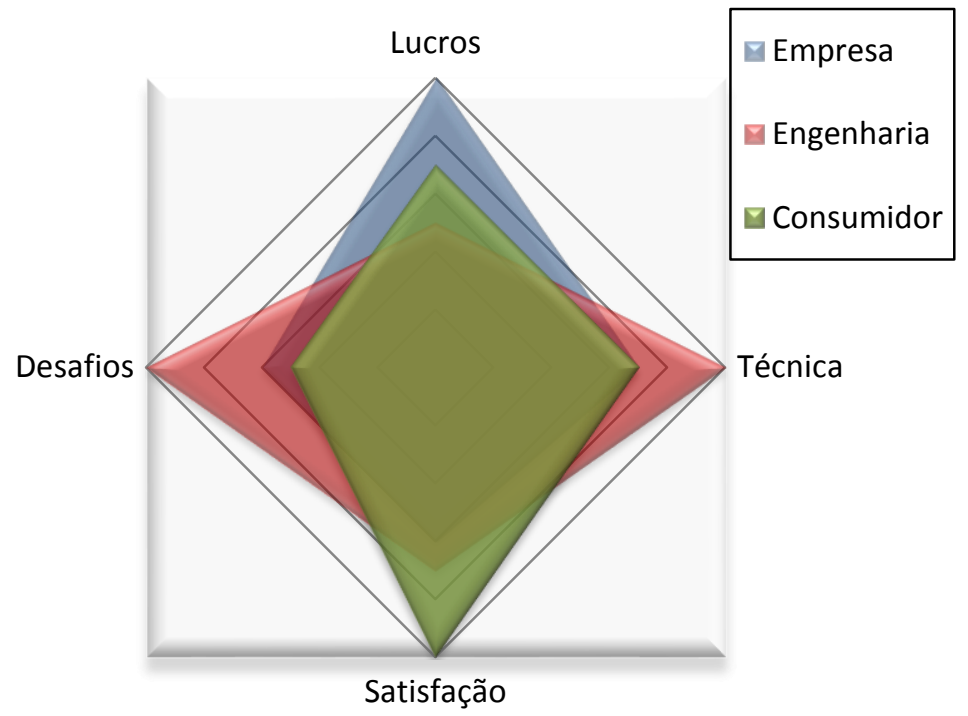

Figura 8 - Exemplo das prioridades de diversas áreas quanto ao produto carro (autor) 
Vale ressaltar que existem diferentes necessidades conforme o ponto de vista das partes envolvidas no ciclo de geração e comercialização do automóvel (figura 8). As necessidades são distintas, porém apresentam um lugar comum que pode ser alcançado e deste modo atender às necessidades dos envolvidos, sejam elas técnicas ou financeiras.

Finalmente, devido às várias interfaces que existem entre os componentes das suspensões, é necessário comentar como esses vários outros componentes interagem entre si e em que situações, atribuindo valores corretos aos fenômenos que ocorrem durante o ato de dirigir. Assim mostrar que existem muitos outros fatores e componentes a serem trabalhados para refinar o veículo tais como coxins do trem de força, buchas dos sistemas de suspensão e direção. Como consequência permitir que novos desdobramentos para o tema do equilíbrio dos atributos veiculares (conforto e estabilidade) possam ser abordados em outras oportunidades.

Considerando também o aspecto da utilização da teoria dos modelos de Multicorpos, a realização de simulação numérica de modelos complexos de veículos e com alguns graus de liberdade tendo-se uma descrição mais precisa, para avaliação de fenômenos como transferência de carregamento vertical nos pneus durante a realização de uma curva, por exemplo. Isto implica em considerável redução nos custos de todo programa lançado pelas grandes montadoras de veículos e, portanto, o uso da técnica virtual, CAE (Computer Aided Engineering), vem crescendo já há vários anos a fim de aperfeiçoar os projetos de engenharia. Mesmo utilizando modelos simplificados quanto ao detalhamento veicular, os resultados sejam bastante confiáveis e os direcionais iniciais sejam corretos para o desenvolvimento dos projetos nas demais fases dos programas.

Para as análises envolvendo CAE, será considerado um modelo veicular simplificado que possui graus de liberdade adequados para movimentação vertical, rolagem, arfagem e combinação desses movimentos, sendo este montado em MSC/ADAMS, não tendo sido possível a inclusão do movimento de rotação no eixo Z (Guinada - Yaw), pelo fato de aumentar muito a complexidade do modelo adotado. O modelo possui similaridades com alguns estudos empregados em montadoras para o processo de conceituação do veículo de modo a, novamente citando, reduzir o tempo de desenvolvimento dos programas veiculares, porém com boa representatividade dos fenômenos. A figura 9 pode demonstrar os seis graus de liberdade para o automóvel, sendo que no citado modelo são utilizados somente a arfagem, 
rolagem e o movimento de translação vertical, podendo caracterizar assim os movimentos que mais são influenciados pelas molas das suspensões.

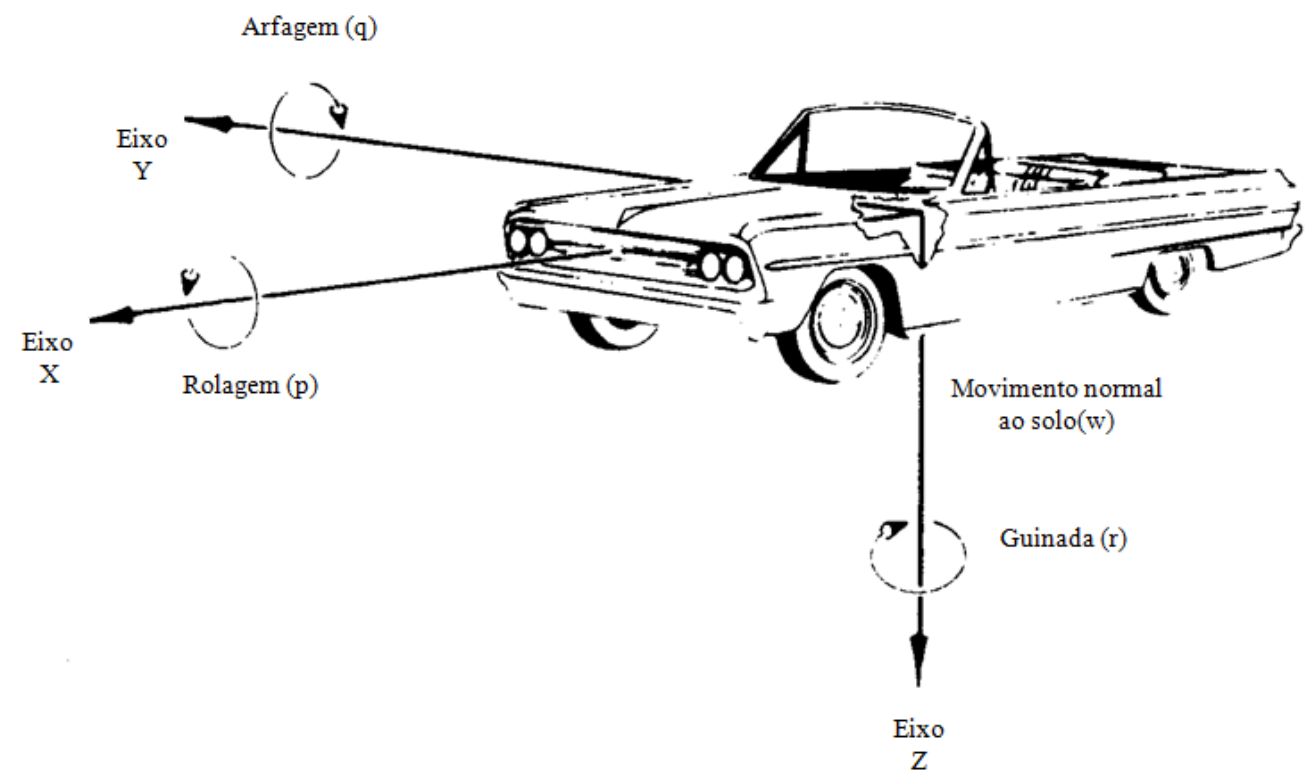

Figura 9 - Sistema de eixos normalizados SAE (SAE-J670)

Como observação importante, nos textos dos próximos capítulos, o termo ride é empregado várias vezes para referenciar as características de conforto durante o ato de guiar e o termo handling para a manobrabilidade dos veículos. Outro termo empregado, controle, se refere tanto ao conforto quanto a estabilidade, pois é empregado para como as massas suspensas e não suspensas do veículo devem ser gerenciadas de modo a atingir o desempenho desejado. 


\section{Capítulo 2 - Revisão bibliográfica}

Desde o surgimento do automóvel, existe a necessidade do controle para estabilizar o controle dinâmico do veículo para seus movimentos. O principal problema é como equipar o veículo com sistemas de suspensão que pudessem gerenciar as massas suspensas durante o ato de dirigir de modo a evitar acidentes e também como evitar que a atividade se tornasse um ato potencialmente insalubre. As pessoas e seus trabalhos abordados neste capitulo são as principais referências neste continente quanto ao entendimento do que são sistemas de suspensão e algumas de suas grandezas e comportamentos para os atributos de conforto e estabilidade tendo como condição de contorno a percepção humana.

Os principais trabalhos que discursam sobre o assunto foram sintetizados e publicados como literatura técnica especializada, sendo assim as principais fontes para o entendimento dos fenômenos estão disponíveis em forma de livros.

\section{1 - Maurice Olley}

Nascido na Gran Bretanha em 1889, Maurice Olley é considerado um dos introdutores das suspensões independentes na América, sendo que sua vida coincide com o desenvolvimento do automóvel. Inicialmente trabalhando para a Rolls-Royce, foi um dos primeiros a introduzir, em Detroit, um dispositivo de testes de ondulações (bump rig) para reproduzir em laboratório alguns eventos das estradas e deste modo incrementar os estudos relativos ao conforto durante a direção.

Olley utilizou como referências os trabalhos de Rowell e Guest. Esses estudos se faziam necessários devido ao fato de que em grande parte do mundo as estradas eram, naquela época, e ainda são hoje, bastante onduladas. Outra importante realização foi a confecção e uso do veículo $\mathrm{K}^{2}$ rig que apresentava a característica de possuir $\mathrm{CG}$, massas e inércia reguláveis e cujo intuito era realizar investigações com molas de suspensão de modo a entender e minimizar as movimentações de carroceria durante a condução do veículo. Durante os testes realizados com o $\mathrm{K}^{2}$ rig, empiricamente ficou definido que o melhor modo de se chegar a um comportamento planar de movimentação da carroceria seria utilizando molas de suspensão com rigidez menor na dianteira do que na traseira. 


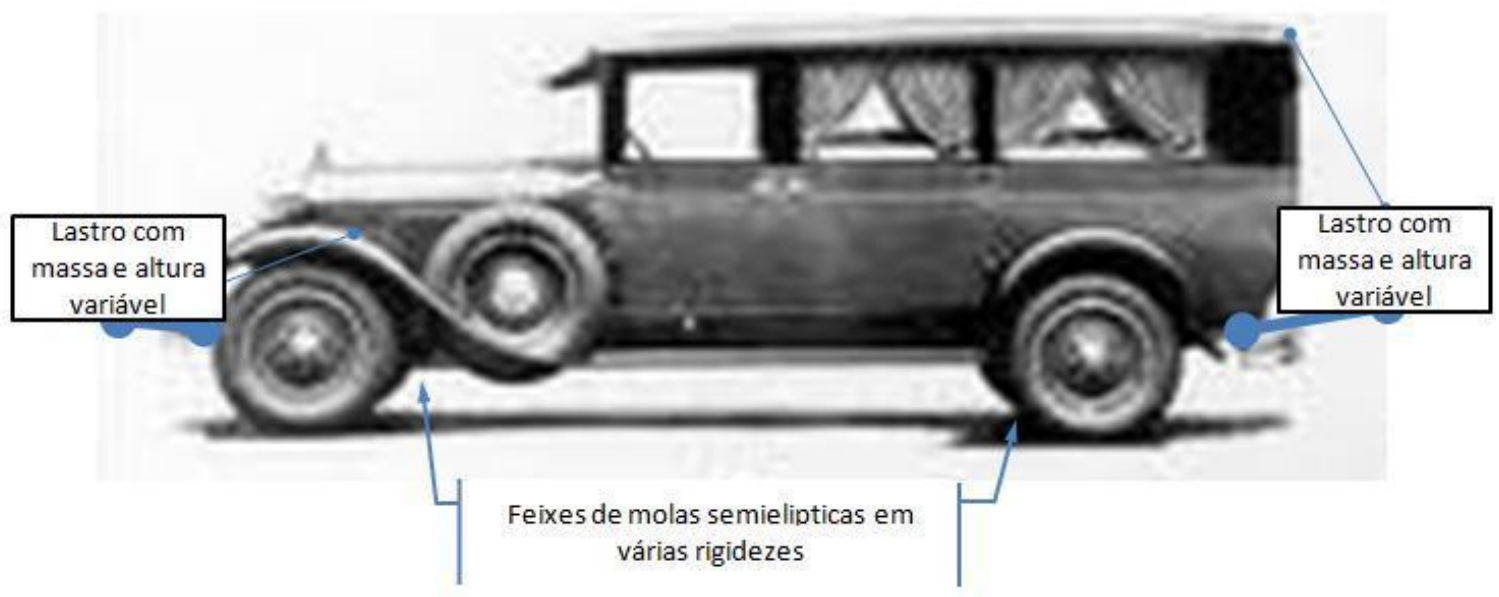

Figura 10 - Conceito do veículo " $K^{2}$ rig" baseado em um Cadillac limousine

As conclusões destes estudos podem ser definidas:

- Uso das frequências naturais não amortecidas para as massas suspensas como métrico para definição das molas das suspensões.

- Uso de modelo com dois graus de liberdade (arfagem e movimento vertical)

- Molas dianteiras devem permitir maior deslocamento que traseiras

- Frequências naturais do movimento vertical e da arfagem devem ser próximas.

- Para a dianteira, a frequência natural deve ser em torno de $1,28 \mathrm{~Hz}$.

\section{2 - Homer S. Rowell e James J. Guest}

Considerando os estudos de Rowell e Guest, temos o seguinte modelo para demonstrar seus conceitos de movimentação de carroceria:

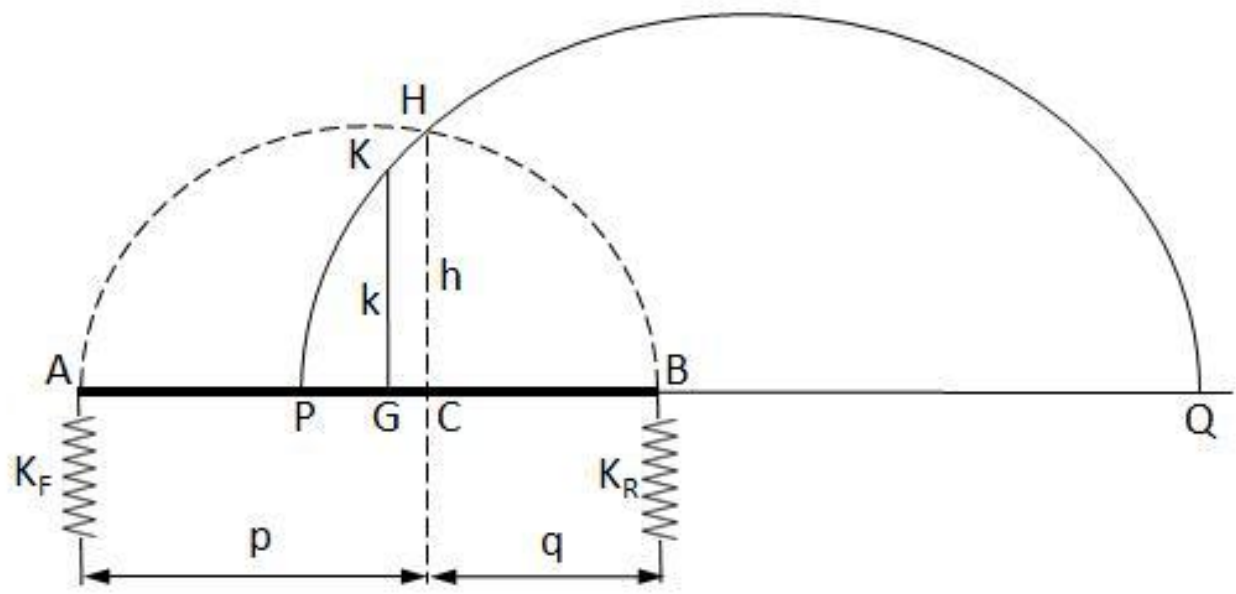

Figura 11 - Representação da definição de centro de mola e centro de rigidez (MILLIKEN, 2002, p308) 
Legenda:
A - Suspensão dianteira (no centro da roda)
B - Suspensão traseira (no centro da roda)
$\mathrm{C}$ - centro de mola
$\mathrm{G}-\mathrm{CG}$ da massa suspensa
$\mathrm{k}$ - Raio de giração da massa suspensa pelo CG
$\mathrm{P}$ - Centro de oscilação dianteiro (arfagem)
Q - Centro de oscilação traseiro (oscilação de carroceria)

Neste diagrama, podem-se verificar vários centros geométricos, os quais são empregados para definir dois graus de liberdade básicos quanto a conforto de rodagem, a arfagem e o balanço vertical.

Assim longitudinalmente temos:

- Centro de mola (C) - ponto onde o carro seria empurrado de modo paralelo ao solo

- Centro de massa $(\mathrm{G})$ - ponto ao redor do qual se consideram os movimentos.

E ainda considerando esta condição, existem três rigidezes:

- Rigidez vertical em $\mathrm{O}=\mathrm{KF}+\mathrm{KR}$

- Rigidez angular em $\mathrm{G}=\mathrm{KFa} 2+\mathrm{KRb} 2$

- Rigidez no G por unidade de rotação em relação a $G$

Estes estudos referem-se à caracterização dos movimentos de arfagem e oscilação vertical. O intuito era verificar a movimentação longitudinal das massas suspensas, sendo que a ideia inicial era fazer com que a carroceria transladasse durante as oscilações de pista deste modo minimizando as acelerações que pudessem ser transmitidas aos passageiros e assim direcionar um melhor conforto.

Podem ser consideradas duas equações de movimento:

$$
\begin{aligned}
& \text { Linear: } m \ddot{z}+\left(K_{F}+K_{R}\right) z+\left(K_{F} a-K_{R} b\right) \theta=0 \\
& \text { Angular: } m k^{2} \ddot{\theta}+\left(K_{F} a-K_{R} b\right) z+\left(K_{F} a^{2}+K_{R} b^{2}\right) \theta=0
\end{aligned}
$$




$$
\begin{gathered}
-\omega^{2} m Z+\left(K_{F}+K_{R}\right) Z+\left(K_{F} a-K_{R} b\right) \Theta=0 \\
-\omega^{2} m K^{2} \Theta+\left(K_{F} a-K_{R} b\right) Z+\left(K_{F} a^{2}+K_{R} b^{2}\right) \Theta=0 \\
{\left[\frac{\left(K_{F}+K_{R}\right)}{m}-\omega^{2}\right] Z+\frac{\left(K_{F} a-K_{R} b\right)}{m} \Theta=0} \\
\frac{\left(K_{F} a-K_{R} b\right)}{m} Z+\left[\frac{\left(K_{F} a^{2}+K_{R} b^{2}\right)}{m}-\omega^{2} k^{2}\right] \Theta=0
\end{gathered}
$$

Deste retiramos:

$$
\left(\omega^{2}-\alpha\right) \cdot\left(\omega^{2}-\frac{\gamma}{k^{2}}\right)=\frac{\beta^{2}}{k^{2}}
$$

e:

$$
\omega^{4}-\left(\alpha+\frac{\gamma}{k^{2}}\right) \omega^{2}+\frac{\alpha \gamma-\beta^{2}}{k^{2}}=0
$$

Essas são as duas raízes que podem ser encontradas:

$$
\begin{aligned}
& \omega_{1}^{2}=\frac{+\left(\alpha+\frac{\gamma}{k^{2}}\right)+\sqrt{\left(\alpha+\frac{\gamma}{k^{2}}\right)^{2}-4\left(\frac{\alpha \gamma-\beta^{2}}{k^{2}}\right)}}{2} \\
& \omega_{2}^{2}=\frac{+\left(\alpha+\frac{\gamma}{k^{2}}\right)-\sqrt{\left(\alpha+\frac{\gamma}{k^{2}}\right)^{2}-4\left(\frac{\alpha \gamma-\beta^{2}}{k^{2}}\right)}}{2}
\end{aligned}
$$

As raízes $\omega_{1}$ e $\omega_{2}$ têm as propriedades dadas pelas equações (2.13), (2.14), (2.15):

$$
\begin{gathered}
\omega_{1}^{2}+\omega_{2}^{2}=\alpha+\frac{\gamma}{k^{2}} \\
\omega_{1}^{2} \omega_{2}^{2}=\frac{\alpha \gamma-\beta^{2}}{k^{2}}=\frac{\gamma}{k^{2}}\left(\alpha-\frac{\beta^{2}}{\gamma}\right) \\
\omega_{1}^{2}-\omega_{2}^{2}=\sqrt{\left(\alpha+\frac{\gamma}{k^{2}}\right)^{2}-4 \frac{\alpha \gamma-\beta^{2}}{k^{2}}}=\sqrt{\left(\alpha-\frac{\gamma}{k^{2}}\right)^{2}+4 \frac{\beta^{2}}{k^{2}}}
\end{gathered}
$$


É aparente que:

$\alpha=$ é o quadrado da frequência vertical da massa m concentrada em O. Pode ser chamado oscilação paralela $\left(\omega_{0}^{2}\right)$.

$\frac{\gamma}{k^{2}}=\mathrm{o}$ quadrado da frequência angular do carro ao redor do CG G, podemos chamar arfagem $\left(\omega_{p}^{2}\right)$.

$$
\alpha-\frac{\beta^{2}}{\gamma}=\frac{K_{F}+K_{R}}{m}-\frac{\left(K_{F} a-K_{R} b\right)^{2}}{m\left(K_{F} a^{2}+K_{R} b^{2}\right)}=\frac{K_{F} K_{R} l^{2}}{m\left(K_{F} a^{2}+K_{R} b^{2}\right)} \quad \text { esse é o quadrado da frequência }
$$
vertical de uma massa concentrada em $\mathrm{G}$ que pode ser chamada $\omega_{g}^{2}$ oscilação vertical.

Simplificando, temos:

$$
\begin{gathered}
\omega_{1}^{2}+\omega_{2}^{2}=\omega_{p}^{2}+\omega_{0}^{2} \\
\omega_{1}^{2} \omega_{2}^{2}=\omega_{p}^{2} \omega_{0}^{2}
\end{gathered}
$$

Essa é a mais simples definição sobre as duas frequências, de arfagem e movimentação vertical.

Podemos ter três casos especiais:

I - Se $K_{F} a=K_{R} b$, o centro das molas está no centro de gravidade.

$$
\text { Então } \beta=0, \omega_{1}=\omega_{p}, \omega_{2}=\omega_{0}=\omega_{g}
$$

e

$$
\frac{\omega_{1}}{\omega_{2}}=\sqrt{\frac{a b}{k^{2}}}
$$

Quando $\beta=0, \omega_{1}=\omega_{p}, \omega_{2}=\omega_{0}=\omega_{g}$ e $\omega_{p}^{2}=\frac{\gamma}{k^{2}}$ é definido o modo de arfagem em G. Também, se $\omega_{g}^{2}=\alpha$ tem-se o modo de oscilação de carroceria paralela para a massa em G.

II - Se $k^{2}=a b$ pode ser visto que: 


$$
\omega_{1}=\sqrt{\frac{K_{F}}{m \frac{b}{l}}} \text { e } \omega_{2}=\sqrt{\frac{K_{R}}{m \frac{a}{l}}}
$$

O veículo apresenta oscilação como se fossem dois sistemas independentes de massa mola. Ou seja, cada eixo dele oscila de modo independente.

$$
\begin{aligned}
& \text { III - Se } K_{F} a=K_{R} b \text { e ao mesmo tempo } k^{2}=a b \\
& \qquad \omega_{1}^{2}-\omega_{2}^{2}=\frac{l}{m a b}\left(K_{F} a-K_{R} b\right)=0
\end{aligned}
$$

Essa é a única condição necessária para frequências iguais de arfagem e oscilação vertical.

Assim, estipulou-se que se o valor da proporção $k^{2} / a b$ fosse igual a 1 o ride seria bom, porém não foi o que aconteceu durante as avaliações, pois neste caso não existe um centro de oscilação definida (caso III), e a percepção subjetiva era de um veículo sem apoio, sem um padrão de movimento. Os melhores resultados vieram com uma relação próxima de 0,8 , pois assim havia uma marcação, um comportamento a ser percebido como o andar de um cavalo.

Deste modo para um veículo de rua deve-se seguir o primeiro caso.

Estes conceitos foram verificados posterior mente de modo empírico por Olley através do veículo de teste $\mathrm{K}^{2}$ rig. Vale lembrar que estas pesquisas foram realizadas sem se considerar a influência do amortecimento nas suspensões.

\section{3 - William F. Milliken}

Para Willian Milliken, tudo começou durante seu trabalho como gerente no Hangar de desenvolvimento de voo do Laboratório de Aeronáutica Cornell (CAL). Nesta época, trabalhava no que pode chamar de primeiras medições da resposta em frequência de aeronaves em voo e também nos primórdios do sistema que hoje é chamado de fly-by-wire. Posteriormente com o seu envolvimento em corridas automobilísticas e consequente 
necessidade de desenvolvimento dos carros, teve contato e iniciou vários contratos com o campo de provas da GM, onde passou a trabalhar em conjunto com Maurice Olley, Bob Schilling, Ken Stonex, Von Pohlemus, Tom Carmichel na temática do comportamento veicular em estado transiente, tendo como referência a tecnologia de dinâmica aeronáutica e a possibilidade da transferência desta para a dinâmica automobilística.

\subsection{1 - Estudos relacionados ao conforto, o ride}

Considerando o trabalho de Olley no veículo $\mathrm{K}^{2}$ rig e as referências de Rowell e Guest empregadas, seus trabalhos posteriores feitos em conjunto com o mesmo, apresentam o seguinte refinamento:

- Bom ride (conforto) significa não apenas ausência de acelerações, mas também um padrão definido de movimentação.

Como informação adicional os estudos foram realizados sem se levar em consideração o uso de amortecimento, deste modo mais estes comentários devem ser acrescidos:

- Necessidade de amortecimento para minimizar a oscilação da carroceria durante o movimento.

- O melhor controle de amortecimento para o conforto é aquele que é apenas o suficiente para realizar o trabalho de controlar o veículo.

Estes estudos são referentes especificamente a como melhorar o ride do veículo, o seu conforto, levando-se em conta que até então as suspensões mais comuns eram baseadas em feixe de molas semielípticas. O motivo de Olley ser considerado o pioneiro das suspensões independentes na América é que baseado em seus estudos para conforto, ele pode comprovar a necessidade de se ter um sistema de suspensão veicular mais refinado e com componentes com função mais dedicada que pudesse manter a carroceria o mais estabilizada possível de modo a oferecer condições para que houvesse conforto e estabilidade aos passageiros, sendo que até então essa premissa não era detalhada nos projetos. 


\subsection{2 - Estudos relacionados à estabilidade, o handling}

Considerando o modo de se estudar a estabilidade veicular, o seguinte pode ser comentado para as atividades de análise de dinâmica veicular que foram iniciadas por Olley e posteriormente incrementadas por ele e Milliken.

\subsubsection{1 - Comportamento dos pneus}

Os únicos pontos de contato do veículo com o solo são os pneus deste modo eles são as principais fontes de forças e torques que geram controle e estabilidade no veículo. Sua interação com a pista gera as forças para frear acelerar e fazer curvas (MILLIKEN, 1995, p.13-14). Deste modo os estudos sempre devem se iniciar nos pneus.

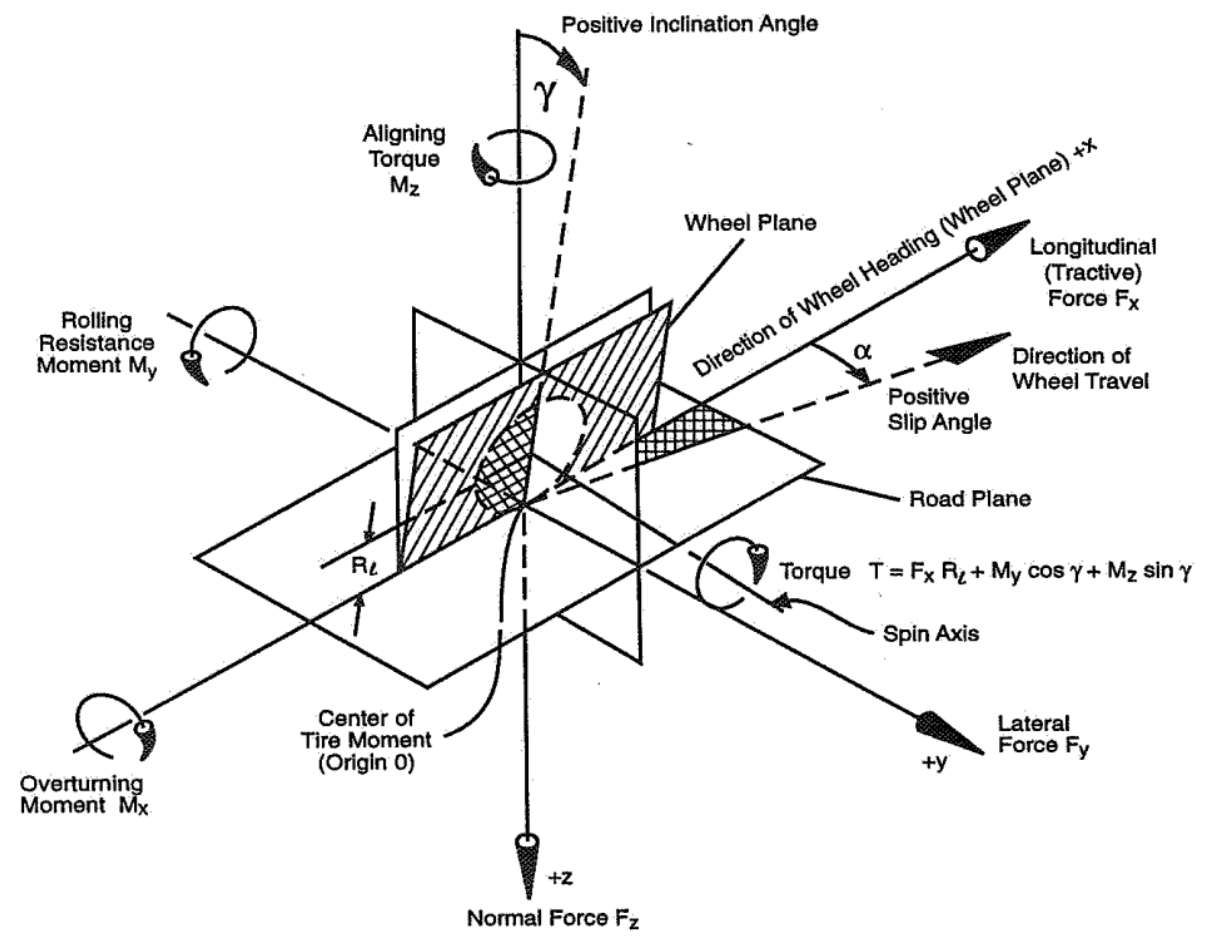

Figura 12 - Sistema de eixos normalizados para pneus da SAE (MILLIKEN, 1995, p.62)

Dado o tema de esta dissertação estar mais relacionado às rigidezes de molas de suspensão este sistema não será abordado de modo mais detalhado. Como referência, a figura 12 apresenta o sistema de eixos normalizados para forças e torques num pneu. 


\subsubsection{2 - Estado estacionário}

É uma das partes das disciplinas para estudo do comportamento dinâmico dos veículos, sempre deve ser complementada com estudos relativos às fases transientes do comportamento, pois considera o veículo em velocidade constante, aceleração lateral constante e sem entradas de movimento transitórias, assim o veículo está em movimento, mas não está transitando entre condições distintas de equilíbrio. Pode ser considerado como um regime permanente, onde seu estado de movimento não se altera com o tempo. Ou seja, a derivada parcial de uma propriedade desse movimento em função do tempo é zero.

$$
\frac{\partial p}{\partial t}=0
$$

Num veículo é quando se esta dirigindo em uma situação onde não existe alteração perceptível do estado do movimento. No capitulo 3 esta consideração terá maior desdobramento, através de alguns critérios para definição de tipo de pistas que correspondam a essa situação.

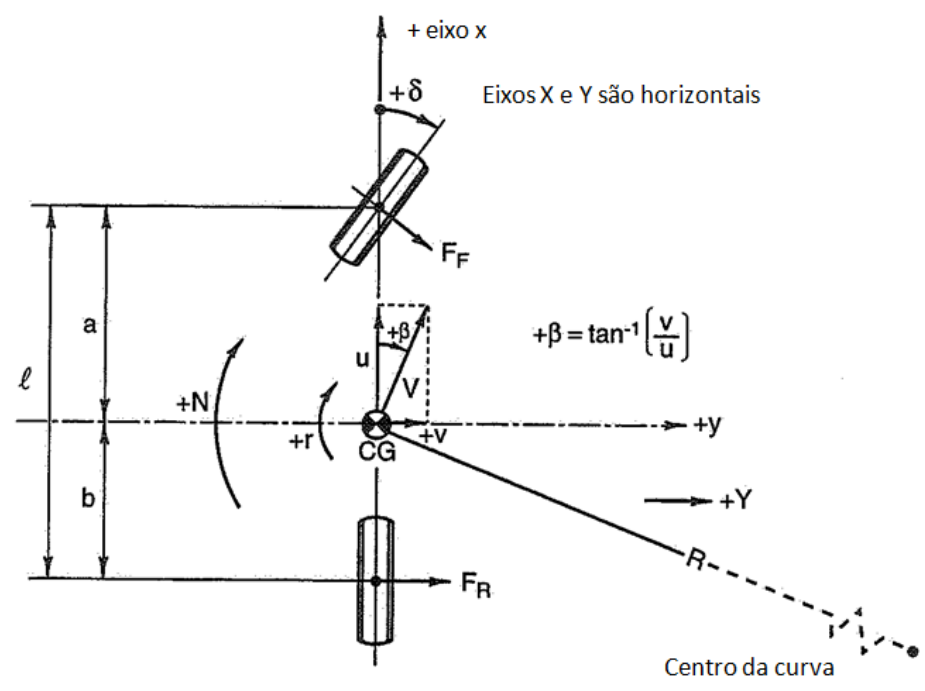

Figura 13 - Modelo da bicicleta para 2 graus de liberdade (MILLIKEN, 1995, p127)

Considerando o modelo da bicicleta, é possível realizar alguns acessos quanto a características de dirigibilidade do veículo. Podendo investigar a rigidez lateral dos pneus dianteiro e traseiro, posição do CG e ângulo de esterço (geométrico). Trata-se de um modelo com dois graus de liberdade, para a figura 13, as duas variáveis de movimento são a 
velocidade lateral $\mathrm{V}$ e a velocidade de rotação $\mathrm{r}$, e a variável de entrada é o ângulo de esterço $\delta$ (entrada vinda do motorista).

\subsubsection{3 - Estado transiente}

Refere-se a situações transitórias do movimento do veículo, deste modo algumas variáveis como, por exemplo, a rotação, aceleração lateral e o caminho descrito pelo veículo apresentam variação em função do tempo. Como informação complementar para os estudos de conforto, ele propriamente pode ser considerado um estado em permanente transição, pois a entradas e excitações ocorrem em função do tempo.

Outro ponto importante é o uso do modelo do sistema massa-mola-amortecedor, pois as análises verticais, de dinâmica veicular, são possíveis através deste conceito.

$$
F(t)=k \cdot x+c \cdot \dot{x}+m \cdot \ddot{x}
$$

onde a massa $(m)$ possui sensibilidade quanto a acelerações $(\ddot{x})$, o amortecimento $(c)$ à velocidade $(\dot{x})$ e a rigidez elástica $(k)$ ao deslocamento $(x)$. Vide a figura 14.

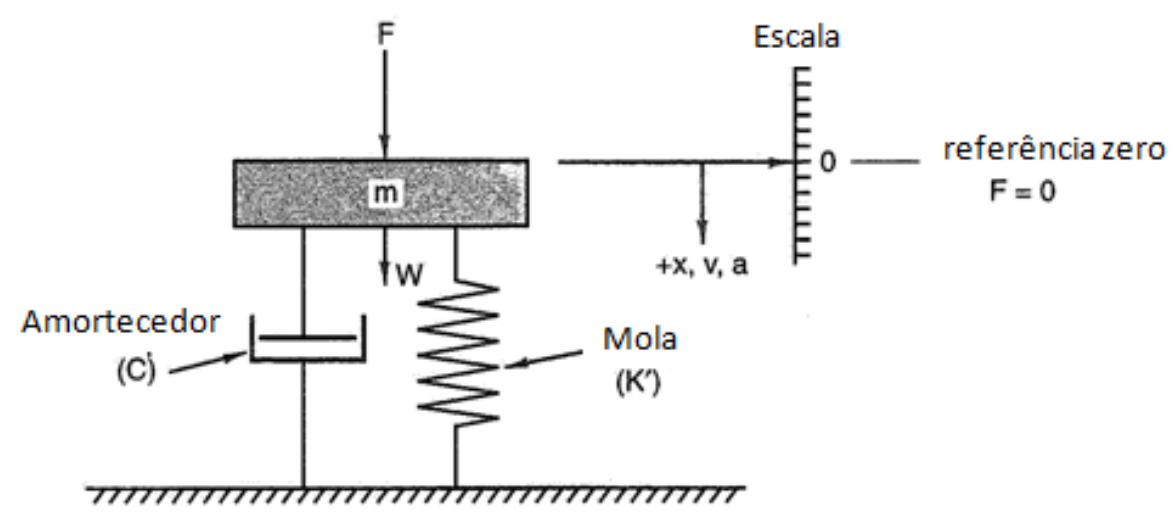

Figura 14 - Exemplo de sistema massa mola amortecedor (MILLIKEN, 1995, p.235)

\section{4 - John C. Dixon}

O autor define o ride do veículo como os movimentos de oscilação vertical, arfagem e rolagem quando em movimentos forçados devido a imperfeições do piso. E relativo à função 
das suspensões veiculares, neste contesto ele define como sendo minimizar o desconforto dos ocupantes. Sendo assim definido, o modo correto de acertar as rigidezes e amortecimentos vai variar segundo a proposta do veículo.

Defende a condição de analisar o comportamento de ride no domínio do tempo, no que se refere a predizer posições, velocidades e acelerações e também no domínio das frequências quando se desejar predizer as características de transmissibilidade e também a revelação de ressonâncias.

\subsection{1 - Análise de ride em função do tempo}

Este tipo de análise considera o comportamento do veículo, seus movimentos enquanto o tempo passa. A velocidade vem da mudança de posições/deslocamentos divididos pelo tempo discorrido ou aceleração multiplicada pelo período de tempo considerado: $\dot{z} T, \dot{z} S, \dot{z} C$.

Para esta demonstração podemos assumir um modelo linear para molas e amortecedores. Tomando como base a figura 14, temos $F_{k^{\prime}}=k^{\prime} z$ e $F_{c}=C \dot{z} S$.

$$
A_{B}=\frac{F_{k^{\prime}}+F_{C}}{m_{B}}
$$

Assim as velocidades e posições discorridas do tempo seguem:

$$
\dot{Z}_{B}=\dot{Z}_{B \text { last }}+A_{B} \Delta t
$$

\subsection{2 - Análise de ride em função da frequência}

Este tipo de análise considera o comportamento do veículo, sua resposta em termos de uma determinada frequência ou estímulo. A figura 15 mostra um gráfico de PSD. 


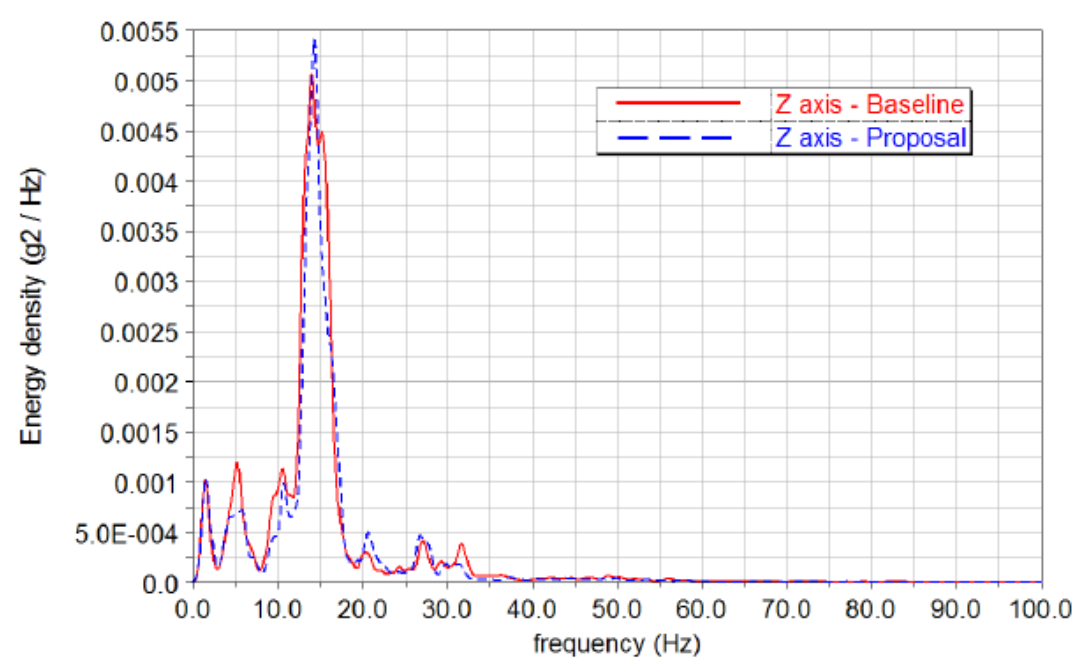

Figura 15 - Exemplo em gráfico de transmissibilidade do piso para o motorista (autor)

\subsection{3 - Handling}

Pode ser traduzida como estabilidade, a capacidade do veículo de manter-se sob controle do motorista de modo seguro e previsível. Neste ponto deve-se citar que um ride mal controlado induz o veículo a apresentar movimentações de carroceria de modo indesejado, causando problemas durante curvas ou frenagens, consequentemente surgindo ângulos de rolagem e arfagem de modo descontrolado devido às variações de acelerações que o controle incorreto de carroceria permite.

Assim para controle em linha reta somente devido a oscilações de piso, pode-se considerar a ressonância da frequência natural da carroceria sendo essa frequência correspondente ao comprimento de onda da rodovia, ou seja, às ondulações de pista e a velocidade em que o veículo trafega. Assim pode-se considerar essa frequência ressonante como:

$$
f=\frac{V}{\lambda}
$$

Onde $\mathrm{V}$ é a velocidade do veículo e $\lambda$ é o comprimento de onda, ou seja, o comprimento da ondulação da pista.

Considerando agora acelerações em linha reta como, por exemplo, frenagem e aceleração, o ângulo de arfagem $\left(\theta_{F T X}\right)$ pode ser visto como: 


$$
\theta_{F T X}=\frac{M_{T X}}{K_{P}}=k_{\theta} A_{X}
$$

Onde:

$M_{T X}=$ Momento da transferência de carga longitudinal

$K_{P}=$ Rigidez de mergulho do veículo

$k_{\theta}=$ Gradiente de mergulho

$A_{X}=$ Aceleração longitudinal do veículo

Finalmente quando se contornam curvas, analogamente ocorre um momento lateral devido à transferência de cargas e existe um ângulo de rolagem:

$$
\theta_{F T Y}=\frac{M_{T Y}}{K_{R}}=k_{\theta} A_{Y}
$$

$M_{T Y}=$ Momento da transferência de carga transversal

$K_{R}=$ Rigidez de rolagem do veículo

$k_{\varnothing}=$ Gradiente de rolagem

$A_{X}=$ Aceleração lateral do veículo

\subsection{4 - Compromisso entre conforto e estabilidade}

Considerando os atributos para conforto e estabilidade, muitos componentes exercem influencia no veículo, porém os mais representativos acabam sendo as molas e os amortecedores, pois no caso de um carro de passeio eles são as maiores influencias no controle e na isolação da carroceria.

Considerando-se típicos carros de passeio, pode-se partir dos seguintes parâmetros empíricos para melhor visualizar este compromisso:

Dados empíricos:

$\mathrm{Q}_{\mathrm{R}}$ - nota subjetiva para qualificação de conforto

$\mathrm{Q}_{\mathrm{H}}$ - nota subjetiva para qualificação de estabilidade

$\mathrm{K}_{\mathrm{R} 1}$ - valor típico de rigidez de mola para conforto (frequência natural de $1 \mathrm{~Hz}$ )

$\mathrm{K}_{\mathrm{R} 2}$ - valor típico de rigidez de mola para estabilidade (frequência natural de 1,5Hz) 
E sabendo que:

$$
\text { Frequência natural: } f=\frac{1}{2 \pi} \sqrt{\frac{k}{m}}
$$

Partindo das considerações acima, geram-se duas curvas qualitativas baseadas em impressões subjetivas de avaliação, sendo uma para ride e outra para handling (figura 16). As curvas auxiliam a demonstrar a percepção subjetiva relacionada às frequências de mola das suspensões. Nelas verifica-se que existe uma frequência natural em que se maximiza a percepção de conforto (aceleração vertical) e outra que maximiza a percepção de estabilidade, o handling (carroceria estabilizada), sendo para o segundo as frequências mais altas significam dificuldade em se manter adequada a movimentação da roda em relação à carroceria e em relação ao perfil da pista.

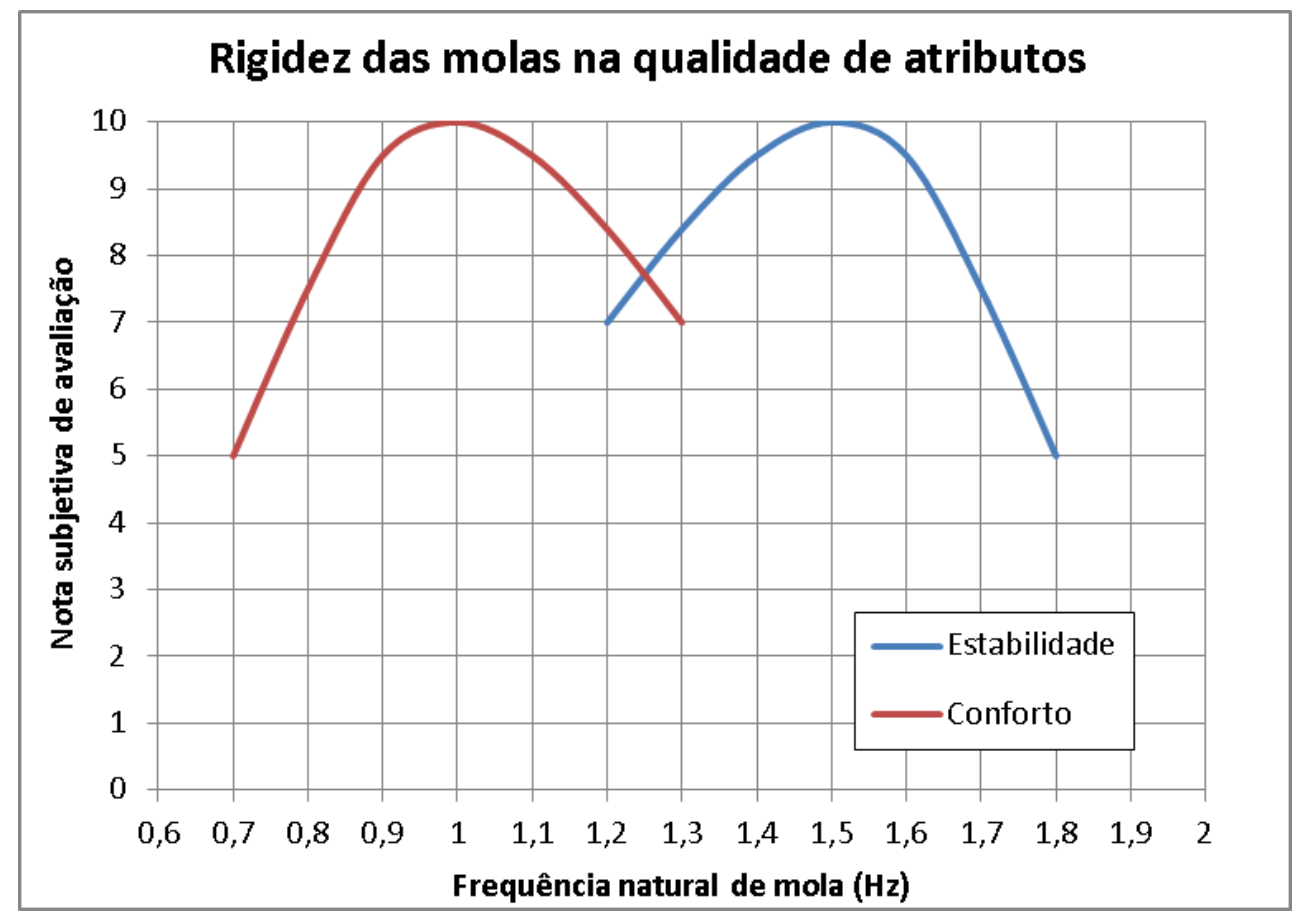

Figura 16 - Comportamento qualitativo das molas (Dixon, 1999, p133)

Tomando essas duas curvas, quando se mesclam elas, gera-se o gráfico $Q_{R}$ em função de $\mathrm{Q}_{\mathrm{H}}$ (subjetivo), ou seja um loop qualitativo dessas curvas (figura 17), para esta condição temos os seguinte:

. Ao redor do melhor conforto: pode-se incrementar a rigidez e melhorar a estabilidade com mínima perda de conforto. 
. Ao redor da melhor estabilidade: pode-se reduzir um pouco a rigidez e ter melhorias substanciais de conforto.

Deste modo existe uma pequena faixa de frequências de ride para as suspensões, as quais permitem uma otimização para o compromisso entre estabilidade e conforto. Assim é possível minimizar pontos negativos (pouco controle) e manter os pontos positivos (controle adequado). Não esquecendo que para cada classe de veículo essas curvas irão variar um pouco, sendo que as frequências podem ser mais altas ou baixas do que os valores exatos apresentados nas curvas. Como exemplo, um veículo utilitário pode necessitar de frequências de suspensão menores que um esportivo devido à posição dos centros de gravidade e da geometria e tipo das suspensões.

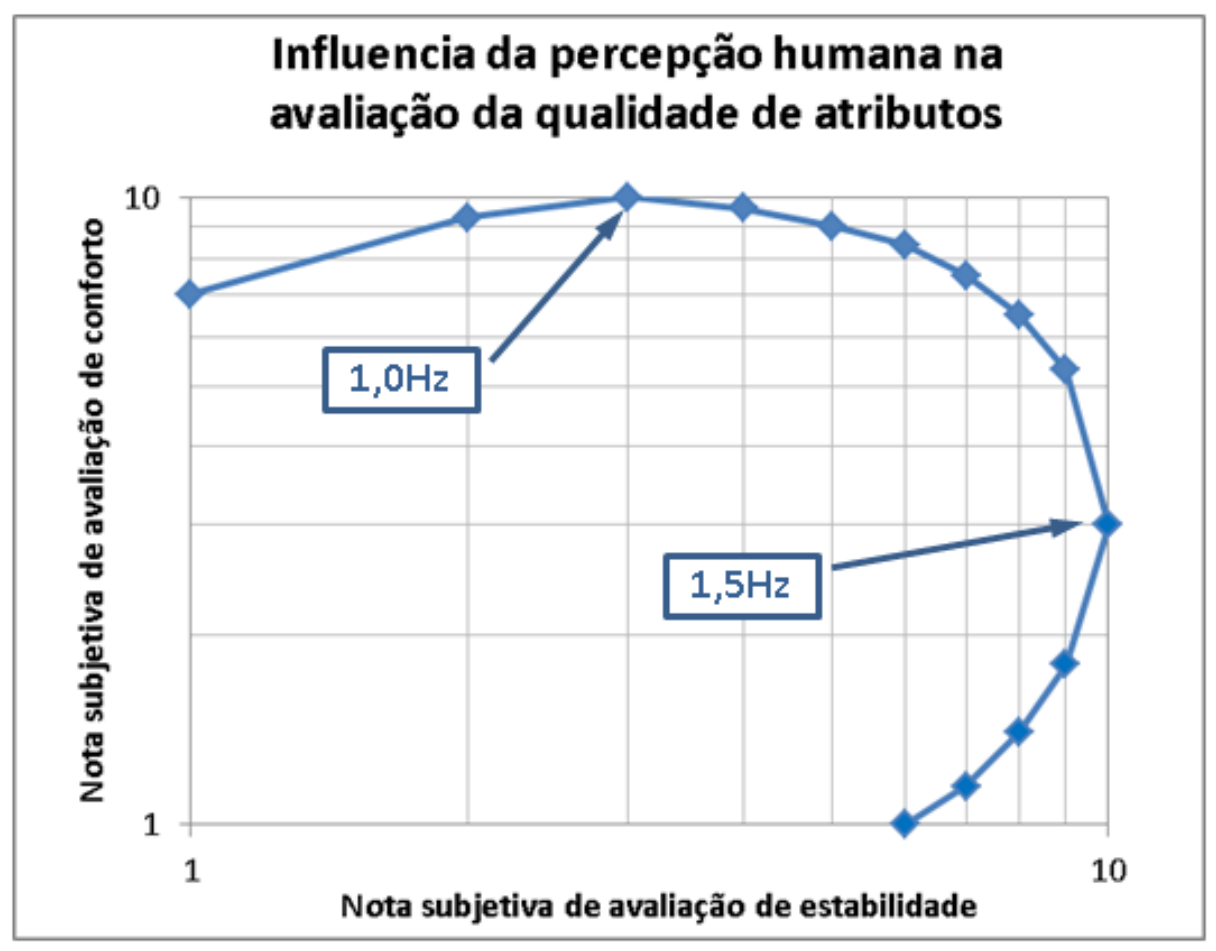

Figura 17 - Loop qualitativo para conforto e estabilidade (Dixon, 1999, p133)

A curva é logarítmica devido a percepção humana não ser linear. Complementando, no tópico de revisão teórica relativa à interface de NVH com a dinâmica veicular, existem detalhes de como o corpo humano responde a diferentes estímulos vibracionais, sendo neste caso, vibrações de baixas frequências, o controle das massas suspensas. 


\section{5 - Michael Blundell e Damian Harty}

Em seu livro The Multibody Systems Approach to Vehicle Dynamics (2004), os autores procuram analisar alguns princípios dinâmicos e principalmente a ligação entre dois caminhos que sempre são controversos, os resultados de simulação e os resultados práticos nos veículos, partindo como base o uso do método dos sistemas de multicorpos.

Segundo Michael Blundell, a dinâmica veicular se cerca de dois aspectos diretamente relacionados ao comportamento da maquina, o primeiro é a isolação e o segundo é o controle (figura18). Nesta figura o autor apresenta de modo bastante funcional e completo através de um diagrama de blocos a interação dos fatores que influenciam o desenvolvimento da dinâmica veicular. Seguindo sua análise; a isolação é referenciada na separação do condutor das perturbações decorrentes do uso, sendo elas tanto devido a condições do mundo exterior como internas do próprio veículo; o Controle se refere ao comportamento do veículo em resposta às necessidades do motorista.

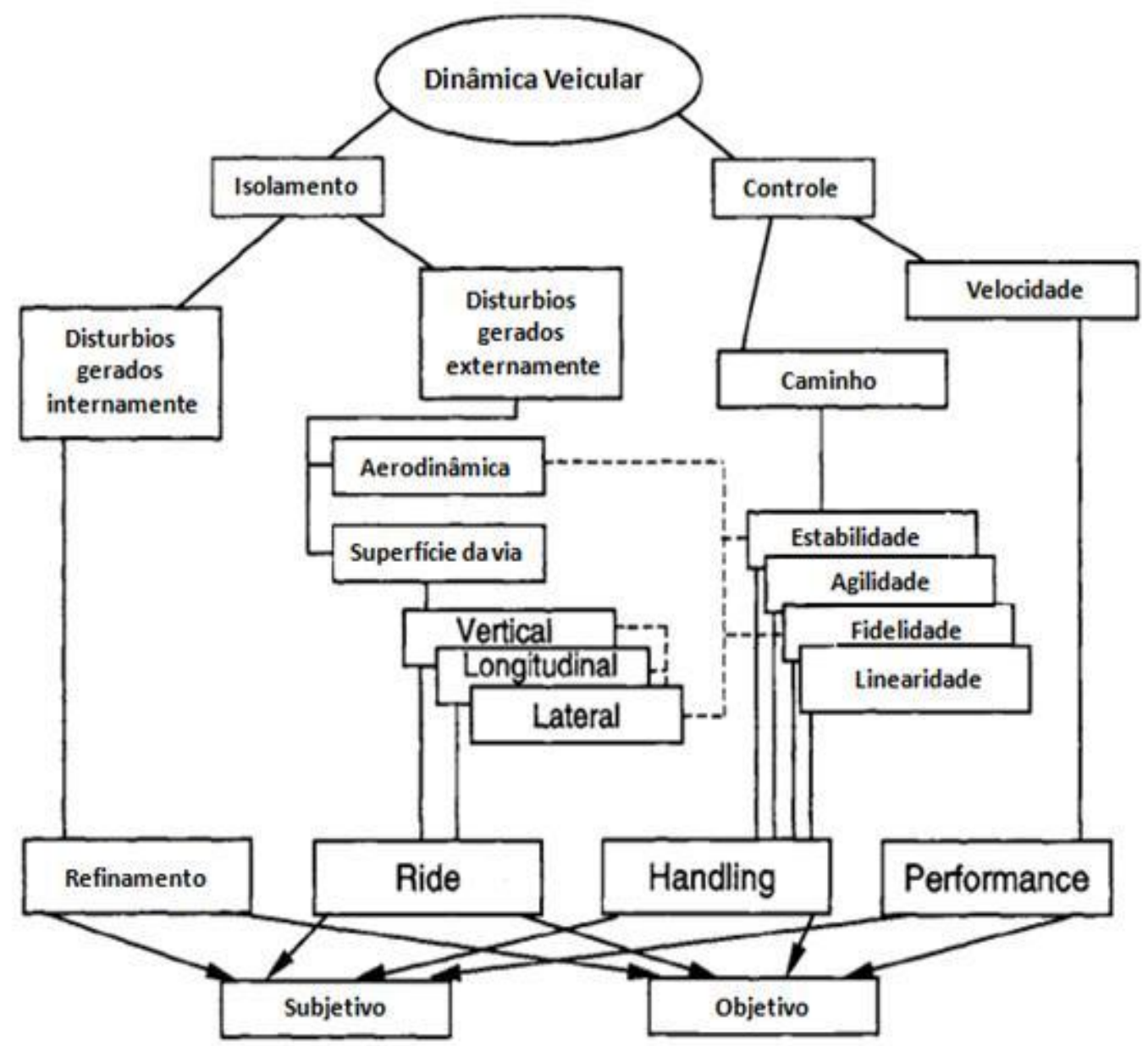

Figura 18 - Interações da dinâmica veicular (BLUNDEL, 2004, p.3) 
Tomando como base o método de sistemas de multicorpos, a ideia é a realização de análises cinemáticas estáticas, quase estáticas e dinâmicas do sistema mecânico. Para isso, é necessário ter um correto entendimento de toda a teoria que envolve a resolução das equações do movimento. Considerando o método de sistemas multicorpos, o primeiro ponto a ser entendido e consequentemente desenvolvido é a teoria dos vetores, para que se possam calcular as variações de geometria e mudanças na orientação dos corpos, sendo que as forças e momentos direcionarão nas definições das formulações dinâmicas a serem utilizadas.

\section{6 - Dinâmica dos multicorpos aplicada ao automóvel}

O método dos chamados multicor os tem sido bastante empregado e difundido no meio automobilístico. A aplicação do conhecimento dos fundamentos da dinâmica é muito importante. Quase todos os problemas práticos estão relacionados a um conjunto de peças ou aglomerado delas. O comportamento do geral do sistema é afetado por peças individuais que aplicam forças entre elas mesmas ou apresentam interações e restrições em certos modos. Um método de formulação e solução destes problemas é a chamada dinâmica dos multicorpos. (RAHNEJAT, 1998, Prefacio).

O seu livro "Dinâmica de multicorpos - Veículos, Máquinas e Mecanismos” permite o aprofundamento, de modo bastante funcional, nos conceitos dos sistemas de multicorpos e sua aplicação na automobilistica.

Como outra citação, pode-se adotar um caso de movimento cinemático planar de um corpo rígido (figura19). Neste caso uma barra rígida $\mathrm{AB}$, seguindo um movimento planar de rotação através de um ângulo infinitesimal $\varnothing$. As duas extremidades, pontos A e B movem se suas posições iniciais A1 e B1 para as posições A2 e B2. O ponto P para a rotação $\emptyset$ da barra está no bissetor das linhas A1A2 e B1B2 e equidistantes do seu par A1, A2 e B1,B2: $\mathrm{PA} 1=\mathrm{PA} 2$ e PB1=PB2. Note que PA e PB são normais aos caminhos percorridos pelos pontos A e B em qualquer situação. Deve-se lembrar de que as velocidades dos pontos A e B são tangenciais aos seus caminhos. No entanto PA e PB são normais as velocidades vA e vB em qualquer tempo. Usando o sistema polar de coordenadas segue:

$$
\omega=\varnothing \cdot k=\left(\frac{d ø}{d t}\right) \cdot k
$$


$\varnothing=$ uma rotação infinitesimal e

$$
v_{A}=\mathrm{v}_{A} \cdot e_{\varnothing} \text { e } P_{A}=\mathrm{P}_{A} \cdot e_{\varnothing}
$$

como

$$
v_{A}=\omega^{\wedge} P_{A}
$$

e similarmente:

$$
v_{B}=\omega^{\wedge} P_{B}
$$

Agora subtraindo equações (2.31) e (2.32) temos:

$$
v_{B / A}=v_{B}-v_{A}=\omega^{\wedge}\left(P_{B}-P_{A}\right)=\omega^{\wedge} A B
$$

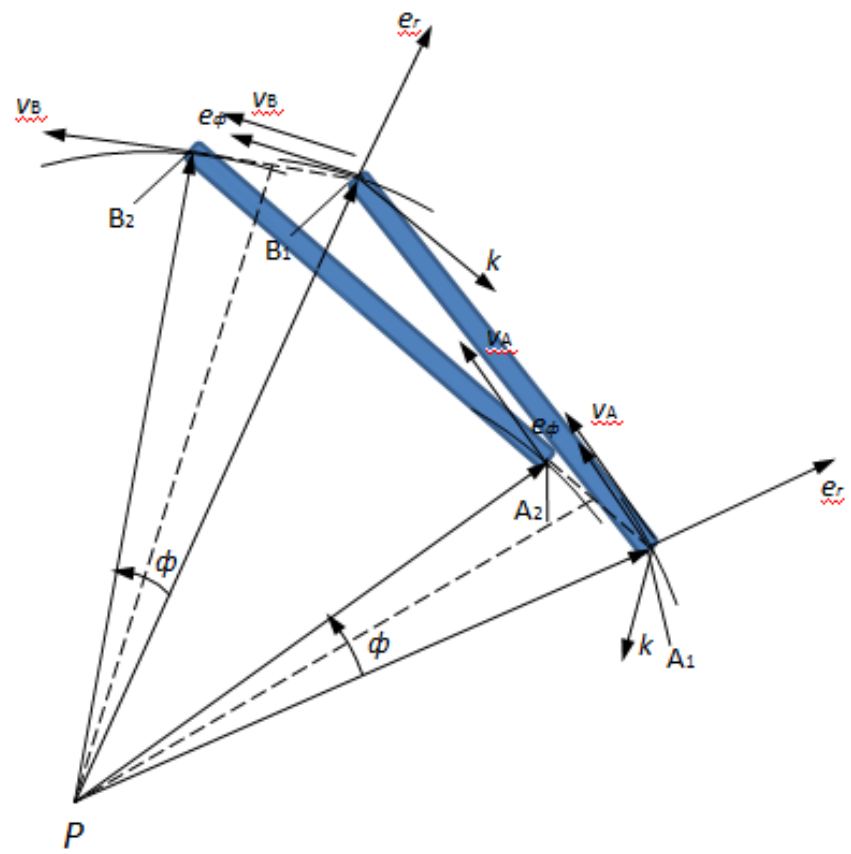

Figura 19 - Representação do exemplo de cinemática planar (Ranejat, 1998, P46)

"Como modo de finalizar essa introdução, os autores Michael Blundell e Damian Harty, apresentam o seguinte raciocínio:" Existem dois elementos para os quais se podem endereçar os problemas da dinâmica veicular. "O primeiro é o especialista prático de ride e handling, e o segundo, o especialista teórico”. O intuito deles é apresentar material que seja adequado a todos os que vivem entre estes dois polos, e estão sempre à frente no processo de projeto veicular, tomando vantagem das possibilidades existentes na computação. (BLUNDEL, 2004, Prefácio) 


\section{7 - Teoria linear básica e mecânica analítica}

Em seu paper publicado no IMechE, os autores Lukowski, Momot, Kraemer e Kunz (LUKOWSKI, 2008) dissertam sobre como representar o automóvel como um sistema mecânico regido por equações diferencias lineares com coeficientes constantes e como ele é dependente do comportamento dos pneus em sua faixa linear (foco deste trabalho) e não linear. Esta publicação permite demonstrar a influência do pneu no comportamento do veículo numa situação estacionária de estabilidade devido a sua massa e posição de centro de gravidade, servindo como pontos iniciais para definir a característica de subesterço ou sobreesterço do veículo e como seus pneus são exigidos para o comportamento desejado.

Neste estudo, foi dada preferência pelo método da mecânica analítica, através das equações de Lagrange, pois deste modo pode-se demonstrar, e assim ser possível acrescentar a influência da velocidade (energia cinética) nas análises da situação de curva de raio constante. Este direcional, porém necessita que as coordenadas empregadas sejam inerciais (ou verdadeiras), ou seja, se na integração da velocidade do corpo no tempo sejam equivalentes às correspondentes coordenadas da localização do corpo.

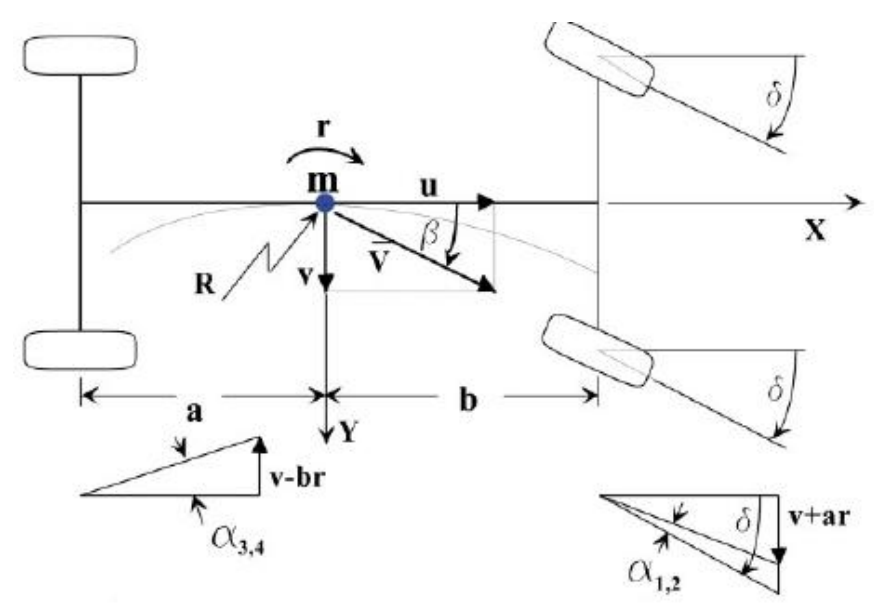

Figura 20 - Representação do modelo de veículo e ângulos de escorregamentos dos pneus (LUKOWSKI, 2009, p2).

Como este modelo apresenta um sistema móvel de coordenadas, ou seja, o veículo realizando uma curva (figura20) é interessante adotar uma perspectiva diferente, o uso de equações chamadas de quase coordenadas.

$$
\sum F_{x}=\frac{d}{d t}\left(\frac{d T}{d u}\right)-r \frac{d T}{d v}
$$




$$
\begin{gathered}
\sum F_{y}=\frac{d}{d t}\left(\frac{d T}{d u}\right)+r \frac{d T}{d v} \\
\sum M_{z}=\frac{d}{d t}\left(\frac{d T}{d u}\right)-v \frac{d T}{d u}+u \frac{d T}{d v}
\end{gathered}
$$

Energia cinética do modelo:

$$
T=\frac{1}{2} m V^{2}+\frac{1}{2} I_{z z} r^{2}
$$

A velocidade translacional do modelo possui duas componentes $u$ e $v$ :

$$
V^{2}=u^{2}+v^{2}
$$

Assim, chega-se a três equações diferencias que descrevem o movimento do veículo com graus de liberdade longitudinal, lateral e rotacional:

$$
\begin{aligned}
& \sum F_{x}=m(\dot{u}-r v) \\
& \sum F_{y}=m(\dot{v}+r u) \\
& \sum M_{z}=I_{z z} \dot{r}
\end{aligned}
$$

Considerando a faixa linear de uso, tem-se: $\dot{u}=\dot{r}=0$

Para um pequeno deslocamento das rodas dianteiras: $u \approx V$

E considerando a faixa linear, as forças em curva são linearmente relacionadas ao ângulo de escorregamento dos pneus (figura 21).

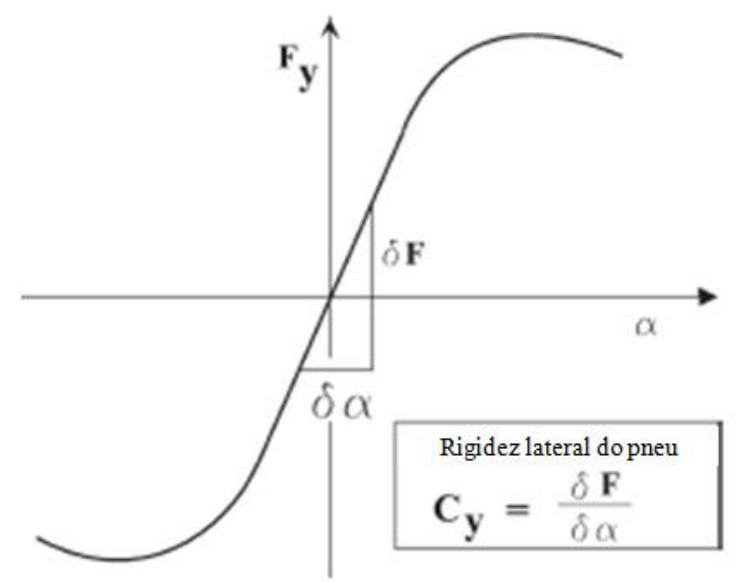

Figura 21 - Curva de escorregamento do pneu conforme autores (LUKOWSKI, 2008, p4) 
Sendo assim, podemos ter:

$$
F_{y w i}=-\left(\frac{\partial F_{y i}}{\partial \alpha i}\right) \alpha_{i}
$$

Para o eixo dianteiro:

$$
F_{y w}=\left.\frac{\partial F_{y}}{\partial \alpha}\right|_{f} \alpha_{f}
$$

Para o eixo traseiro:

$$
F_{y w}=\left.\frac{\partial F_{y}}{\partial \alpha}\right|_{r} \alpha_{r}
$$

O momento de guinada (YM) é definido por eles como:

$$
Y M=\left.\alpha \frac{\partial F_{x}}{\alpha}\right|_{f}-\left.\frac{\partial F_{y}}{\alpha}\right|_{r}
$$

Ou seja, a diferença dos escorregamentos dos pneus no eixo dianteiro e dos pneus do eixo traseiro. Assim, o veículo pode ser sobreesterçante (YM>0), neutro (YM=0) e subesterçante $(\mathrm{YM}<0)$.

Apesar de não levar em consideração a rolagem da carroceria e as transferências laterais de carga, essa análise permite compreender o que é a faixa linear de dirigibilidade em curvas e como os pneus e a posição da massa do veículo são importantes para definir seu comportamento tal qual demonstrado por Milliken em sua publicação (Milliken, 1995, p123).

E complementando a possibilidade de seguir a análise levando-se em conta a energia cinética, para uma manobra de estado estacionário não é necessário que o veículo tenha amortecimento, pois os elementos elásticos tais como molas, batentes e barras estabilizadoras podem gerenciar o balanço de energia cinética/potencial de modo a manter estabilidade na situação estacionária. Quando ocorre uma variação de energia, uma variação de estado em função do tempo, aí sim é necessária a presença de amortecedores

\section{8 - Caracterização dos níveis de vibração}

O material apresentado na tese de doutorado de Alexandre Balbinot é um direcional correto para se entender as definições de conforto e como ele é importante, sob a ótica da saúde, para os ocupantes do veículo. Basicamente, o conteúdo desta tese de doutorado se 
refere às normas ISO 2631e ISO 5349 de modo a definir a influencia das vibrações e asperezas no corpo humano e qual a sua tolerância sem que haja riscos à saúde.

De um modo genérico, o conforto veicular se refere a como o veículo transmite aos seus ocupantes todas as irregularidades das vias e como sua carroceria é controla após ser excitada por essas mesmas irregularidades.

O conceito de estado transiente pode ser aplicado ao conforto veicular, já que se refere a entrada de energia num sistema devido a um evento e transmissão da oscilação resultante através de sistema até que os ocupantes do veículo sejam atingidos por ela. Essa energia proveniente das vibrações.

Nesta tese, o corpo humano pode ser visto como um sistema massa/mola/amortecedor e, consequentemente, essa energia proveniente da interação do veículo com a via afeta de modo negativo a saúde das pessoas.

Tabela 1 - Sensibilidade do corpo a vibrações

\begin{tabular}{cll}
\hline Frequência (hz) & Sensibilidade & Fonte de vibrações \\
\hline 0 a 2 & Sistema vestibular & barcos, veiculos, aeronaves \\
\hline 2 a 30 & Biomecânica, ressonancia do corpo & veiculos, aeronaves, guindastes \\
\hline$>20$ & Musculos tendões e pele & ferramentas e máquinas \\
\hline & & Chaffin et al.,1999
\end{tabular}

Para um veículo de passageiros, vale ressaltar que o objetivo não é evitar doenças resultantes da exposição às vibrações, mas sim, otimizar o conforto de modo a fazer do ato de dirigir uma atividade adequadamente prazerosa.

A figura 22 serve de exemplo para ilustrar como cada frequência de ride pode interferir no corpo humano e assim, como consequência, causar desconforto ou até mesmo fadiga. 


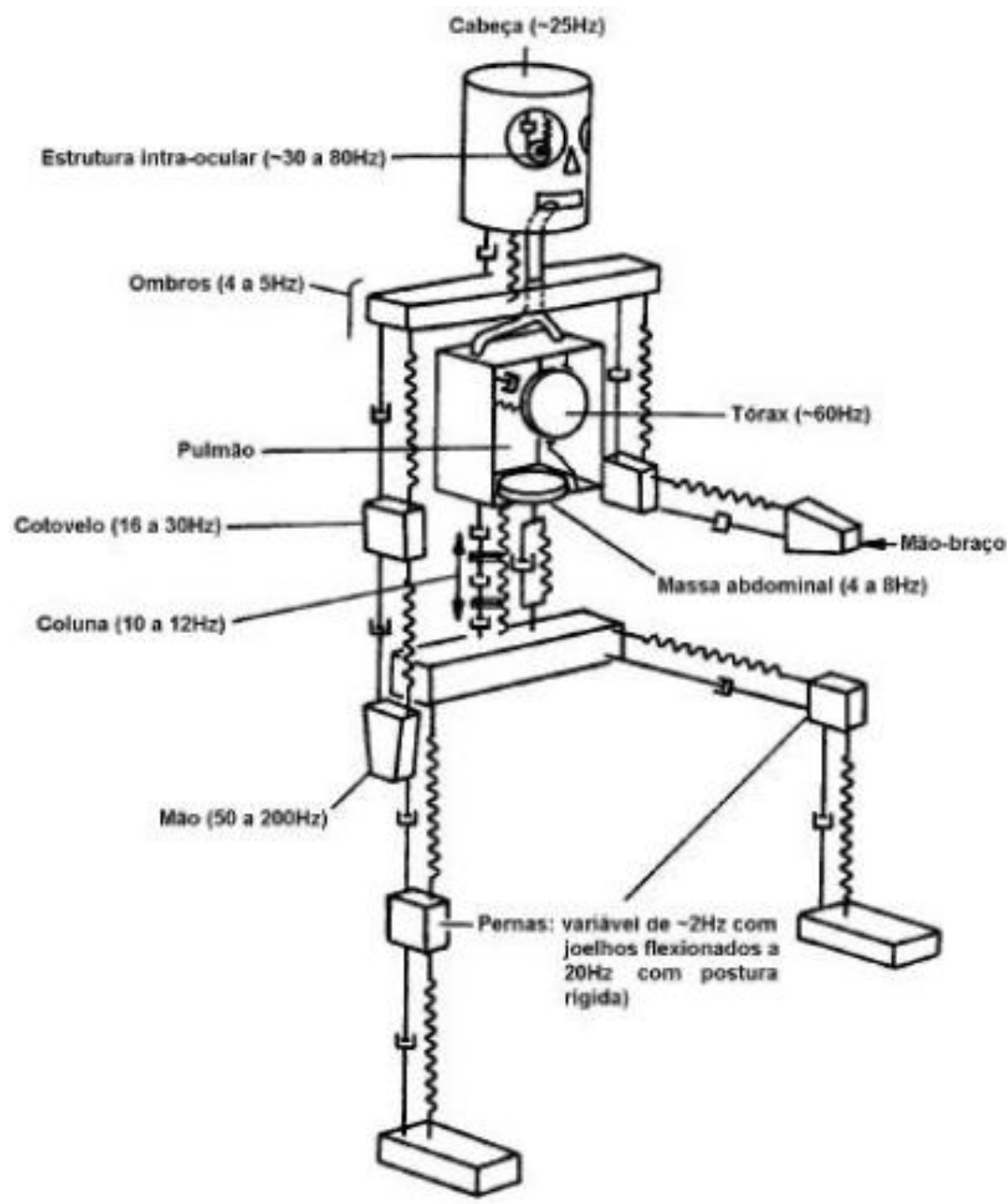

Figura 22 - Sistema mecânico representando o corpo humano sujeito a vibração vertical (Balbinot, 2001, p21)

\section{9 - Métodos da energia}

Novamente citando, devido ao automóvel ser um sistema dinâmico, apresentar necessidades de controle dinâmico, um modo correto de estuda-lo é através da conservação da energia.

Segundo Dixon, para o compromisso de controle das suspensões, conforto e estabilidade (ride/handling), existe uma faixa de valores para as molas das suspensões que permite o melhor balanço para estabilidade e conforto, para o amortecedor, as mesmas considerações podem ser feitas. No caso dos amortecedores, por se tratar de um componente de dissipação de energia, a quantia dessa dissipação deve ser ajustada para que ocorra o melhor isolamento e controle de carroceria, ou seja, isolamento da massa suspensa das 
imperfeições do solo à medida que o veículo se desloca. Assim, existe sensibilidade do trabalho realizado pelas suspensões em função do tempo.

Na publicação de Lukowski (IMechE), ele emprega a mecânica lagrangeana para exemplificar a analise de um veículo realizando uma curva, assim é possível fugir das típicas análises estacionárias onde se demonstra somente uma imagem congelada do que o veículo esta realizando e passa-se a ter um panorama completo onde se pode verificar o comportamento do veículo em várias situações das transições de estado de movimento, podendo demonstrar equilíbrio estacionário ou alguma situação transitória dele.

A mecânica lagrangeana é uma formulação da mecânica clássica que combina a conservação do momento linear com a conservação da energia. É uma potente ferramenta matemática e equivalente a qualquer outra formulação da mecânica, como, por exemplo, o newtoniano.

Na mecânica lagrangiana, a trajetória de um sistema de partículas é obtida resolvendo as equações de Lagrange em uma de suas duas formas, chamadas equações de Lagrange de primeira espécie, que trata as restrições explicitamente como equações adicionais, geralmente utilizando os multiplicadores de Lagrange e as equações de Lagrange de segunda espécie (Dvorak R., Freistetter F., 2005. p. 24), que incorpora as restrições diretamente na escolha das coordenadas generalizadas. Resolver as equações de Lagrange é equivalente a encontrar o caminho que minimiza a integral da função de Lagrange $L$ no tempo.

Dado um conjunto de coordenadas generalizadas $q=\left\{q_{i}\right\}$ para descrever o sistema físico estudado, a Lagrangiana de qualquer sistema o caracteriza de forma unívoca e pode apresentar as seguintes dependências funcionais, $L=L\left(q_{i}, \dot{q}_{i}, t\right)$ em que $\dot{q}_{i}=\frac{d q_{i}}{d t}$ são as velocidades generalizadas.

Pelo Princípio de Hamilton, que nos diz que o trajeto real da partícula, entre os instantes $t_{i}$ e $t_{f}$ é aquele que minimiza a ação $S \equiv \int_{t_{i}}^{t_{f}} L\left(q_{i}, \dot{q}_{i}, t\right)$. Fixados os extremos da trajetória no espaço de configuração. Encontramos as equações de Euler-Lagrange

$$
\frac{\partial L}{\partial q_{i}}-\frac{d}{d t}\left(\frac{\partial L}{\partial \dot{q}_{i}}\right)=0
$$

que são equações diferenciais parciais de segunda ordem em $t$. 
No caso de um sistema não conservativo (ou dissipativo), temos:

$$
\frac{\partial L}{\partial q_{i}}-\frac{d}{d t}\left(\frac{\partial L}{\partial \dot{q}_{i}}\right)=-Q_{i}^{e x t}
$$

em que

$$
Q_{i}^{e x t}=\sum_{j}^{N} \vec{F}_{j}^{e x t} \cdot \frac{\partial \vec{r} j}{\partial q_{i}}
$$

são as forças generalizadas externas.

A Mecânica Lagrangeana é baseada num formalismo escalar mais simples e geral, quando comparado ao formalismo vetorial de Newton. Com isso é capaz de descrever igualmente bem fenômenos a baixas velocidades ou a velocidades relativísticas. $\mathrm{O}$ único aspecto que difere entre cada caso é a Função de Lagrange.

Em um sistema clássico, por exemplo, temos que $q_{i}=r$ (aqui estamos assumindo que as coordenadas generalizadas são os módulos dos vetores posição de cada partícula que compõem o sistema) e a Função de Lagrange define-se como:

$$
L(r, r, t)=T(r, \dot{r}, t)-U(r)
$$

Em que $T=\frac{1}{2} m \dot{r}^{2}$ é a Energia Cinética e $U$ é a Energia Potencial de Interação.

Quanto às equações de Euler-Lagrange, temos:

$$
\frac{\partial L}{\partial q_{i}}-\frac{d}{d t}\left(\frac{\partial L}{\partial \dot{q}_{i}}\right)=\frac{\partial L}{\partial r}-\frac{d}{d t}\left(\frac{\partial L}{\partial \dot{r}}\right)=0
$$

A Mecânica de Lagrange tem a vantagem de resolver elegantemente problemas complexos, sendo um bom exemplo do grau de abstração embutido no formalismo de Lagrange a simplicidade com que podemos deduzir as Leis de Conservação a partir das simetrias do espaço-tempo. Deixa-se, aqui, a título de exemplo, a dedução da Conservação do Momento Linear: 
Sendo o espaço homogêneo (invariância sob translação espacial), tem-se que $\frac{\partial L}{\partial r}=0$. Num sistema isolado (conservativo), pelas equações de Euler-Lagrange, temos $\frac{d}{d t}\left(\frac{\partial L}{\partial \dot{r}}\right)=0$. Definindo $p=\frac{\partial L}{\partial \dot{r}}$, chegamos a $\frac{d p}{d t}=0$

Assim o emprego da mecânica Lagrangeana na dinâmica veicular permite um melhor equacionamento dos fenômenos estaticos, estacionários e transientes. A principal area de interesse é justamente a que compreende o estado estacionario e o transitorio, o ride/handling na dinâmica veicular. 


\section{Capítulo 3 - Revisão teórica}

\section{1 - Faixa linear}

Dá-se o nome de faixa linear à faixa onde o uso do veículo apresenta comportamento dinâmico conforme uma reta, ou seja, os ganhos, movimentos, são de característica linear não apresentando outros comportamentos (exponenciais, logarítmicos entre outros).

Segundo a matemática temos duas propriedades que devem ser satisfeitas:

. Superposição: $f(x+y)=f(x)+f(y)$.

. Homogeneidade (de grau 1): $f(\alpha x)=\alpha f(x)$ para todo $\alpha$.

O motivo para se empregar esta faixa de utilização, a linear é a simplificação do modelo, assim de modo a permitir estudar especificamente as molas de suspensão. Por outro lado, os modelos simplificados devidamente correlacionados, são boas ferramentas para conceituar modificações e configurações das suspensões veiculares mais rapidamente e com adequada precisão, economizando recursos durante um programa veicular, ou seja, fazendo com se tenha um resultado mais próximo da realidade, antes de se ter o veículo físico.

O modelo definido nesta dissertação pode também ser atualizado para que seu uso seja estendido às faixas não lineares. A grande diferença é que os elementos considerados devem sofrer a adição de outros componentes de modo que o conjunto formado possibilite incrementar de modo progressivo o controle da carroceria. Ou seja, em vez de se utilizar molas de rigidez linear apenas deve-se acrescentar um batente de suspensão com uma curva de rigidez exponencial.

Para veículos de passeio, e considerando sua estabilidade (controle) em curvas o valor convencionado como boa prática para representar o limite desta faixa é $0,5 \mathrm{~g}$ de aceleração lateral (figura 23).

Complementando o conceito, a figura 24 apresenta uma típica curva de rigidez de suspensão automotiva, sendo nela representada uma mola helicoidal de rigidez linear e um batente de Poliuretano de rigidez progressiva complementando a rigidez inicial da mola nos regimes não lineares de operação. 
Nestes dois gráficos pode-se perceber a grande influência que os pneus têm no veículo como um todo, pois os únicos pontos de contato que o veículo tem com o solo são seus pneus e cada um possui uma área de contato equivalente à mão humana apenas.

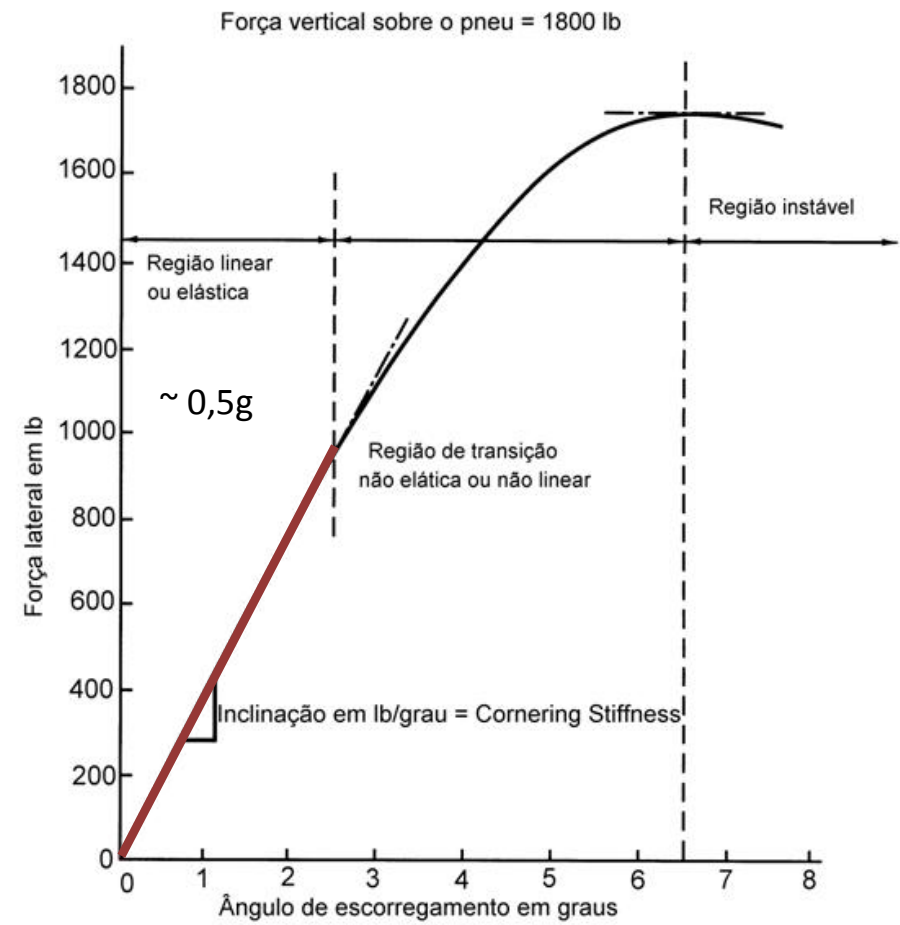

Figura 23 - Representação de típica curva de escorregamento de pneus (Milliken, 1995, p25)

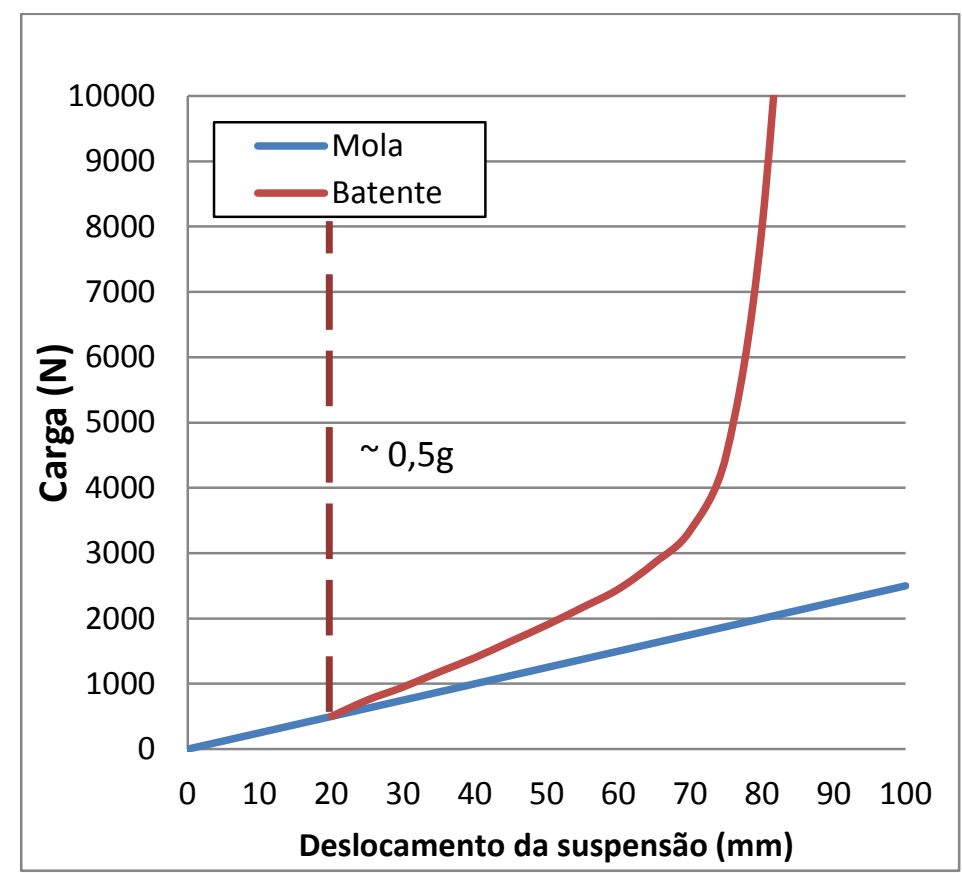

Figura 24 - Rigidezes de mola e batente de suspensão (autor) 
Considerando o ride, o conforto, as acelerações que os componentes da massa não suspensa sofrem e que são introduzidas nas suspensões devido ao perfil da pista, são muito maiores e por se tratar de uma condição de regime transiente, seu tratamento acaba incluindo os amortecedores e as buchas de material elastomérico.

Para este trabalho, uma das condições de contorno empregada é o uso do conjunto molas lineares e amortecedores. Isto é possível, pois devido à restrição à faixa linear de $0,5 \mathrm{~g}$ de aceleração linear lateral, é definido empiricamente como boas práticas de direcionais de projetos, que os batentes não devem atuar nesta faixa de uso. Já os amortecedores devem apresentar atuação em qualquer condição em que as suspensões apresentem velocidade (movimento).

\section{2 - Geometria da suspensão}

Não será abordada nesta dissertação, mas possui influência no comportamento dinâmico do veículo, pois além de sustentar as massas suspensas e manter os únicos pontos de apoio do veículo em contato como o solo, as suspensões também devem compensar e gerenciar os esforços e cargas que a massa suspensa permite devido à reação de forças dos pneus com o solo (figura 25). Assim os ângulos que a suspensão gera nos pneus (figura 26) são necessários para otimizar sua aderência e assim permitir equilíbrio dinâmico adequado durante a direção.

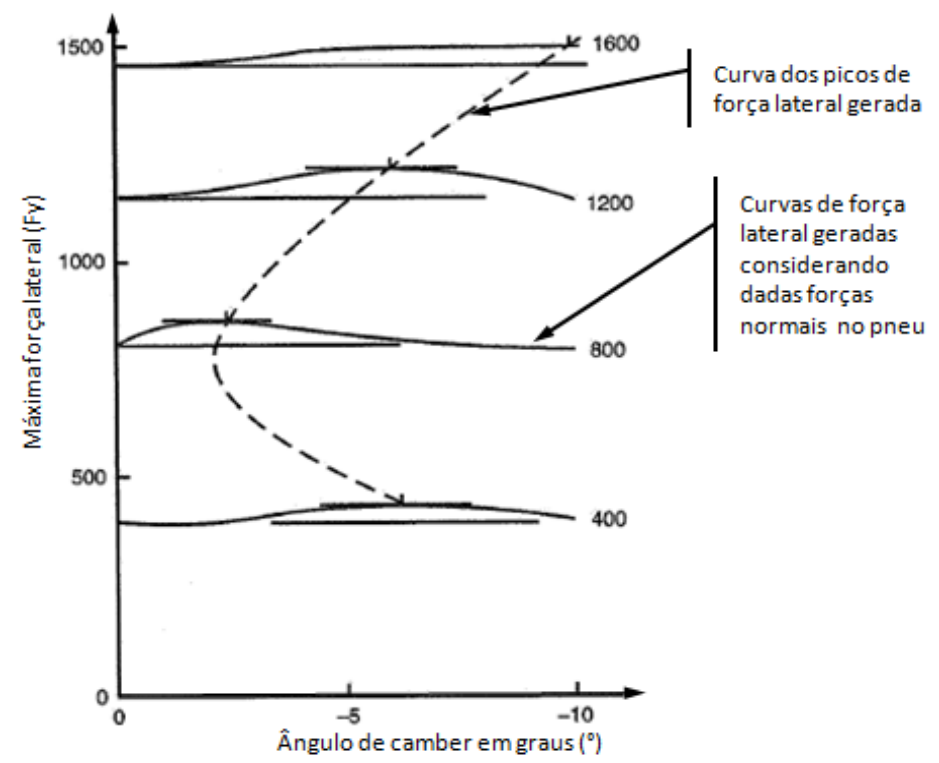

Figura 25 - Gráfico de força lateral em função da cambagem de um pneu (MILLIKEN, 1995, p49) 

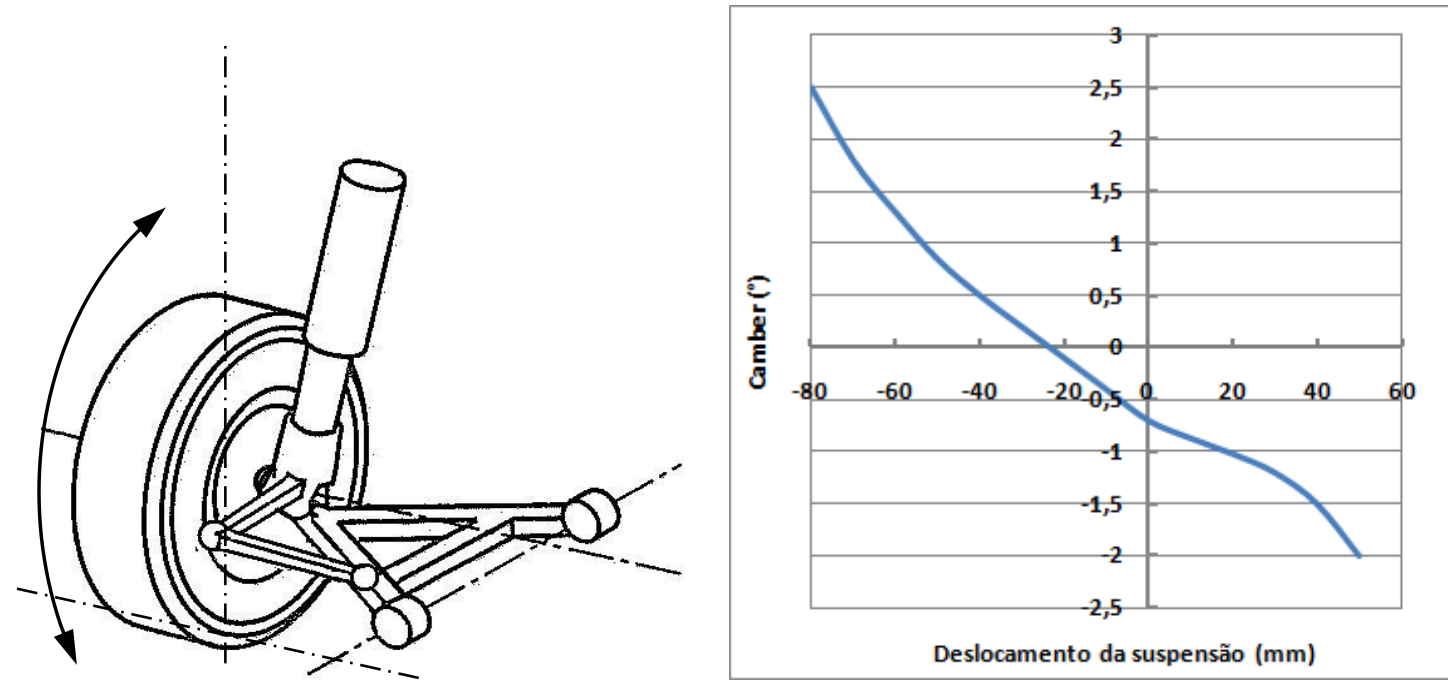

Figura 26 - Exemplo de curva de cambagem e uma suspensão tipo McPherson (autor)

Na figura 26 ainda, segue um exemplo de suspensão tipo McPherson e o arco de seu movimento vertical, pois principalmente nestas situações são gerados os ângulos de camber. Deve ser lembrado que os ângulos de camber são apenas um dos parâmetros definidos para o trabalho da suspensão.

Para complementar este conceito e direcioná-lo para o foco desta dissertação, tem-se o seguinte:

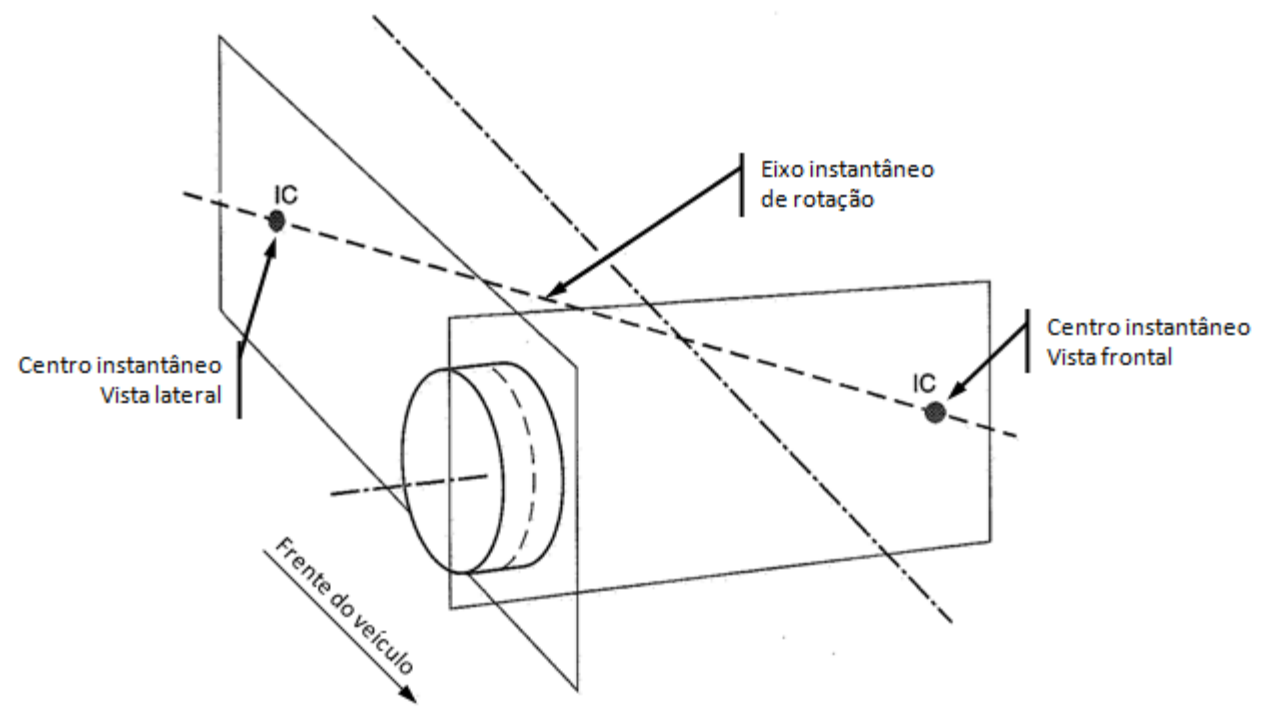

Figura 27 - Conceito cinemático de eixo instantâneo (MILLKEN, 1995, p613) 


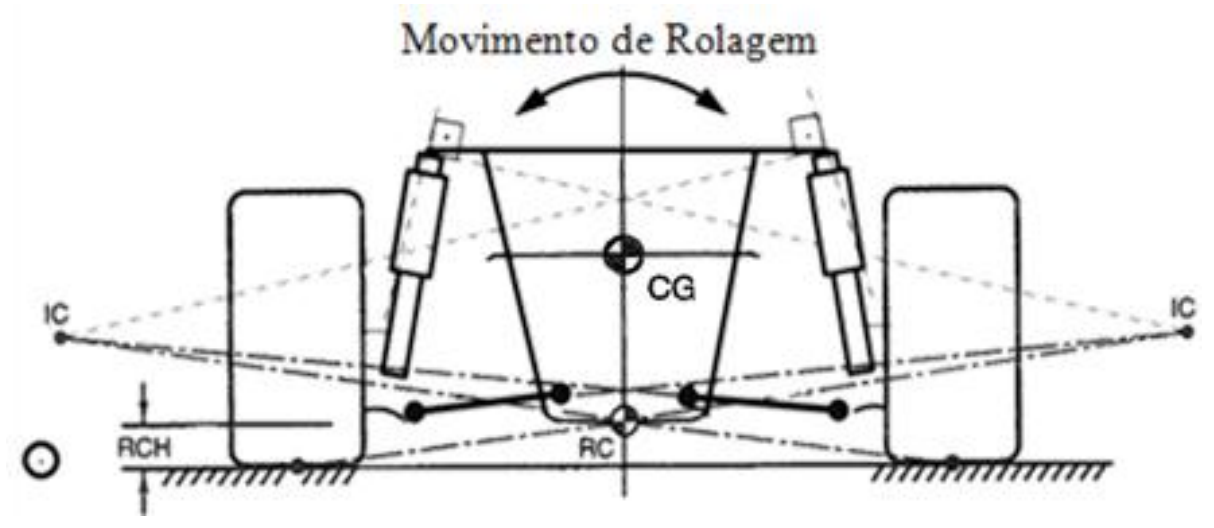

Figura 28 - Construção do centro de rolagem (autor)

Essas duas figuras, 27 e 28, são necessárias para mostrar como ocorre a rolagem da carroceria do veículo durante uma curva e também como a cinemática da suspensão trabalha para garantir o correto uso dos pneus. A carroceria se movimenta tendo o centro de rolagem como seu pivô e se sustenta nas molas e nas suspensões. Assim, as molas da suspensão são necessárias para se sustentar e controlar a carroceria durante o ato de guiar.

Tipicamente, o primeiro paço para se definir uma suspensão veicular é relativo aos estudos de geometria e cinemática. Após, são definidas as rigidezes das molas e demais componentes necessários para se permitir controle do ponto de vista de gerenciamento da energia que circula no sistema de suspensão devido a sua movimentação e após isso, inclui-se amortecimento para controlar as condições transientes que venham a ocorrer.

De um modo geral, a suspensão deve compensar todos os movimentos que a carroceria apresente e que como consequência cause variações do contato da interface do pneu com o solo. Como exemplo, abaixo está um circulo de atrito (figura 30), melhor dizendo elipse. Nele estão representadas as forças laterais e longitudinais para uma série de ângulos e proporções de escorregamento.

Trata-se de um modo de representar como os pneus podem gerenciar forças e permitir comportamentos dinâmicos desejados. 


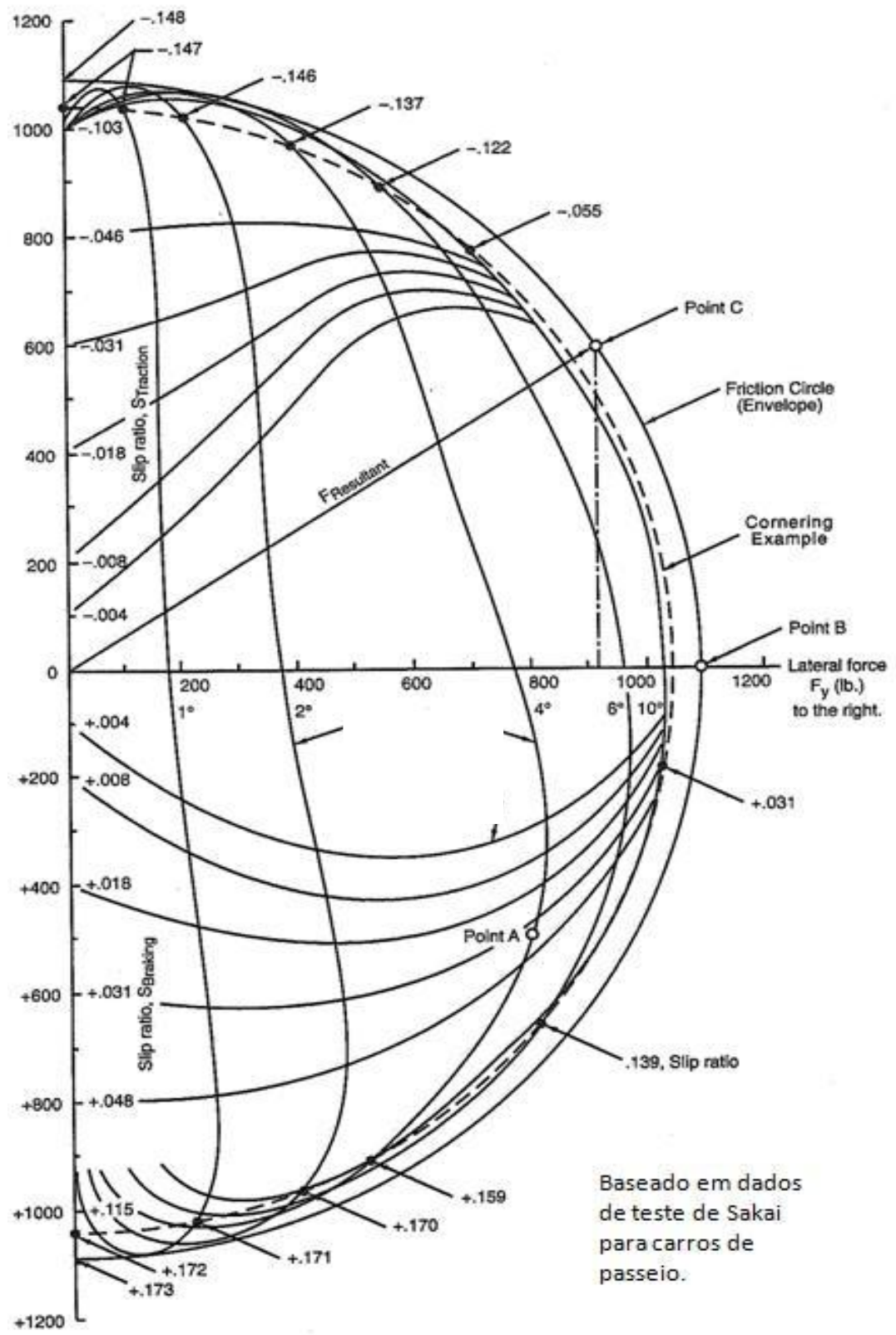

Figura 29 - Meio diagrama de circulo de atrito (Milliken, 1995, p58)

Em adição, o pneu também apresenta características de rigidez e amortecimento, assim, suas propriedades verticais influem diretamente no conforto do veículo. E também fazem parte da definição de rigidez vertical da suspensão (figura 29). De uma maneira simplificada o pneu pode ser representado por uma estrutura de molas arranjadas radialmente (figura 30). 


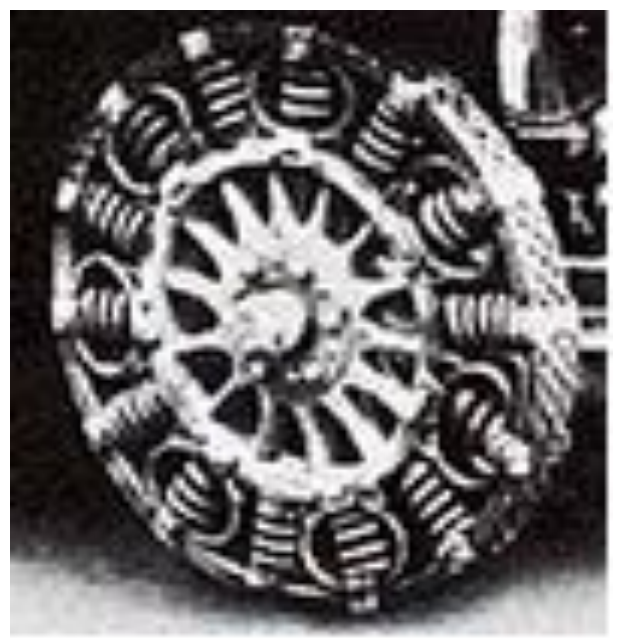

Figura 30 - Exemplo de protótipo de "pneu" executado com molas

Assim, para a representação da associação resultante das molas com os pneus em uma suspensão, tem-se:

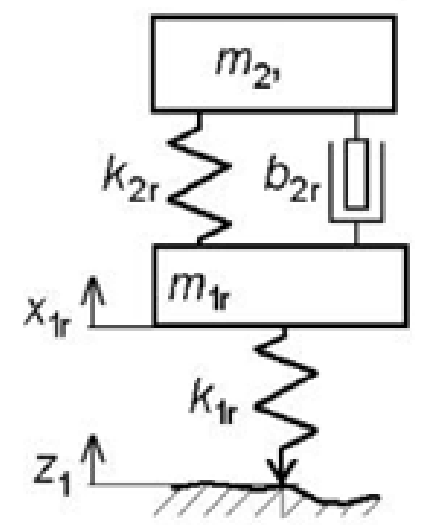

Figura 31 - Representação de quarto de carro de suspensão e pneu

Da figura 31 temos uma associação de molas em série, assim:

$$
\frac{1}{K_{\text {res }}}=\frac{1}{K_{1 r}}+\frac{1}{K_{2 r}}
$$

Onde:

$\mathrm{K}_{\text {res }}$ Rigidez resultante

$\mathrm{K}_{1 \mathrm{r}} \quad$ Rigidez vertical do pneu

$\mathrm{K}_{2 \mathrm{r}} \quad$ Rigidez da mola da suspensão 


\section{3 - Estabilidade}

O objetivo de se prover o veículo com adequado controle é fazer com que esteja apto a realizar sua função de transportar pessoas e carga nas mais variadas situações de pista e solicitação sempre tendo como referência determinadas premissas de projeto. Novamente tomando referências vindas da aeronáutica, "As qualidades de handling são aquelas qualidades ou características que governam a facilidade e precisão com as quais o operador está apto a realizar os trabalhos requeridos no suporte da função do veículo" (Cooper, G.E., and Harper, R.P (1969)).

Devem-se diferenciar esses dois termos que são constantemente empregados, a Dinâmica é o comportamento do veículo propriamente dito por ele mesmo em uma condição de "open loop", ou seja, sem sistemas de controle ou mesmo motorista. O handling, a estabilidade, provém dos esforços necessários vindos do motorista para manter o controle do veículo de modo seguro.

Quando se fala na estabilidade, no controle, deve-se ter em mente uma estimativa de onde as manobras executadas podem ser localizadas no que se refere à movimentação das suspensões. Na figura 32 existe um direcional com algumas situações visitadas durante determinados tipos de manobras e situações dinâmicas. Sendo as ocorrências no eixo z, o foco deste trabalho.

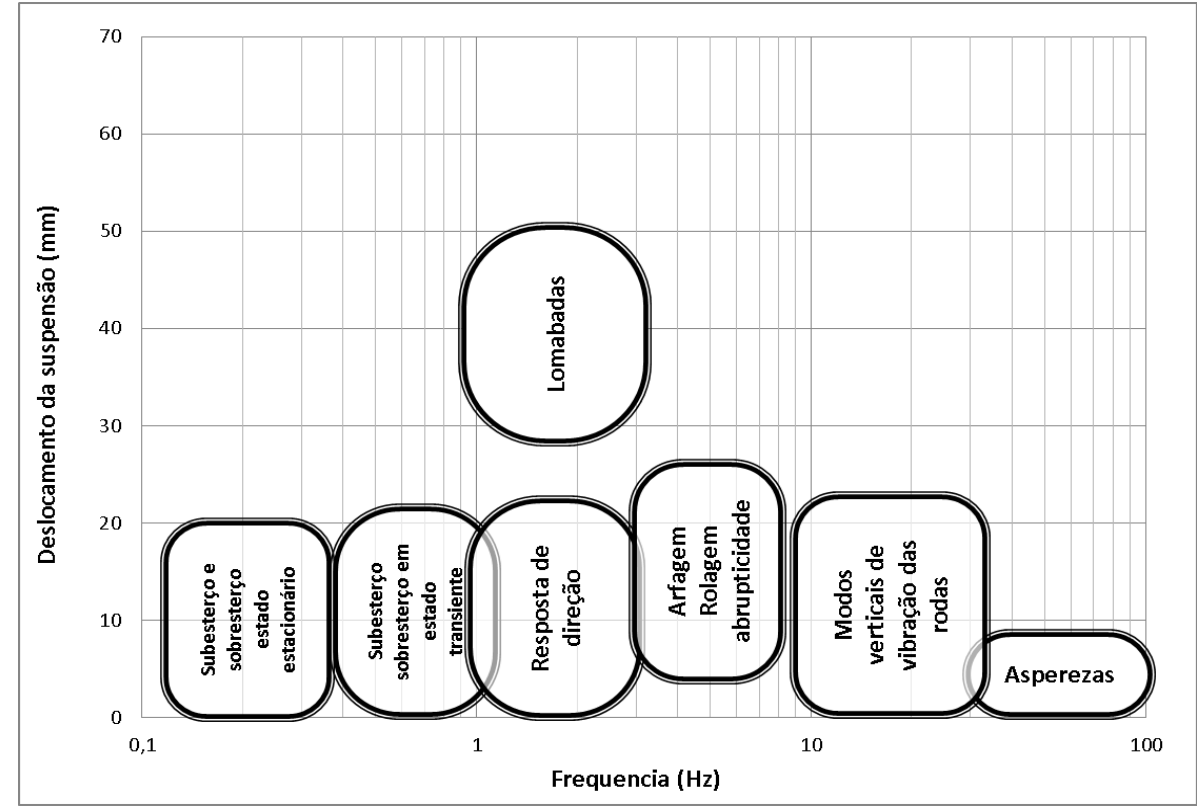

Figura 32 - Influências dos eventos de ride/handling nas suspensões (autor) 
Esse cuidado é necessário para que quando do período de desenvolvimento e acerto do veiculo seu comportamento e equilíbrio sejam devidamente ajustados para se evitar que algum atributo de conforto ou estabilidade seja afetado de modo negativo.

Os dois próximos itens a serem discorridos se referem a dois estados em que um veículo pode se colocar quando está em uma curva. O estado estacionário se refere ao período durante o contorno onde suas variáveis de movimento não sofrem variação em função do tempo discorrido e o estado transiente é aquele onde o veículo está apresentando variações de aceleração, velocidade, escorregamento, esterço em função do tempo discorrido. O primeiro ocorre durante a curva, o segundo quando se está entrando ou saindo da mesma.

A figura 33 a seguir representa a abordagem feita acima para que se possam visualizar os próximos tópicos.

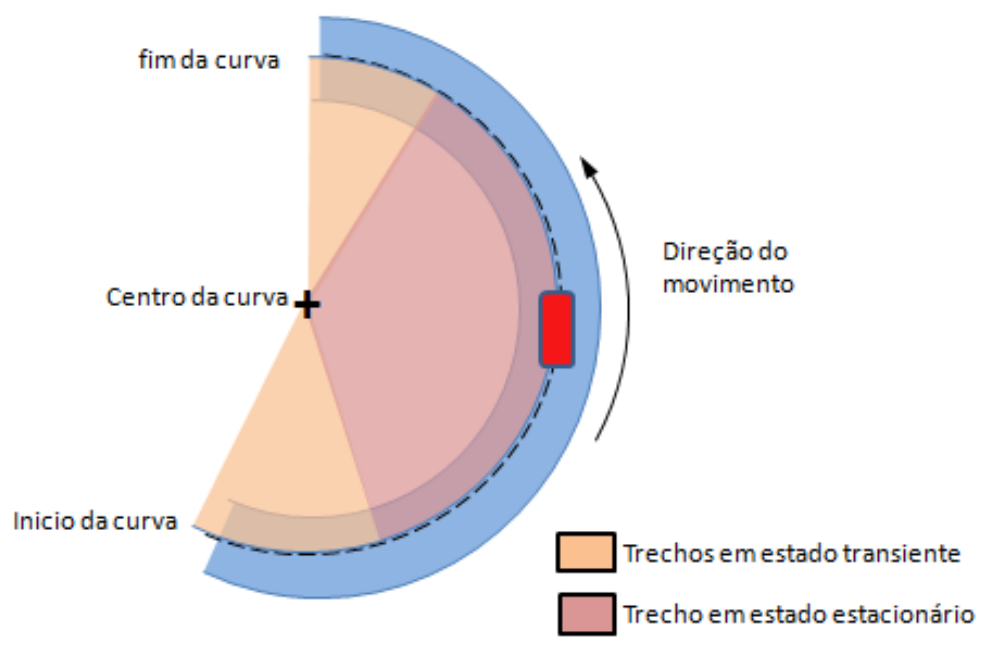

Figura 33 - Estados do movimento em uma curva (autor)

\subsection{1 - Estado estacionário}

No estado estacionário, as variáveis do movimento não sofrem mudanças em função do tempo. Para este estado, um modelo pode ser comumente empregado devido a suas características, o modelo da bicicleta, sendo suas características as seguintes:

- Sem transferência de carga lateral

- Sem transferência de carga longitudinal

- Sem movimentos de carroceria de mergulho ou arfagem

- Pneus na faixa linear 
- Velocidade constante

- Sem influência da aerodinâmica

- Controle da posição

- Sem efeitos de suspensão ou deformações

Basicamente este modelo pode ser utilizado para se estudar efeitos de rigidez de pneus, localização de $\mathrm{CG}$, e ângulo de esterço para movimentos de rotação (eixo Z) e escorregamentos laterais, que determinam o caminho e atitude do veículo (Milliken, p127, 1995).

A figura 34 representa este modelo:

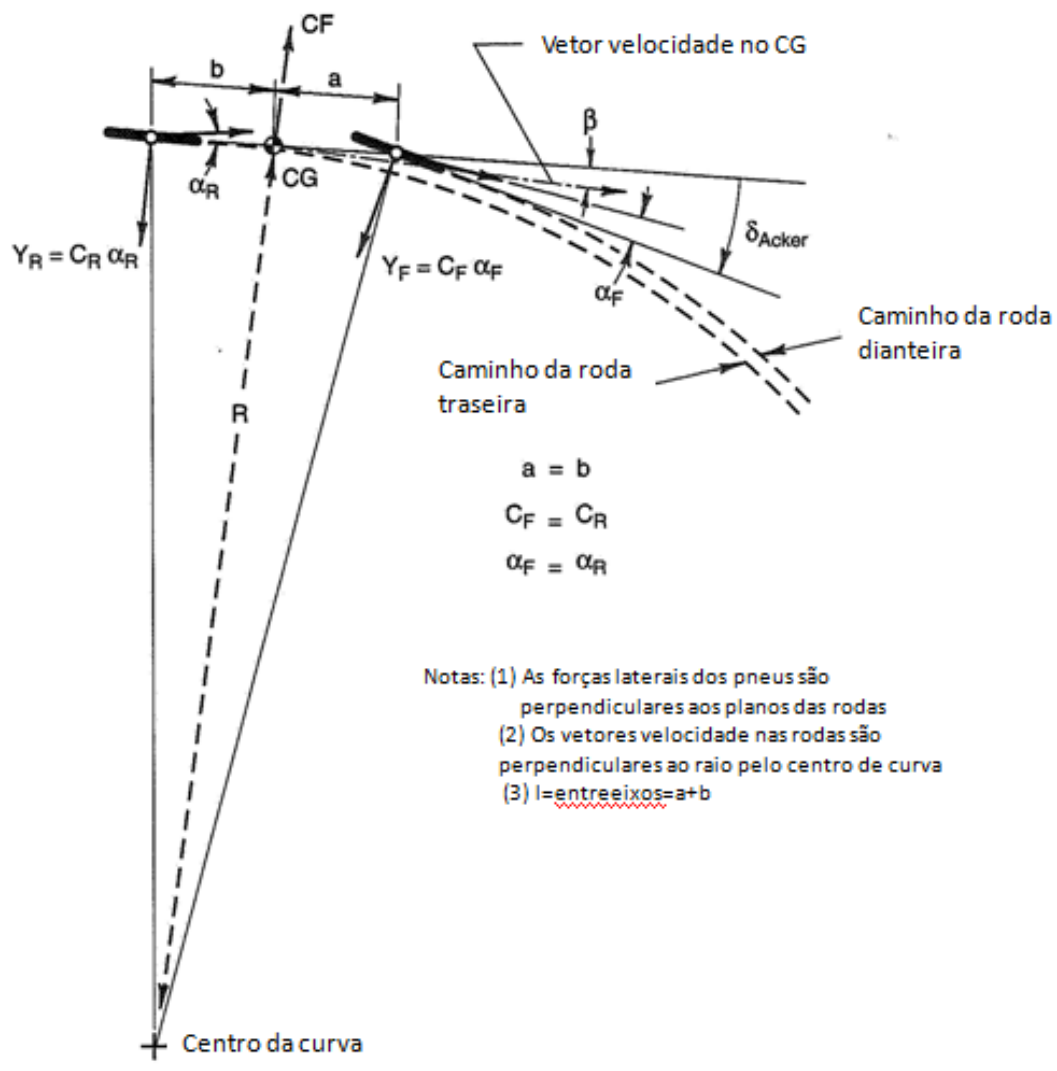

Figura 34 - Representação do modelo da bicicleta (Milliken, 1995, p131)

Deve-se salientar que seus pontos negativos deste modelo para esta dissertação se referem a não possibilidade de apresentar sensibilidade ao funcionamento da suspensão e suas rigidezes. Partindo-se deste ponto o modelo acima citado serve para demonstrar a definição do que é estado estacionário. Como as considerações para conforto e estabilidade estudadas aqui tem a ver diretamente com a rigidez das suspensões e sua geometria o seguinte modelo 
(figura35) pode apresentar as entradas mais adequadas de modo a complementar o modelo inicial:

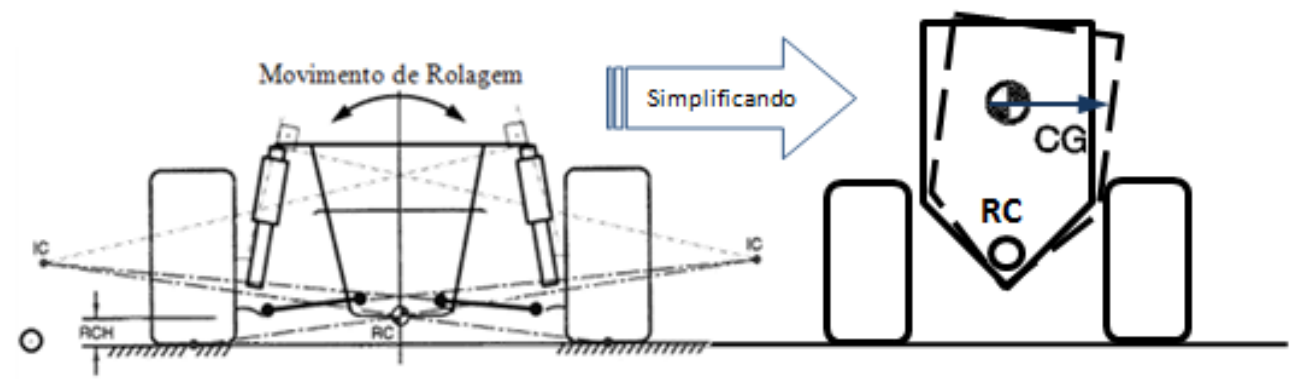

Figura 35 - Modelo para análise de rolagem (autor)

A ideia de estado estacionário para este modelo se refere a não utilizar a variação de aceleração lateral em função do tempo, mas sim apresentar sensibilidade à aceleração lateral e deste modo mostrar as transferências de carga que ocorrem em cada eixo, podendo assim serem demonstrados os motivos e condições de contorno para se buscar o compromisso de estabilidade e conforto.

Para a situação acima podemos ter o seguinte:

$$
\begin{gathered}
\frac{\emptyset}{A_{Y}}=\frac{-W H}{K_{F}+K_{R}}=K_{\emptyset} \\
\frac{\Delta W_{F}}{A_{y}}=\frac{W}{t_{F}}\left[\frac{H K_{F}}{K_{F}+K_{R}}+\frac{b}{l} z_{R F}\right] \\
\frac{\Delta W_{R}}{A_{y}}=\frac{W}{t_{R}}\left[\frac{H K_{R}}{K_{F}+K_{R}}+\frac{a}{l} Z_{R R}\right]
\end{gathered}
$$

Onde:

$\varnothing$ Ângulo de rolagem

Ay Aceleração lateral

W Peso do veículo

H Distância do CG ao eixo de rolagem

$\mathrm{K}_{\mathrm{F}}$ Rigidez de rolagem do eixo dianteiro

$K_{R}$ Rigidez de rolagem do eixo traseiro

$\mathrm{K}_{\varnothing}$ Rigidez de rolagem do veículo

b Distância do eixo traseiro ao CG

a Distância do eixo dianteiro ao CG

1 Entreeixos do veículo 
$\mathrm{Z}_{\mathrm{RF}} \quad$ Distância do roll center dianteiro ao solo

$\mathrm{Z}_{\mathrm{RR}}$ Distância do roll center traseiro ao solo

$t_{F} \quad$ Bitola dianteira

$t_{R} \quad$ Bitola traseira

Essas equações regem a transferência de carga durante as curvas. Elas estão simplificadas para se enxergar exatamente a movimentação entre frente e trás e a transferência de carga de um lado para outro (Milliken, p683, 1995).

Voltando à figura 35, ela representa um eixo do veículo apenas, porém o mesmo deve ser entendido para todos os outros eixos que o veículo possa ter. Melhor definindo, o comportamento dinâmico do veículo também é ditado pela interação entre os eixos dianteiro e traseiro. As imagens a seguir (figuras 36 e 37), retiradas da internet, demonstram de modo mais saliente como ocorrem essas transferências de carga durante a direção do veículo em curvas.

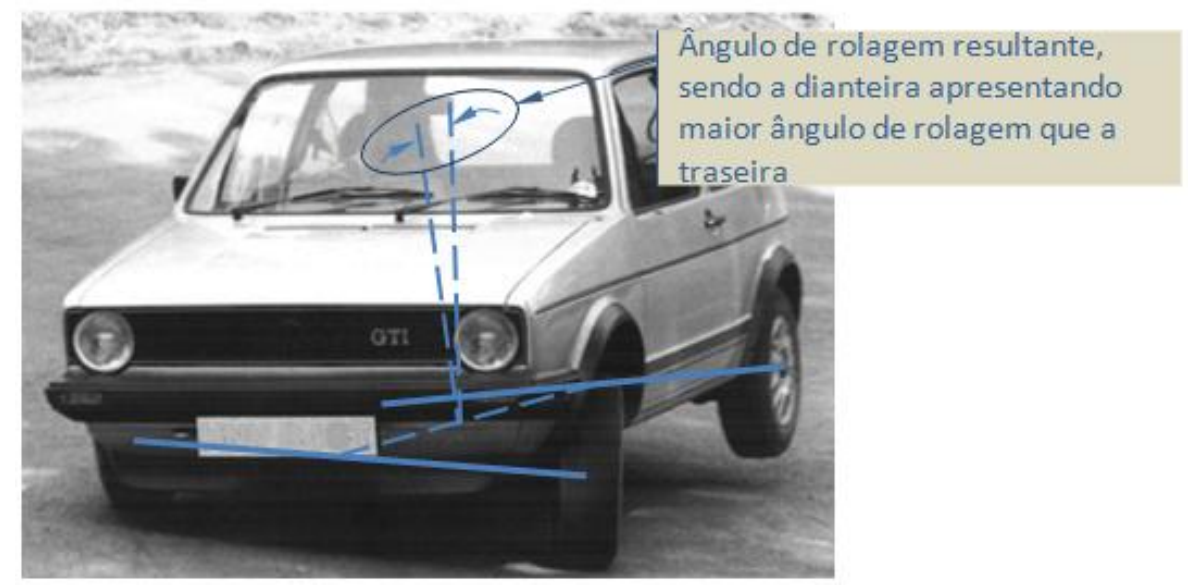

Figura 36 - Veículo apresentando maior ângulo de rolagem na dianteira

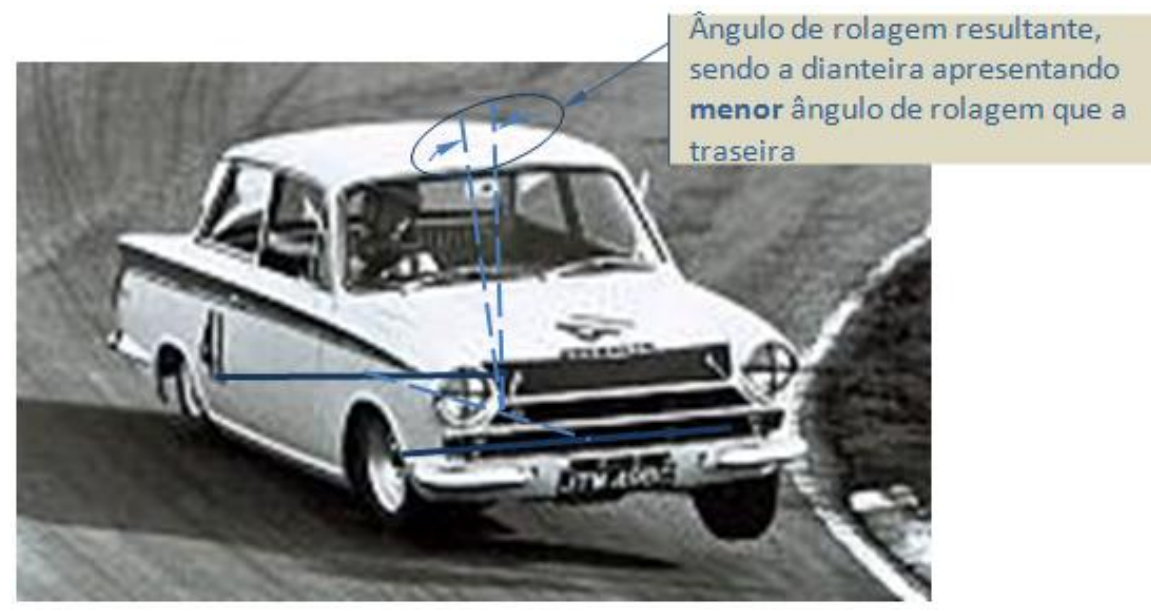

Figura 37 - Veículo apresentando maior ângulo de rolagem na traseira 
A ideia das imagens é mostrar como acontece o fenômeno da rolagem da carroceria em algumas situações de direção.

A análise apresentada a seguir se refere a um veículo subesterçante, pois quando se pensa em veículos de rua, esse é o comportamento em estado estacionário correto, por apresentar maior segurança de direção para o motorista comum.

Para o modelo de bicicleta (figura 38), adota-se a posição do CG a $1 / 3$ do eixo dianteiro baseado na medida do entreeixos, assim teremos $2 / 3$ do peso no eixo dianteiro e $1 / 3$ no eixo traseiro e o eixo dianteiro recebendo $2 / 3$ da carga em curvas e o eixo traseiro $1 / 3$. Considerando ainda mesma rigidez em curva para a dianteira e a traseira, $\alpha_{F} / \alpha_{R}=2$. Sendo $\alpha_{1}=$ ângulo de escorregamento. Também $A_{Y}=a_{Y} / g$.

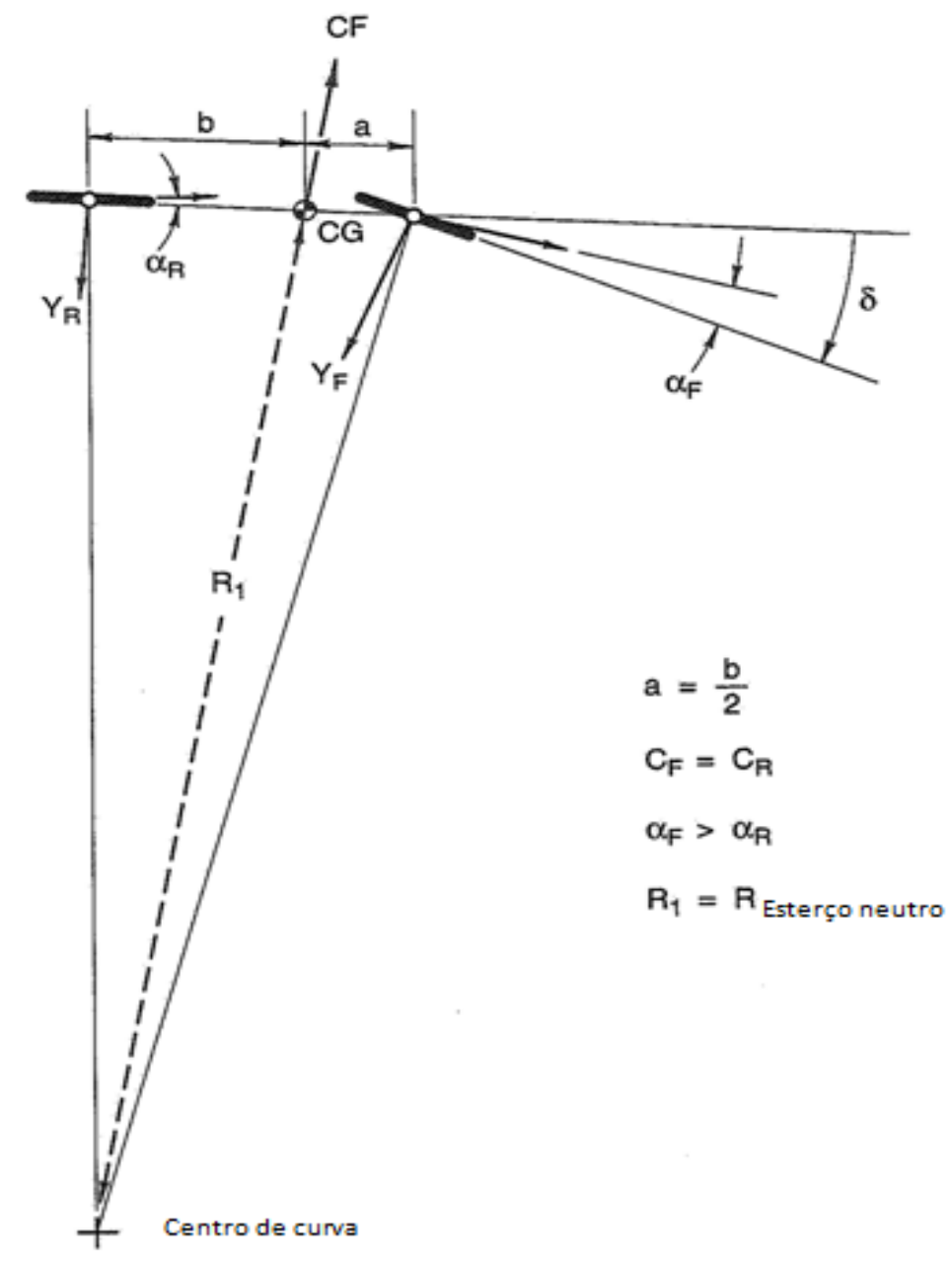

Figura 38 - Modelo da bicicleta considerando influência do CG

Lembrando que para um veículo de comportamento neutro, $\alpha_{1}$ é igual para a dianteira e traseira e $W A_{y}=2 C \alpha_{1}$, desde que $C_{F}=C_{R}=C$ e $\alpha_{F}=\alpha_{R}=\alpha_{1}$. 
Na situação de veículo subesterçante:

$$
W A_{Y}=C\left(\alpha_{F}+\alpha_{R}\right)=C\left(2 \alpha_{R}+\alpha_{R}\right)=3 C \alpha_{R}=2 C \alpha_{1}
$$

$\mathrm{ou}$

$$
\alpha_{R}=\frac{2}{3} \alpha_{1}
$$

também

$$
W A_{y}=\frac{3}{2} C \alpha_{F}=2 C \alpha_{1}
$$

ou

$$
\alpha_{F}=\frac{4}{3} \alpha_{1}
$$

Deste modo a figura para o modelo de bicicleta torna-se o que está representado na figura 38. De modo a representar melhor o que acontece, podemos observar os gráficos da figura 39.

No primeiro, pode-se verificar o aumento do ângulo de esterço em relação ao ângulo de Ackerman, indicando o escorregamento do eixo dianteiro. No segundo, o comparativo dos ângulos de escorregamento do eixo dianteiro e traseiro, neste caso demonstrando a característica de subesterço. O comportamento linear apresentado segue até $0,5 \mathrm{~g}$ de aceleração lateral.

Vale lembrar que estes estudos possuem como condição de contorno, a condição de subesterço ser devida localização do CG do veículo. Qualquer situação que venha a modificar os ângulos de escorregamento da dianteira e traseira como, por exemplo, variações de geometria de suspensão e suas rigidezes, cargas aerodinâmicas, medidas diferentes de pneus, amortecimento, podem acarretar em mudança da situação de equilíbrio. Assim, voltando ao escopo deste trabalho e observando o veículo como um todo deve se acrescentar as características de geometria e rigidez. 

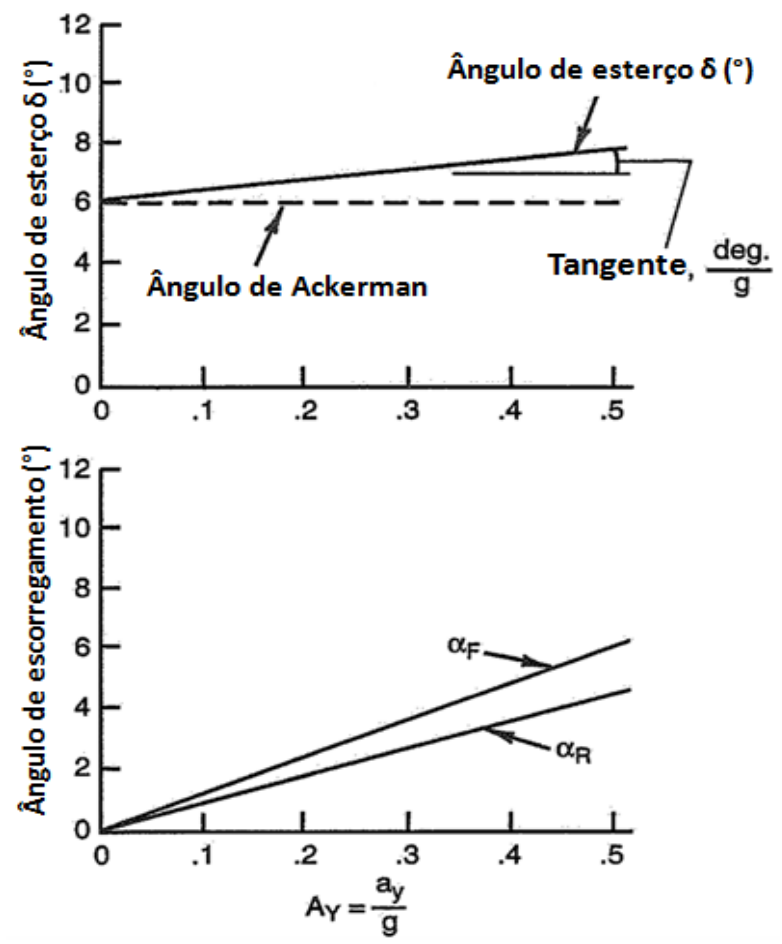

Figura 39 - Característica de subesterço pra o exemplo do modelo de bicicleta (Milliken, 1995, p139)

\subsection{2 - Rigidez torcional}

Para os veículos atuais, é necessário um componente que permita acrescentar valores de rigidez ao sistema de suspensão para que deste modo seja possível endereçar controle torcional adequado e também controle vertical adequado. $\mathrm{O}$ controle vertical é devido às molas/batentes e possuem dupla função de controle de carroceria, quanto a estabilidade e controle de oscilações/vibrações para permitir conforto devido ao uso do veículo. Para o controle lateral durante as curvas, é necessário adicionar um componente que permita compensar a falta de rigidez que os componentes elásticos possam apresentar. Normalmente é empregada a chamada barra estabilizadora.

Para complementar a ideia de rigidez torcional do tópico anterior, deve-se ter em mente o seguinte:

- A função da barra estabilizadora, também chamada de barra anti-rolagem é complementar a rigidez torcional no veículo.

. Sua rigidez deve ser somada à do conjunto de molas/batentes das suspensões 
Deste modo têm-se:

. Alavanca da instalação da barra estabilizadora:

$$
K_{W}=\frac{K_{b} I_{b}}{57,3}
$$

Onde:

$K_{w}=$ Rigidez efetiva aproximada na roda (lb/in)

$K_{b}=$ Rigidez da barra estabilizadora (lb.in/deg)

$I_{b}=$ Relação de instalação da barra estabilizadora (deg/in)

. Contribuição da barra estabilizadora para o roll total:

$$
k_{\emptyset B}=k_{\theta B} I_{B}^{2}\left(\frac{T^{2}}{L^{2}}\right)
$$

Onde:

$k_{\varnothing B}=$ Contribuição da rigidez da barra estabilizadora à rigidez total do veículo (lb.ft/deg)

$k_{I B}=$ Rigidez torcional da barra estabilizadora (lb.ft/deg)

$L=$ braço de alavanca da barra estabilizadora $(\mathrm{ft})$

$I_{B}=$ Relação linear de instalação da bara estabilizadora em deslocamento do movimento do ponto de ancoragem da barra por deslocamento do movimento da roda (in./in.)

$T=$ Bitola (in.)

Os valores estão em sistema britânico para representar a origem da fonte de informação para os cálculos.

Para a geometria, resumida a posição do CG, eixo de rolagem, bitolas e entreeixos, o seguinte pode ser observado (figura 40): 


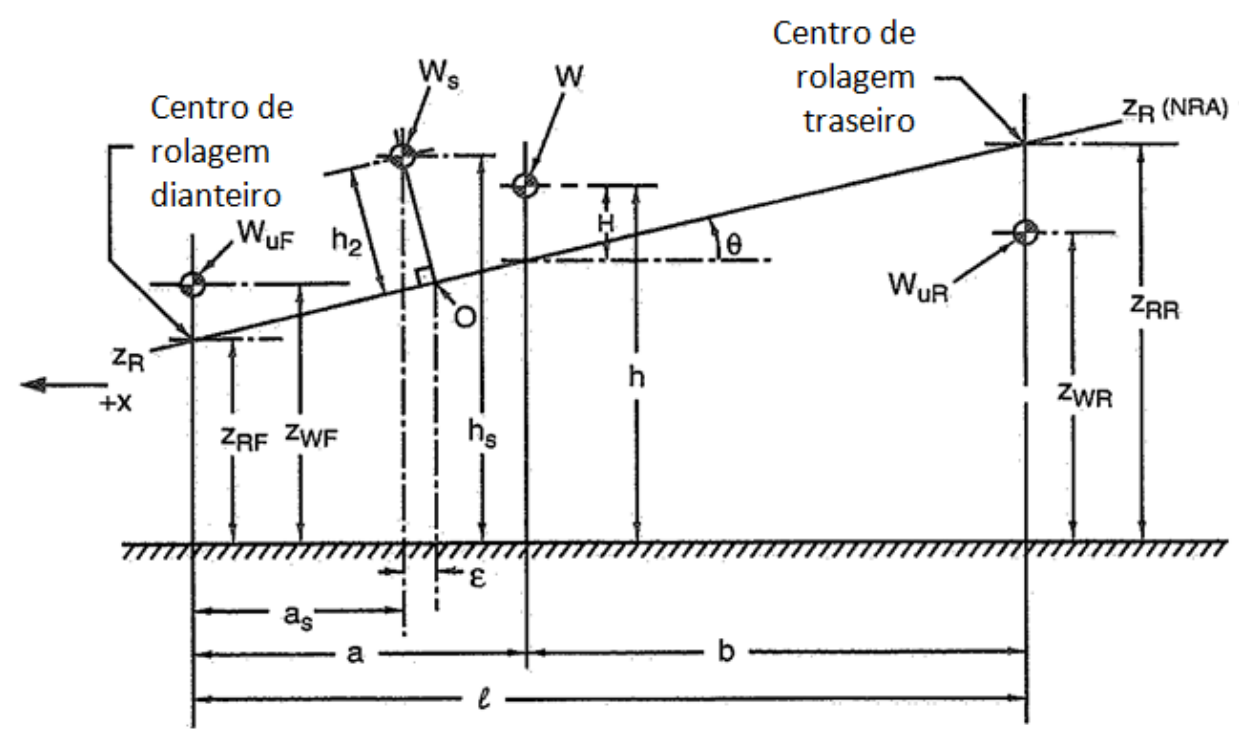

Figura 40 - Geometria base para transferência de carga lateral (Milliken, 1995, p681)

Onde:

$\mathrm{W}_{\mathrm{UF}} \quad$ Massa não suspensa dianteira, na altura $\mathrm{Z}_{\mathrm{WF}}$

$\mathrm{W}_{\mathrm{UR}} \quad$ Massa não suspensa traseira, na altura $\mathrm{Z}_{\mathrm{WR}}$

$\mathrm{W}_{\mathrm{S}} \quad$ Peso da massa suspensa, na altura $\mathrm{h}_{\mathrm{S}}$ e perpendicular a distância $\mathrm{h}_{2}$ da NRA

W Peso total do veículo na altura h e distancia vertical H do NRA

$\mathrm{Z}_{\mathrm{RF}}, \mathrm{Z}_{\mathrm{RR}}$ Alturas dos centros de rolagem dianteiro e traseiro

$\theta \quad$ Inclinação do eixo de rolagem neutro (radianos)

Para esta figura, a explicação é a seguinte:

Quando em curva, a aceleração lateral produz a força $F_{S}=-W_{S} A_{Y}$ e assim em torno de $\mathrm{O}$ surge o momento $M_{S}=-W_{S} h_{2}\left(A_{Y}-\emptyset\right)$, onde $\emptyset=$ ângulo de rolagem da carroceria.

Assim para a rigidez à rolagem tem-se a equação:

$$
\frac{\emptyset}{A_{Y}}=\frac{-W_{S} h_{2}}{K_{F}+K_{R}-W_{S} h_{2}}=K_{\emptyset}
$$

Que é a sensibilidade à aceleração lateral.

Em seguida o momento $\mathrm{M}_{\mathrm{S}}$ é dividido para a dianteria e traseira, fazendo com que produzam sua própria transferência de carga. Incluindo também suas reações inerciais $\mathrm{W}_{\mathrm{UF}} \mathrm{e}$ $\mathrm{W}_{\mathrm{UR}}$. 
Assim para o eixo dianteiro temos:

$$
\frac{\Delta W_{F}}{Y}=\frac{W_{S}}{t_{F}}\left[\frac{h_{2} K_{F}^{\prime}}{K_{F}+K_{R}-W_{S} h_{2}}+\frac{l-a_{S}}{l} Z_{R F}\right]+\frac{W_{u F}}{t_{F}} Z_{W F}
$$

Onde:

$$
K_{F^{\prime}}=K_{F}-\left(l-a_{s}\right) W_{s} h_{2} / l
$$

Para o eixo traseiro temos:

$$
\frac{\Delta W_{R}}{Y}=\frac{W_{S}}{t_{R}}\left[\frac{h_{2} K_{R^{\prime}}}{K_{F}+K_{R}-W_{S} h_{2}}+\frac{a_{S}}{l} z_{R R}\right]+\frac{W_{u R}}{t_{R}} Z_{W R}
$$

$$
\text { Onde: } K_{R^{\prime}}=K_{R}-a_{s} W_{s} h_{2} / l
$$

As seguintes condições de contorno podem ser empregadas de modo a facilitar o entendimento do fenômeno:

$$
\begin{aligned}
\mathrm{W}_{\mathrm{uF}} & \approx \mathrm{W}_{\mathrm{uR}} \approx 0 \\
\mathrm{~W}_{\mathrm{s}} & \approx \mathrm{W} \\
\mathrm{a}_{\mathrm{s}} & \approx \mathrm{a} \\
\mathrm{h}_{2} & \approx \mathrm{H} \\
\mathrm{h}_{\mathrm{s}} & \approx \mathrm{h} \\
\mathrm{K}_{\mathrm{F}^{\prime}} & \approx \mathrm{K}_{\mathrm{F}} \\
\mathrm{K}_{\mathrm{R}^{\prime}} & \approx \mathrm{K}_{\mathrm{R}}
\end{aligned}
$$

Deste modo, simplificando temos:

$$
\begin{gathered}
\frac{\emptyset}{A_{y}}=\frac{-W H}{K_{F}+K_{R}}=K_{\emptyset} \\
\frac{\Delta W_{F}}{A_{Y}}=\frac{W}{t_{F}}\left[\frac{H K_{F}}{K_{F}+K_{R}}+\frac{b}{l} z_{R F}\right] \\
\frac{\Delta W_{R}}{A_{Y}}=\frac{W}{t_{R}}\left[\frac{H K_{R}}{K_{F}+K_{R}}+\frac{a}{l} z_{R R}\right]
\end{gathered}
$$

Novamente falando em aceleração lateral, ela é baseada no comportamento do pneu, assim não importa como a suspensão seja configurada, a quantia de aceleração lateral que o carro pode atingir ainda é ditada pelos pneus (figura 41). 


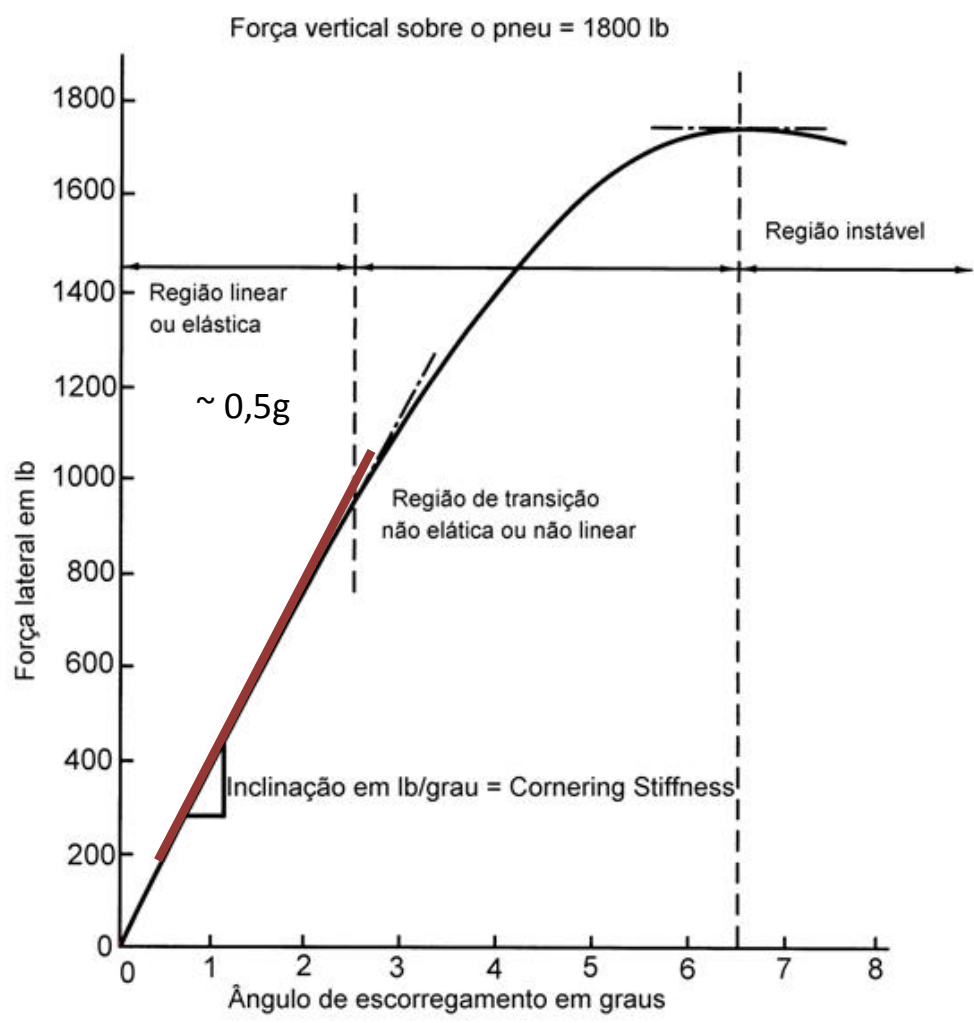

Figura 41 - Faixa linear de um pneu (Milliken, 1995, p25)

Devendo ser lembrado que em veículos atuais é comum o uso de barras estabilizadoras, assim temos as seguintes considerações:

Rigidez de rolagem do veículo devido às molas/batentes:

$$
K_{\emptyset S}=K_{\emptyset S F}+K_{\emptyset S R}
$$

Rigidez de rolagem devida à barra estabilizadora:

$$
K_{\varnothing B}=K_{\varnothing}-K_{\varnothing S}
$$

. Alavanca da instalação da barra estabilizadora:

$$
K_{W}=\frac{K_{b} I_{b}}{57,3}
$$

. Contribuição da barra estabilizadora para o roll total:

$$
k_{\emptyset B}=k_{\theta B} I_{B}^{2}\left(\frac{T^{2}}{L^{2}}\right)
$$


Deve existir uma proporção entre as rigidezes dos eixos traseiro e dianteiro de modo a equilibrar o veículo quando em curvas e não permitir que assuma uma condição estacionária de tendência muito subesterçante ou sobreesterçante. Sendo para veículos de rua o objetivo é o subesterço.

Considerando a transferência total de carga:

$$
\frac{T L T}{A_{Y}}=\frac{W_{T} h}{T_{\text {ave }}}
$$

Para a rigidez dianteira:

$$
\frac{F L T}{A y}=\frac{12\left(k_{\emptyset F}\right) \emptyset}{T_{F}}+\frac{W_{S F} Z_{F}}{T_{F}}+\frac{W_{U F} W_{R F}}{T_{F}}
$$

Assim, deve se ter em mente a distribuição de massas no veículo para o eixo dianteiro e traseiro de modo a haver uma proporção nas rigidezes para cada eixo. Como referência os valores de rigidez torsional devem estar dentro de um intervalo de cerca de $4 \%$ em relação à distribuição de massa. Essas observações são referentes à condição de estado estacionário e limitada à faixa linear.

\subsection{3 - Estado transiente}

Neste estado, as variáveis do movimento sofrem mudanças em função do tempo. Assim, um estado i é dito transiente se, dado que comecemos num estado i existe uma probabilidade diferente de 0 de nunca retornarmos a i. Formalmente, deixar a variável randômica Ti ser o primeiro tempo de retorno ao estado i (o tempo da excitação).

$$
T_{i}=\inf \left\{n \geq 1: X_{n}=i \mid X_{0}=i\right\}
$$

Essa transitoriedade significa passando em função do tempo ou o estado de ser breve. $\mathrm{Na}$ aplicação automotiva, é um evento de vida curta devido a uma rajada de energia em um sistema, causado por uma repentina mudança de estado. A fonte da energia transiente pode ser um evento interno ou próximo. Sendo que essa energia passa a transitar para outras partes do sistema causando uma oscilação. Num automóvel pode ser um movimento, vibração ou aspereza causada pela pista. 
Novamente apresentando um sistema massa mola amortecedor na figura42:

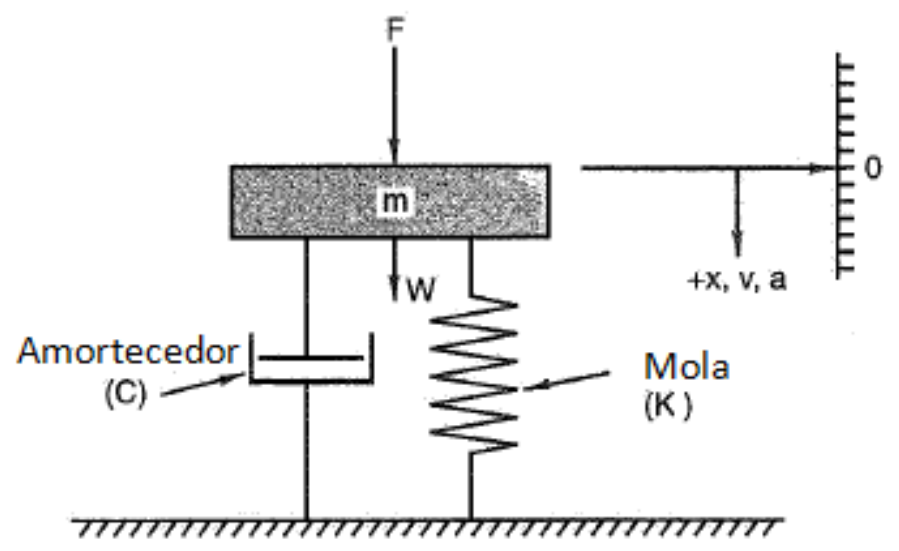

Figura 42 - Sistema massa-mola-amortecedor ((Milliken, 1995, p235)

Sendo que a equação do movimento pode ser interpretada como:

$$
F=\frac{W a}{g}+C V+K x
$$

De um modo resumido pode-se colocar que uma análise dinâmica deste sistema massa-mola-amortecedor deve apresentar dois fatores principais, a frequência natural não amortecida e a constante de amortecimento.

Sendo a frequência natural não amortecida:

$$
f_{n}=\frac{1}{2 \pi} \sqrt{\frac{K}{m}}
$$

E a constante de amortecimento:

$$
\xi=\frac{1}{2}\left(\frac{c}{m \cdot f n}\right) \quad \text { [adimensional] }
$$

Para esta análise devemos substituir a formula da frequência natural (3.2) na da constante de amortecimento (3.3):

$$
\xi=\frac{1}{2}\left(\frac{c}{\sqrt{K \cdot m}}\right)
$$

Assim, para uma suspensão automotiva, a equação 3.29 pode ser vista da seguinte forma: 


$$
C=\xi \cdot 2 \cdot \sqrt{K \cdot m}
$$

De onde podemos enxergar da seguinte maneira gráfica (figura43) e associar ao movimento das suspensões:

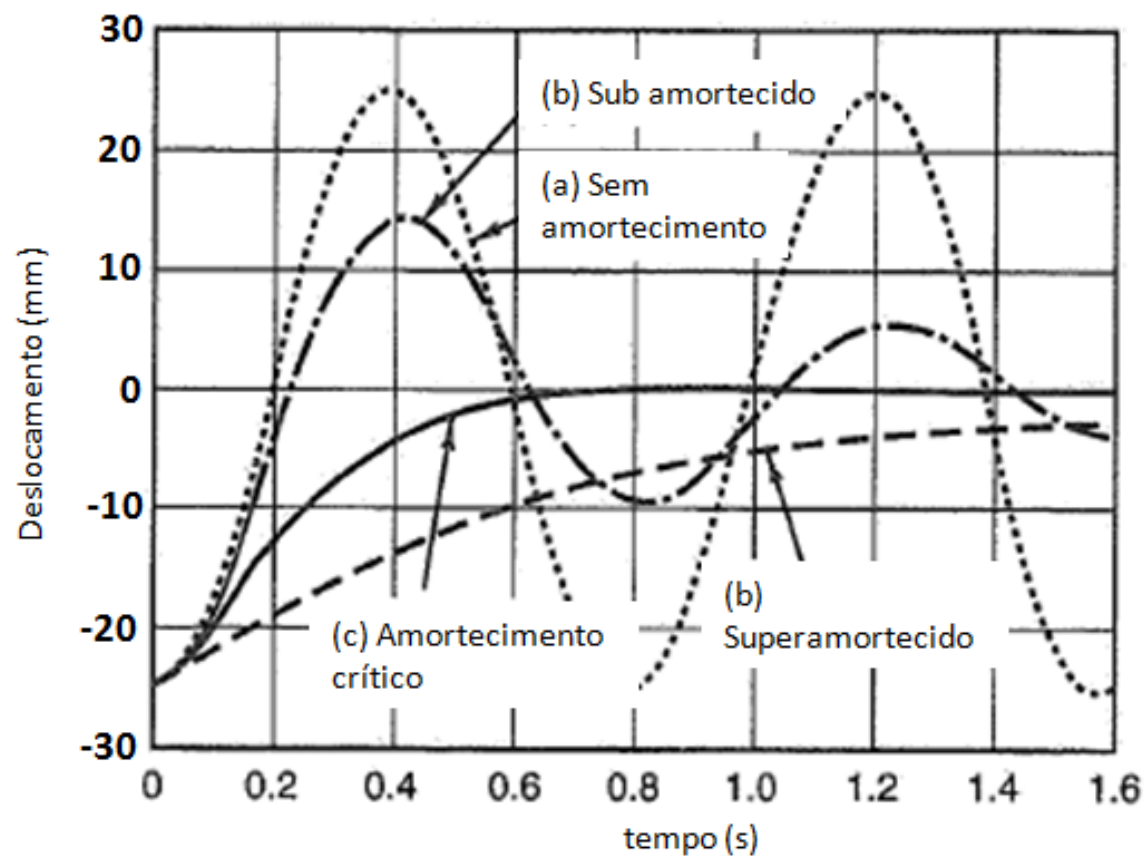

Figura 43 - Resposta transiente para tipos de amortecimento (Milliken, 1995, p238)

Para a suspensão automotiva, isso significa que, considerando as várias situações transientes em manobras e movimentações de carroceria, existe uma condição de amortecimento (carga de) que melhor vai endereçar a necessidade de controle, para estabilizar a carroceria ou isolá-la do leito carroçável naquele momento no tempo. Assim além de apresentar rigidezes adequadas para controle em situações estacionárias durante a direção, as suspensões veiculares também devem apresentar controle em situações transientes com o mesmo intuito de estabilizar um movimento.

\subsection{4 - Precisão e estabilidade direcional}

Neste tópico serão apresentadas algumas ideias a respeito das buchas das suspensões. Devido à cinemática e também à elastocinemática das suspensões veiculares, assim como o perfil das pistas e o ato de conduzir, as entradas dos movimentos no eixo z (vertical) do veículo não se originam somente no eixo vertical, mas são resultantes de movimentos que vem dos três eixos 
normalizados. Assim é necessário apresentar informações sobre como a suspensão se movimenta para que não ocorram direcionais errados sobre análises e condução dos trabalhos.

Como exemplo, a figura 44 apresenta um típico braço inferior de suspensão tipo McPherson.

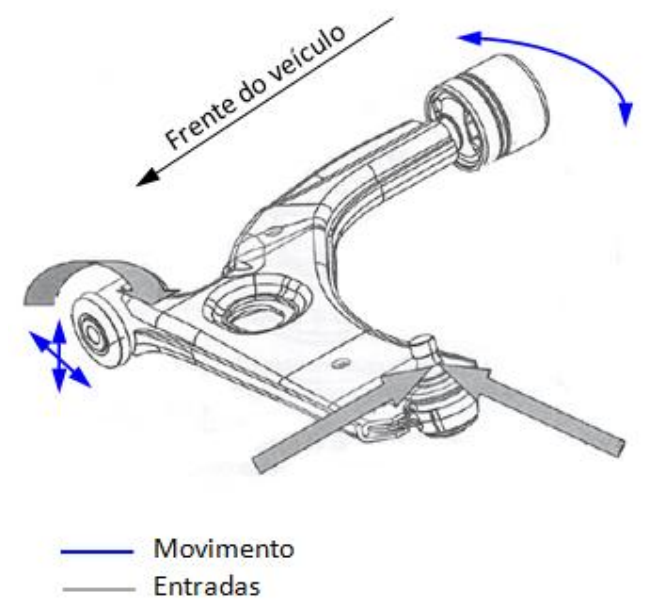

Figura 44 - Típico braço inferior de controle (autor)

Daí se verifica que todas as entradas de movimentos devidas à utilização do veículo apresentam uma componente no plano XY (horizontal), assim do ponto de vista de conforto e estabilidade dependendo de como as suspensões reagem, pode-se salientar ou reduzir uma determinada vibração, melhorar ou piorar a estabilidade durante manobras.

Os dois gráficos a seguir, figura 45 e 46, apresentam resultados de variações de controle em um veículo em que as rigidezes das buchas de suspensão foram alteradas. A percepção para o motorista é de um veículo mais preciso, na figura 45, o veículo com as peças propostas apresenta maior definição de torque durante o esterço do volante, ou seja, para uma determinada quantia de esterço, o torque percebido demonstra maior crescimento de esforço, ou seja, percepção de rodas realizando o movimento direcional. Também o comportamento torna-se mais previsível (figura 46), o veículo responde de modo linear ao comando do motorista quando se realiza alguma manobra ou mesmo durante a condução em linha reta, o movimento é realizado conforme o esperado. 


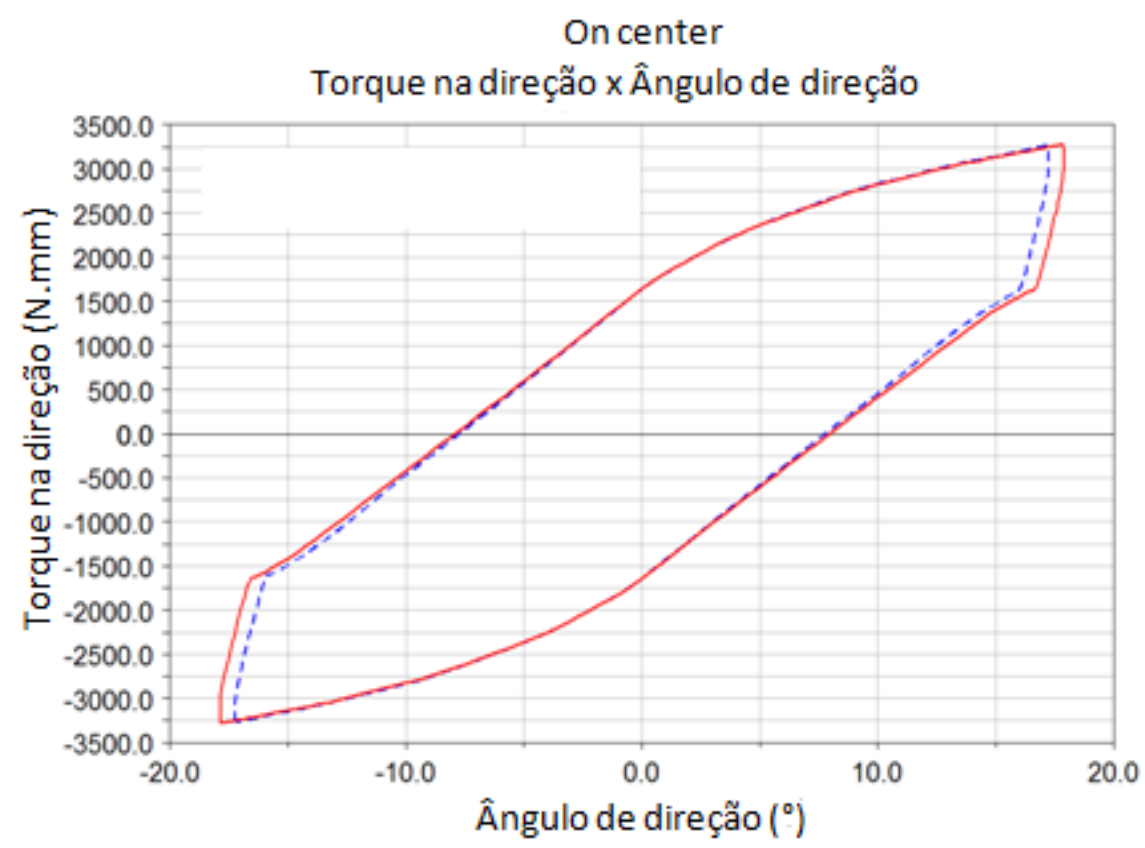

Figura 45 - Aumento do torque de esforço na direção em função do ângulo de esterço

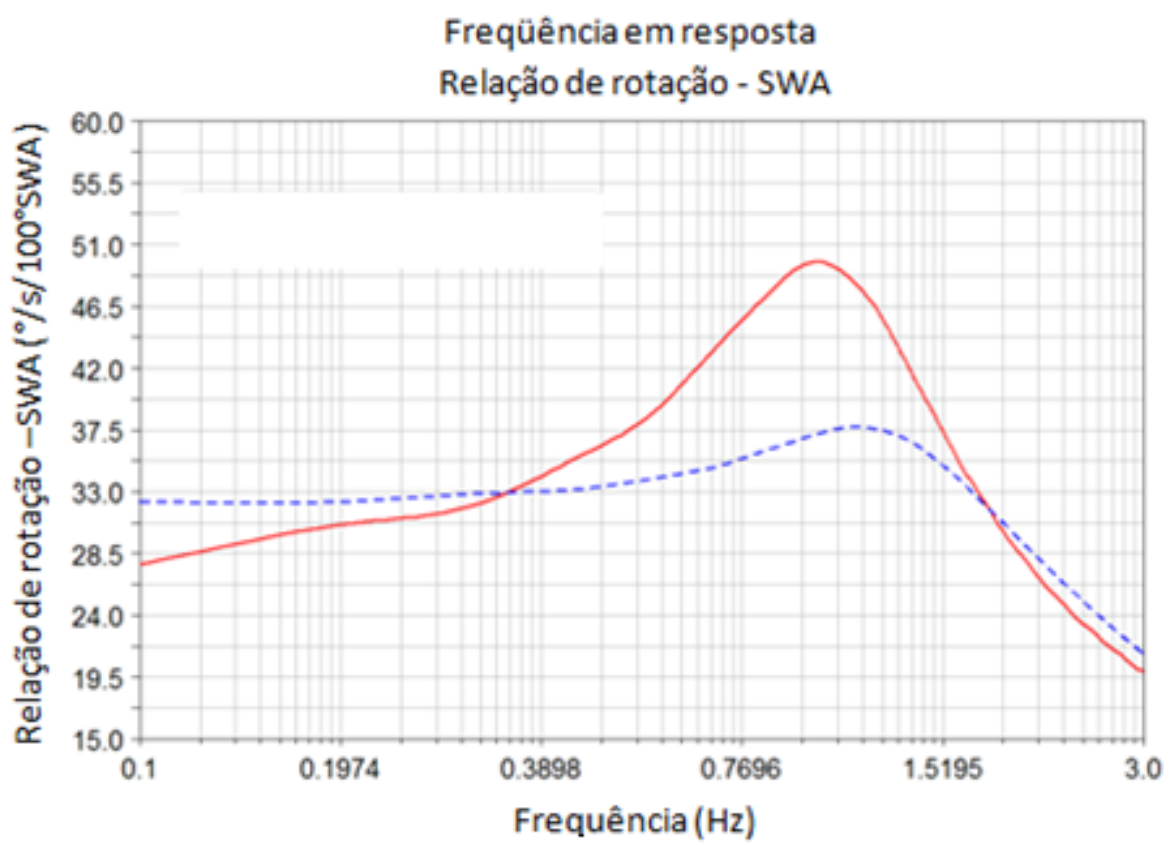

Figura 46 - Resposta de rotação (veículo) em função da frequência do esterço

Considerando o aspécto do conforto, os gráficos a seguir (figuras 47 e 48) apresentam as diferenças de densidade de energia que podem aparecer para os eixos $\mathrm{Y}$ horizontal e $\mathrm{Z}$ vertical da suspensão. Assim, dependendo do tipo de evento por onde o veículo transita e qual problema encontrado, não caberiam mudanças na dinâmica vertical do veículo, como exemplo nas molas, amortecedores e batentes. 


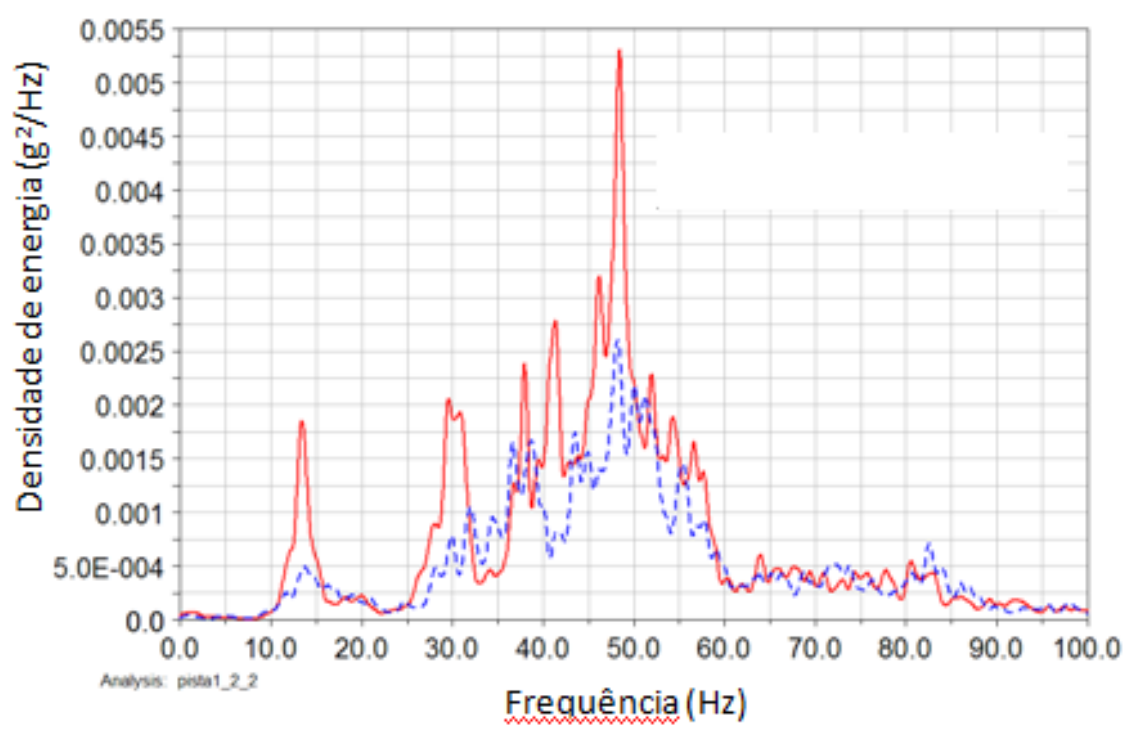

Figura 47 - PSD da energia passante pela suspensão (eixo Y)

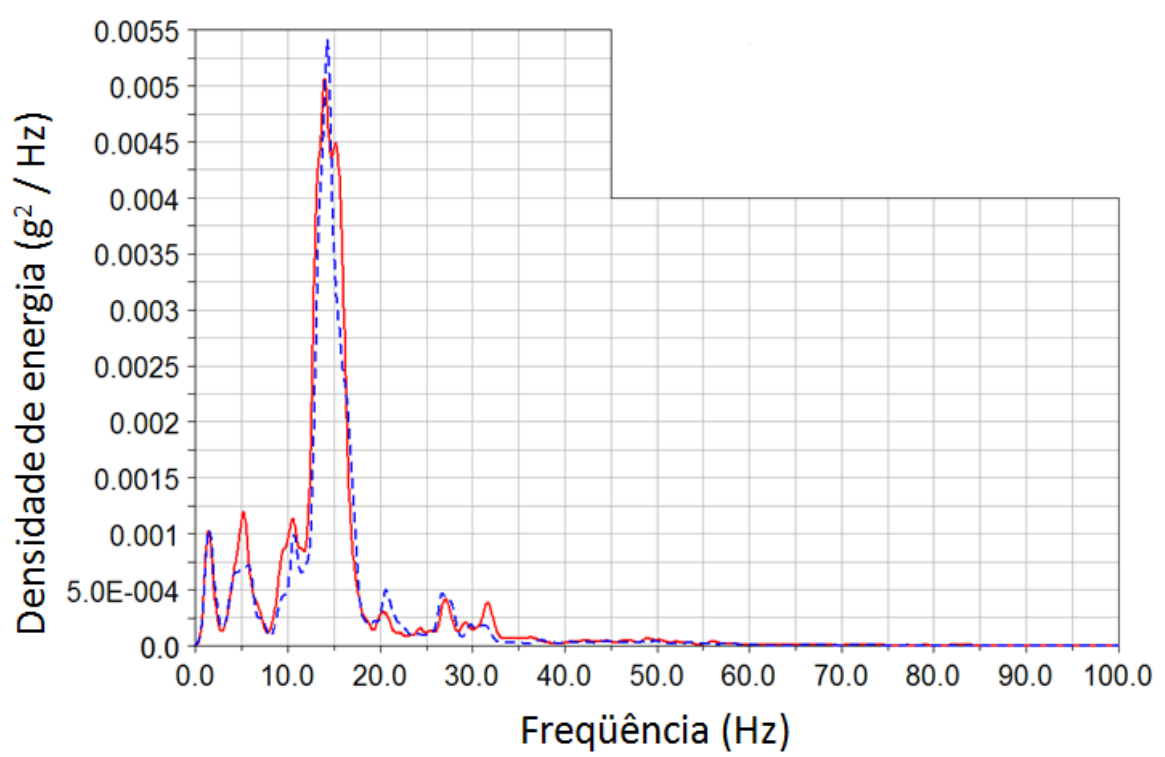

Figura 48 - PSD de energia passada pela suspensão (eixo Z)

Considerando o eixo Y, houve uma melhora na percepção de asperezas, no eixo Z, não houve variação significativa do volume de energia nos eventos, porém provocou uma mudança na percepção de uma vibração de cerca $14 \mathrm{~Hz}$, sendo que a energia transmitida aumentou no pico (PMPO), porém reduziu na faixa média das frequências afetadas (RMS).

Maiores detalhes sobre estas análises voltadas para ride estão nos tópicos a seguir relativos a conforto e sua análise matemática. 


\section{4 - Conforto}

Apesar das excitações ocorrerem nos três eixos normalizados, nesta dissertação só é apresentado o eixo Z, pois é neste que repousa a atuação predominante do conjunto de molas e amortecedores quando de um típico veículo de uso em rua.

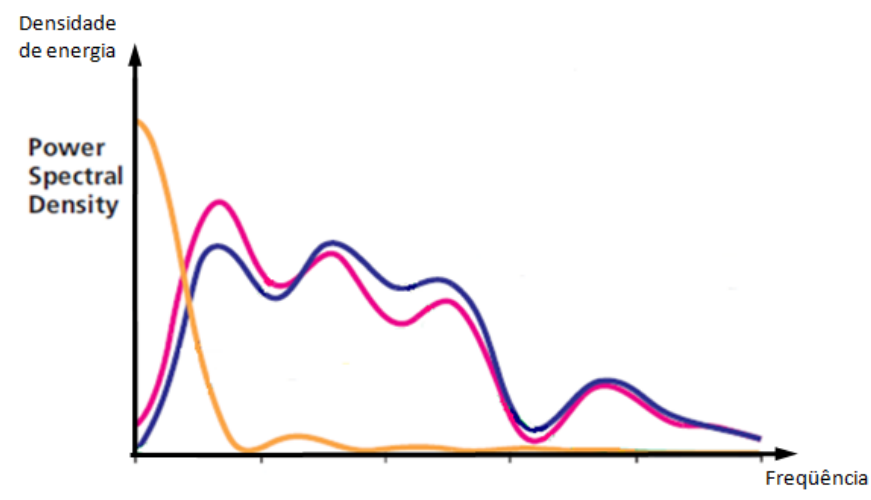

Figura 49 - Ilustração de PSD para analise de ride (autor)

A isolação e consequente caracterização do conforto (figura 49) são referentes à separação do motorista das perturbações devidas ao uso do veículo. Essas perturbações podem ser divididas em duas frentes: perturbações geradas pelo veículo propriamente dito e as outras perturbações que são impostas pelo exterior, do leito em que transita.

Citando novamente os pneus, como são os únicos pontos de contato do veículo com o solo, também são bastante influentes no conforto, na possibilidade de isolamento das perturbações exteriores e por apresentar movimento (rotação), ele próprio pode ser uma fonte de perturbações (figura50).

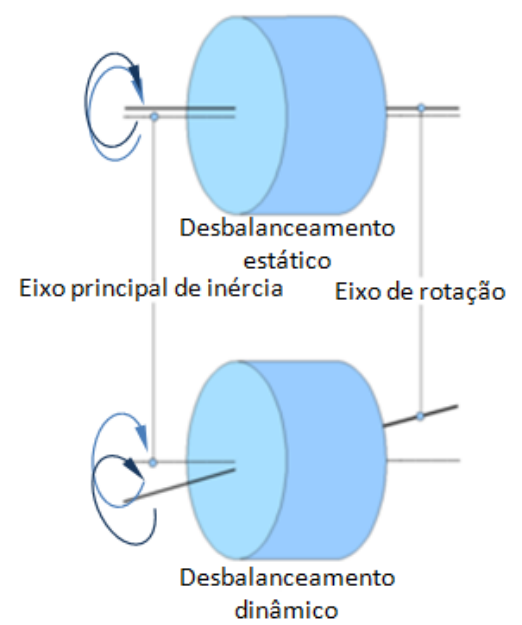

Figura 50 - Ilustrações de desbalanceamento em pneus( 


\subsection{1 - Lugar comum com NVH}

A qualidade do conforto (ride) pode ser quantificada utilizando um critério baseado na absorção de energia. Essa energia absorvida é derivada de medições de acelerações introduzidas aos ocupantes do veículo durante a passagem pelos eventos. A princípio, a absorção de energia pelo veículo e consequente transferência para os ocupantes, é função da velocidade do veículo e do perfil do terreno e é caracterizado por deslocamentos em condição RMS (root-mean square), (vide Apêndice A - NVH e sua interface com a dinâmica veicular).

Também citando as normas ISO 2361, deve se expor que as vibrações danosas ao organismo humano situam-se entre $1 \mathrm{hz}$ e $80 \mathrm{hz}$, ou seja, na faixa que é considerado ride secundário do veículo.

Como citado anteriormente no gráfico apresentado na figura 49, as manobras e solicitações para estabilidade são de baixa frequência e usualmente estão em valores de até cerca $3 \mathrm{~Hz}$, correspondendo a movimentação de carroceria. Esse é principalmente considerado no chamado ride primário e que ainda está sob o domínio dos atributos da estabilidade.

Para o chamado ride secundário, começa a serem consideradas todas as vibrações e asperezas que não são dissipadas e circulam pelos componentes do veículo e são absorvidas pelos ocupantes. Nesta faixa podem ser considerados desde as entradas devidas ao perfil da pista até vibrações vindas do trem de força (figura 51). Este último sendo bastante atuante devido ao fato de sua operação causar liberação de energia sob forma de calor, ruído e vibrações.

Dado o gráfico abaixo, é percebido um pico de energia na faixa de $14 \mathrm{~Hz}$ que apresenta maior correlação com a movimentação do motor que com o trabalho das suspensões em si (capitulo 5 Conclusões e Comentários). Este é a chamada vibração de trem de força, ou seja, uma região de frequências onde ocorre ressonância com frequências do trem de força, sendo este tratado como massa suspensa na massa suspensa e seu sistema de coxins como suspensões, a figura 52 mostra um modelo simplificado e como o trem de força pode amplificar ou anular a perturbação resultante para algumas frequências de ride. 


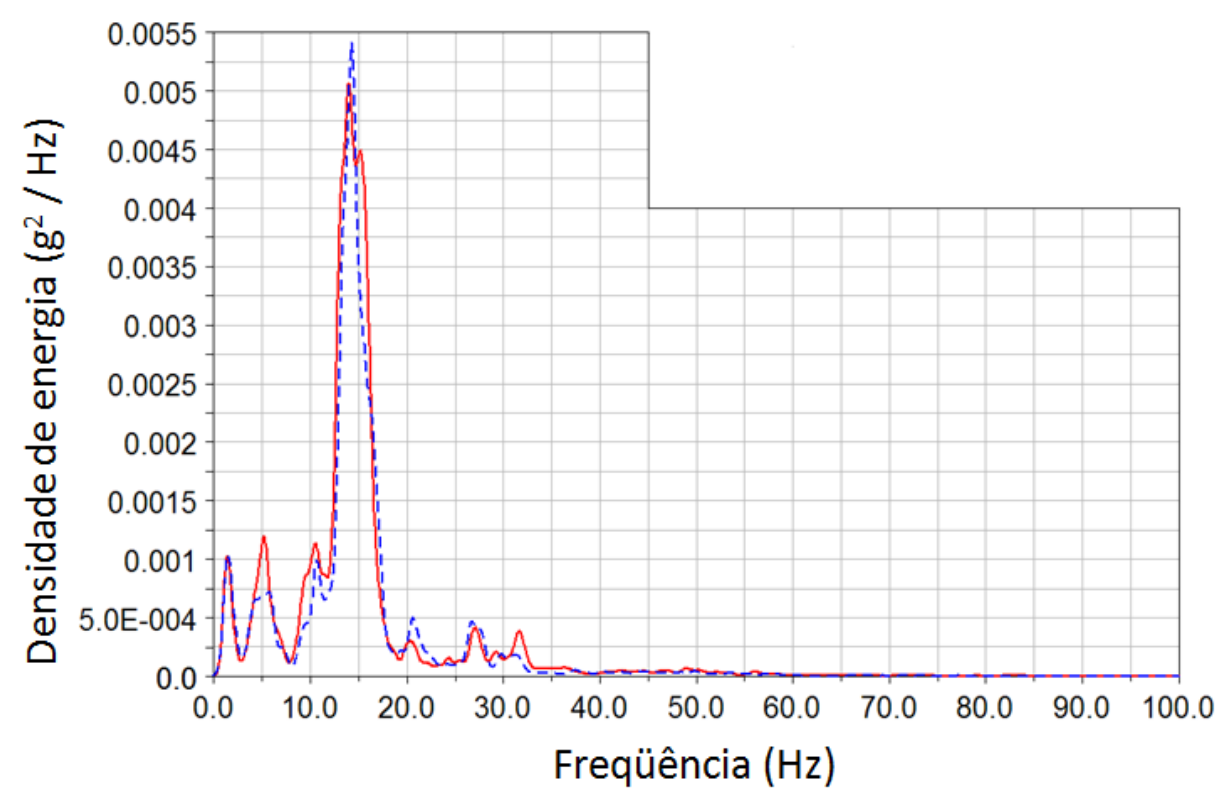

Figura 51 - exemplos de densidade de energia absorvida

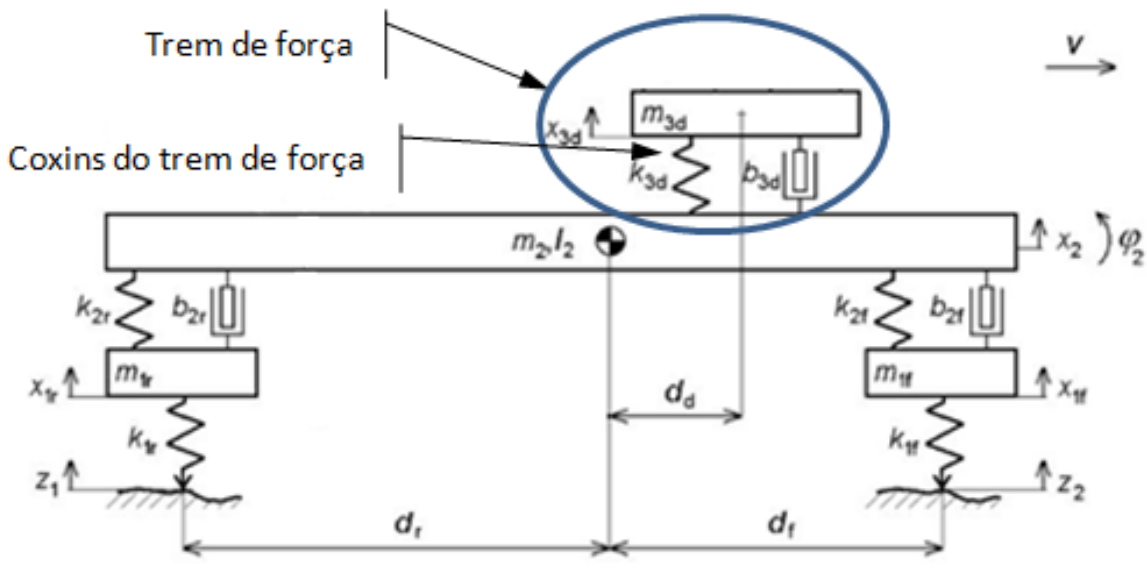

Figura 52 - Modelo simplificado do veículo e seu trem de força

Este princípio de uma massa atuante no controle vibracional foi aplicado na fórmula 1 como uma forma de melhorar as características de ride do monoposto (figura 53), permitindo que em situações de pista irregular como quando passando por zebras, ele possa manter as rodas mais tempo em contato com o solo e consequentemente manter por mais tempo as acelerações longitudinal e lateral. Maiores detalhes estão no Apêndice A - Vibrações do trem de força e dinâmica veicular. 


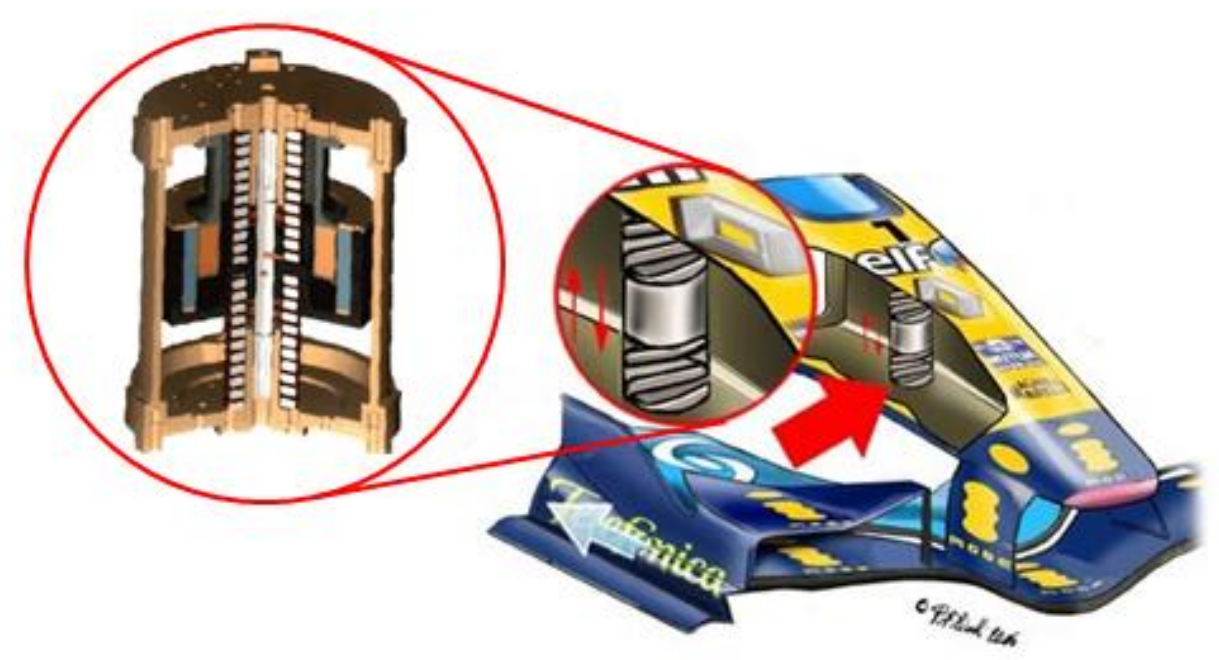

Figura 53 - Ilustração do DMS empregado na F1 para melhoria de aderência (site Formula1, julho 2006)

No capítulo de conclusões e comentários para futuros trabalhos serão discorridos maiores detalhes. Também a importância deste item é devido ao fato de todos os veículos com motores de 4 cilindros em linha apresentarem maior pré-disposição a vibrações durante seu funcionamento devido ao seu desbalanceamento natural.

Para o intuito deste trabalho sua influência não será estudada. Outro ponto a ser considerado são as buchas e isoladores de elastômeros presentes nos componentes de suspensão, estes itens são normalmente confeccionados em borracha e cuja função é permitir isolamento de vibrações de frequências mais altas que possam se propagar pelos componentes da suspensão.

\subsection{2 - Análises matemáticas para Ride}

Inicialmente é necessário definir dois tipos básicos de superfícies para estradas e vias. A primeira pode ser chamada de estrada "estacionaria", e a segunda, estrada "transiente". A estrada "estacionaria" é dita assim quando as entradas devidas à pista são suaves o suficiente para que não signifique à suspensão do veículo, variação de uma situação e assim não existir alteração perceptível do estado do movimento. A estrada "transiente" justamente altera o estado do movimento do veículo.

Como exemplo de calculo para classificação das estradas é possível citar o cálculo da variância da energia vibracional sobre o tempo da medição. Assim: 
Se $\mu=\mathrm{E}(X)$ é a média da variável aleatória $X$ (sendo $X$ a energia das vibrações vindas da estrada), então a variância é:

$$
\operatorname{var}(X)=\mathrm{E}\left((X-\mu)^{2}\right)
$$

Isto é, é o valor esperado do quadrado do desvio de $X$ da sua própria média. Em linguagem comum isto pode ser expresso como "A média do quadrado da distância de cada ponto até a média". É assim a "média do quadrado dos desvios". A variância da variável aleatória "X" é geralmente designada por $\operatorname{var}(X), \sigma_{X}^{2}$, ou simplesmente $\sigma^{2}$.

Vale notar que a definição acima pode ser usada quer para entradas aleatórias discretas, quer para contínuas. E exemplificando, dependendo da velocidade em que o veículo transita por uma mesma estrada, ela pode ser considerada "transiente", ou seja, a energia que ela pode causar no veículo pode alterar seu estado de movimento.

Assim, quando se transita por uma autoestrada de asfalto liso com poucas ondulações perceptíveis, se está dirigindo por uma estrada "estacionária", caso a velocidade do veículo seja muito elevada, os eventos passarão a ser mais perceptiveis e podem possibiliar a mudança no estado do movimento do veículo. Ou seja, numa autoestrada dentro das velocidades legais, a necessidade de amortecimento é minimo, porém a medida que a velocidade aumenta ou o piso passa a apresentar muitas irregularidades, é mandatório o aumento de carga nos amortecedores.

Para realizar análises relativas ao ride, podem-se considerar os mesmos princípios de uma análise de sinal em um sistema mecânico, porém com algumas diferenças devido às entradas de vibrações variarem bastante, tanto por parte do leito por onde o veículo transita como pelos próprios sistemas embutidos nele. Nesta dissertação, serão demonstradas as entradas verticais de vibrações devido à suspensão propriamente dita e como elas refletem nos ocupantes (figura 54). 


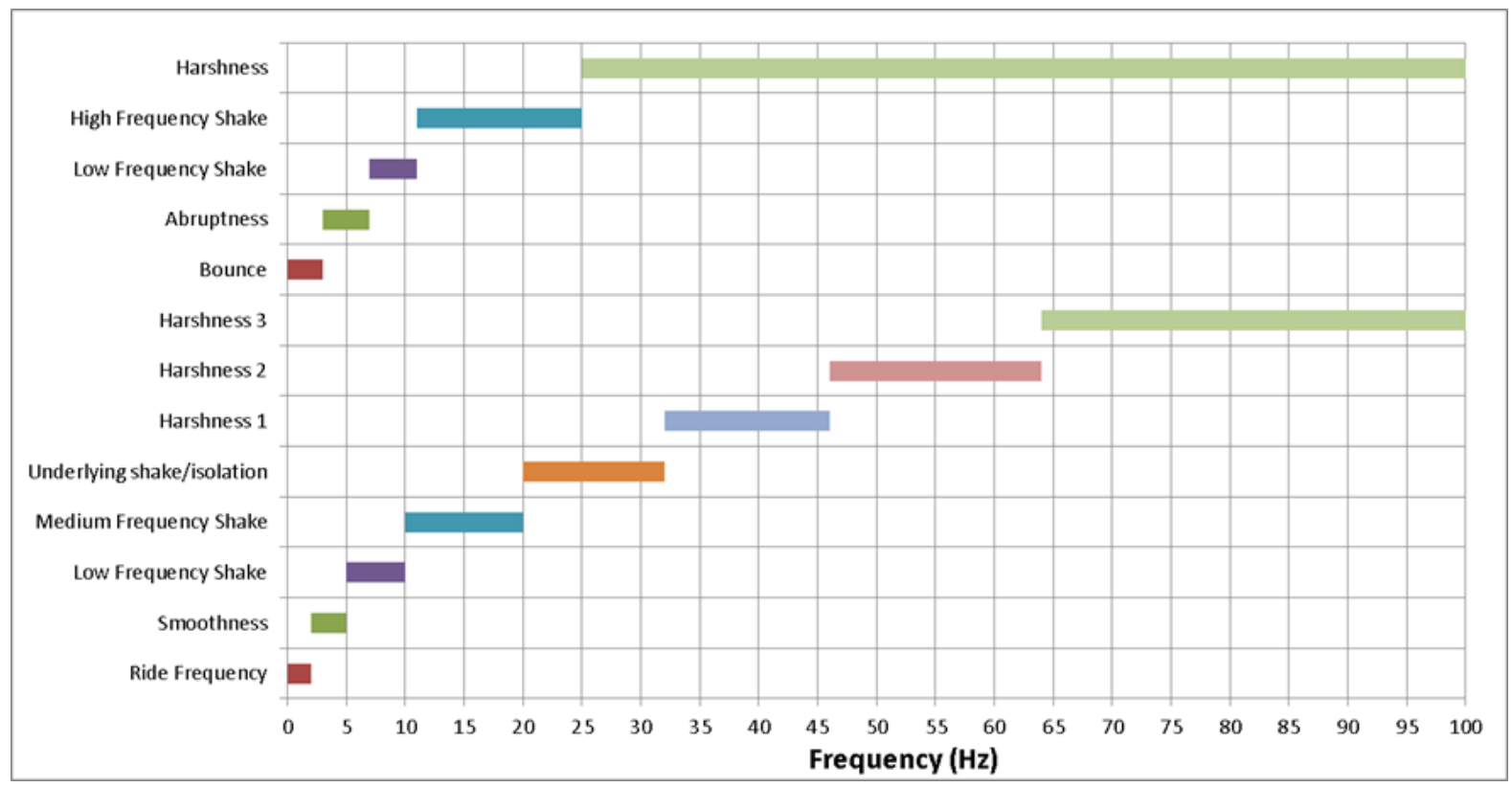

Figura 54 - Diferentes interpretações dos tipos de vibração em veículos

Definida de modo empírico, uma pista de piso de paralelepípedos desalinhados pode oferecer entradas adequadas de vibrações para caracterizar o comportamento das suspensões veiculares para os atributos de ride.

Para sua análise, existem algumas considerações matemáticas que devem ser feitas para que a análise apresente resultados adequados. Esse tipo de pista apresenta medidas invariantes, ou seja, preserva a medida $T$ em um espaço de probabilidade, desde que um conjunto mensurável seu é invariante em $T$ tendo medida 0 ou 1 (metricamente transitivo).

$$
\hat{f}(x)=\lim _{n \rightarrow \infty} \frac{1}{n} \sum_{k=0}^{n-1} f\left(T^{k} x\right)
$$

Considere-se também a média no espaço de $f$, que se define como:

$$
\bar{f}=\int f d \mu,
$$

$\mu$ é uma medida no espaço de probabilidade.

Uma transformação é ergódica, e a medida é invariante, então a média no tempo é igual à média no espaço, exceto talvez para un conjunto de medida 0 (teorema ergótico em forma abstrata de George David Birkhoff). 
Considerando processamento de sinais, um processo estocástico é dito ergótico se suas propriedades estatísticas podem ser deduzidas de uma simples mas suficientemente longa amostra do processo. Assim pode-se discutir a ergodicidade de várias propriedades de um processo estocástico.

Exemplo, um processo $x(t) \operatorname{com} \mu=E[x(t)]$ e auto covariância: $r_{x}(\tau)=E[(x(t)-\mu)(x(t+\tau)-\mu)]$ que não muda com o tempo.

Um modo de estimar essa média com uma média de tempo:

$$
\hat{\mu}_{T}=\frac{1}{2 T} \int_{-T}^{T} x(t) d t
$$

Então se $\hat{\mu}_{T}$ converge em média quadrada, para $\mu$ como $T \rightarrow \infty$, então o processo $x(t)$ é considerado ergótico médio no primeiro momento.

Assim uma pista de paralelepípedos que apresente uma determinada característica de entradas para ride vai apresentar essa característica em qualquer lugar do mundo, desde que seja a mesma pista de paralelepípedos.

Partindo-se da coleta de dados de aceleração no eixo $\mathrm{Z}$ em função do tempo durante a passagem do veículo pela pista definida, realiza-se um pós processamento dos sinais através da FFT (Fast Fourier Transform) e a partir desta gera-se a informação de PSD (Power Spectral Density) e também a integral do sinal da PSD para se obter a somatória da energia que está sendo incidida e absorvida pelos ocupantes do veículo. Partindo dessa explanação temos que:

A FFT é um algoritmo discreto da transformação de Fourier que reduz o numero de cálculos necessários para $\mathrm{N}$ pontos de $2 \mathrm{~N}^{2}$ até $2 N \lg N$, sendo $\lg \log$ aritmo de base 2 . A idéia é dividir uma transformada de tamanho $\mathrm{N}$ em duas transformadas de comprimento $\mathrm{N} / 2$.

$$
\begin{aligned}
& \sum_{n=0}^{N-1} a_{n} e^{-2 \pi i n k / N}=\sum_{n=0}^{N / 2-1} a_{2 n} e^{-2 \pi i(2 n) k / N}+\sum_{n=0}^{N / 2-1} a_{2 n+1} e^{-2 \pi i(2 n+1) k / N} \\
& =\sum_{n=0}^{N / 2-1} a_{n}^{\text {even }} e^{-2 \pi i n k /(N / 2)}+e^{-2 \pi i k / N} \sum_{n=0}^{N / 2-1} a_{n}^{\text {odd }} e^{-2 \pi i n k /(N / 2)},
\end{aligned}
$$


Pode-se visualizar o procedimento acima também através da matriz de Fourier.

A matriz quadrática $\mathrm{n} \times \mathrm{n}$ Fn com as entradas dadas por:

$$
F_{j k}=e^{2 \pi i j k / n}=\omega^{j k}
$$

Para $\mathrm{j}, \mathrm{k}=0,1,2, \ldots, \mathrm{n}-1$, onde $\mathrm{i}$ é o número imaginário $i=\sqrt{-1}$, e normalizado por $1 / \sqrt{n}$ para torná-la unitária.A matriz $\mathrm{F}_{2}$ é dada por:

$$
F_{2}=\frac{1}{\sqrt{2}}\left[\begin{array}{ll}
1 & 1 \\
1 & i^{2}
\end{array}\right]
$$

E a matriz $\mathrm{F}_{4}$ :

$$
\begin{aligned}
& \mathrm{F}_{4}=\frac{1}{\sqrt{4}}\left[\begin{array}{cccc}
1 & 1 & 1 & 1 \\
1 & i & i^{2} & i^{3} \\
1 & i^{2} & i^{4} & i^{6} \\
1 & i^{3} & i^{6} & i^{9}
\end{array}\right]
\end{aligned}
$$

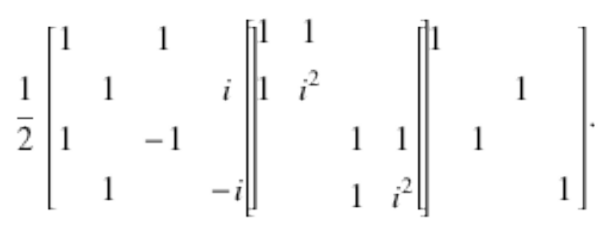

Geralmente:

$$
\mathrm{F}_{2 n}=\left[\begin{array}{cc}
\mathrm{I}_{n} & \mathrm{D}_{n} \\
\mathrm{I}_{n} & -\mathrm{D}_{n}
\end{array}\right]\left[\begin{array}{ll}
\mathrm{F}_{n} & \\
& \mathrm{~F}_{n}
\end{array}\right]\left[\begin{array}{c}
\text { even }- \text { odd } \\
\text { shuffle }
\end{array}\right]
$$

Com:

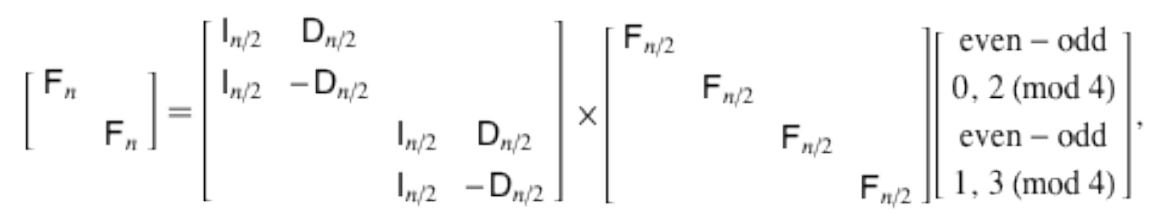

Onde $\ln$ é a matriz identidade $\mathrm{n} \times \mathrm{x}$ e Dn é a matriz diagonal com entradas $1, \omega, \ldots$, $\omega^{n-1}$. Note que a fatorização (que é a base da FFT) tem duas copias de $F_{2}$ no fator central da matriz.

A vibração de um corpo pode ser definida como qualquer movimento executado em torno de um ponto fixo, podendo ser regular, senoidal, irregular, entre outros. Esse fenômeno pode ser definido por três variáveis: a frequência $(\mathrm{Hz})$, a aceleração máxima sofrida $\left(\mathrm{m} / \mathrm{s}^{2}\right)$ e a direção do movimento, sendo considerada em três eixos (figura 55): x (das costas para frente), 
y (da direita para esquerda) e z (dos pés à cabeça). Considerando a percepção no automóvel, a vibração pode ser sentida no corpo inteiro, porém através de várias interfaces como, por exemplo, os pés no assoalho, o tronco no assento, mão no volante ou alavanca de mudança de marchas.

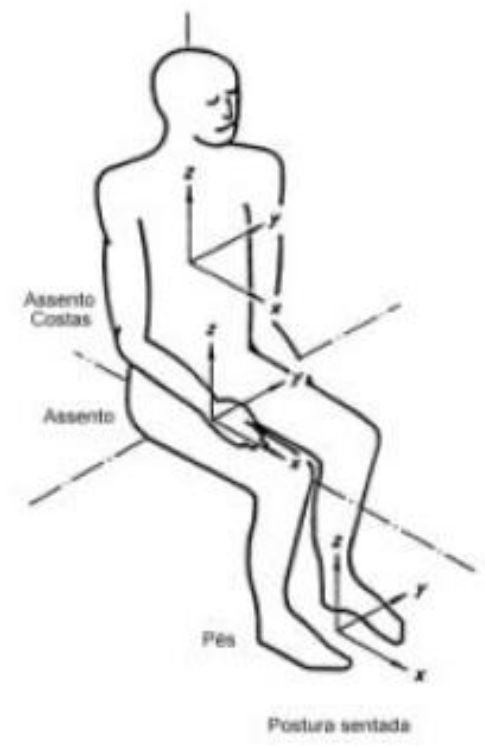

Figura 55 - Orientação normalizada conforme ISO2631-1, 1997

$\mathrm{O}$ ato de dirigir e interagir o veículo produz vibrações que são transmitidas ao conjunto do organismo dos ocupantes. Dependendo da parte do corpo, algumas são mais sensíveis a certas frequências que outras, sendo que tanto podem amortecer a vibração incidida como podem entrar em ressonância, neste caso percebe-se essas partes vibrando durante a direção do veículo. O corpo inteiro apresenta maior sensibilidade na faixa de 4 a 8 $\mathrm{Hz}$, correspondente à frequências na direção vertical (eixo z). Para as direções x e y, as ressonâncias ocorrem de 1 a 2 Hz. Deve-se ter especial atenção ao fato de que as vibrações danosas ao organismo estão nas frequências de 1 a $80 \mathrm{~Hz}$, ou seja, na faixa de frequências em que é considerado o ride do veículo.

Tomando como base esses estudos, quando se fala em termos de energia, os seres humanos podem ser expostos a absorção de cerca de 10-20 watts de energia incidida neles, porém por curtos espaços de tempo, sendo que para períodos prolongados, esse valor cai para cerca de 6 watts.

NVH é a sigla para Noise, Vibrations and Hashness, partindo desta definição, as vibrações e asperezas são um lugar comum com um sub atributo da dinâmica veicular, o 
chamado ride secundário, ou seja, todas as perturbações depois de $3 \mathrm{~Hz}$ até $100 \mathrm{~Hz}$. Assim a tratativa para a resolução dos problemas relacionados pode caminhar em conjunto quando considerados estes aspectos.

A norma ISO 2361 apresenta métodos para quantificar vibrações no corpo humano e assim sua relação com conforto e saúde. Partindo-se desta norma temos os aspectos relacionados a seguir. O parâmetro para avaliação da magnitude da vibração é a aceleração r.m.s (root-mean squared), sendo que para a verificação dos valores é necessário uma ponderação para cada parte do corpo humano, pois este apresenta diferentes respostas à mesma vibração. A fórmula empregada é:

$$
\alpha_{w}=\left[\frac{1}{T} \int_{0}^{T} \alpha_{w}^{2}(t) d t\right]^{\frac{1}{2}}
$$

Onde:

$\alpha_{w}=$ aceleração compensada em função do tempo em $\left[\mathrm{m} / \mathrm{s}^{2}\right]$

$\mathrm{T}=$ Duração da medição realizada em segundos [s]

Para as medições, elas podem ser feitas em terços de oitava e/ou ponderadas em função da frequência. Baseado nos gráficos apresentados na norma ISO (figuras 56, 57 e 58) pode-se verificar a limitação de exposição do ser humano às vibrações, pois apresentam em função das frequências, os limites aceitáveis para a saúde, conforto e fadiga. Para utilizá-los, basta sobrepor os gráficos obtidos de aceleração RMS em função das frequências nos gráficos da norma.

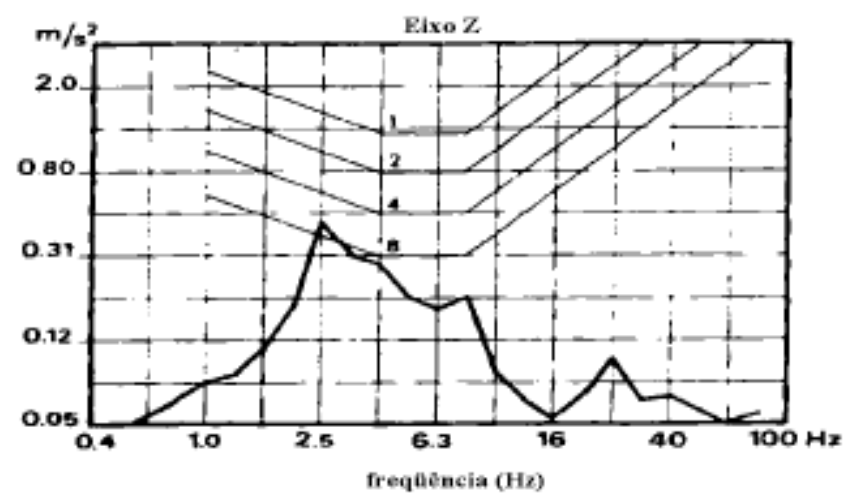

Figura 56 - Exemplo da comparação dos limites da norma ISO com valores medidos (Hansson, et al,.1981) 
As normas BS6055 (1984) e ISO5008 (1979) recomendam quando possível um acelerômetro entre o corpo e o banco ou local onde haja a interface do corpo humano com o apoio por onde chega a vibração.

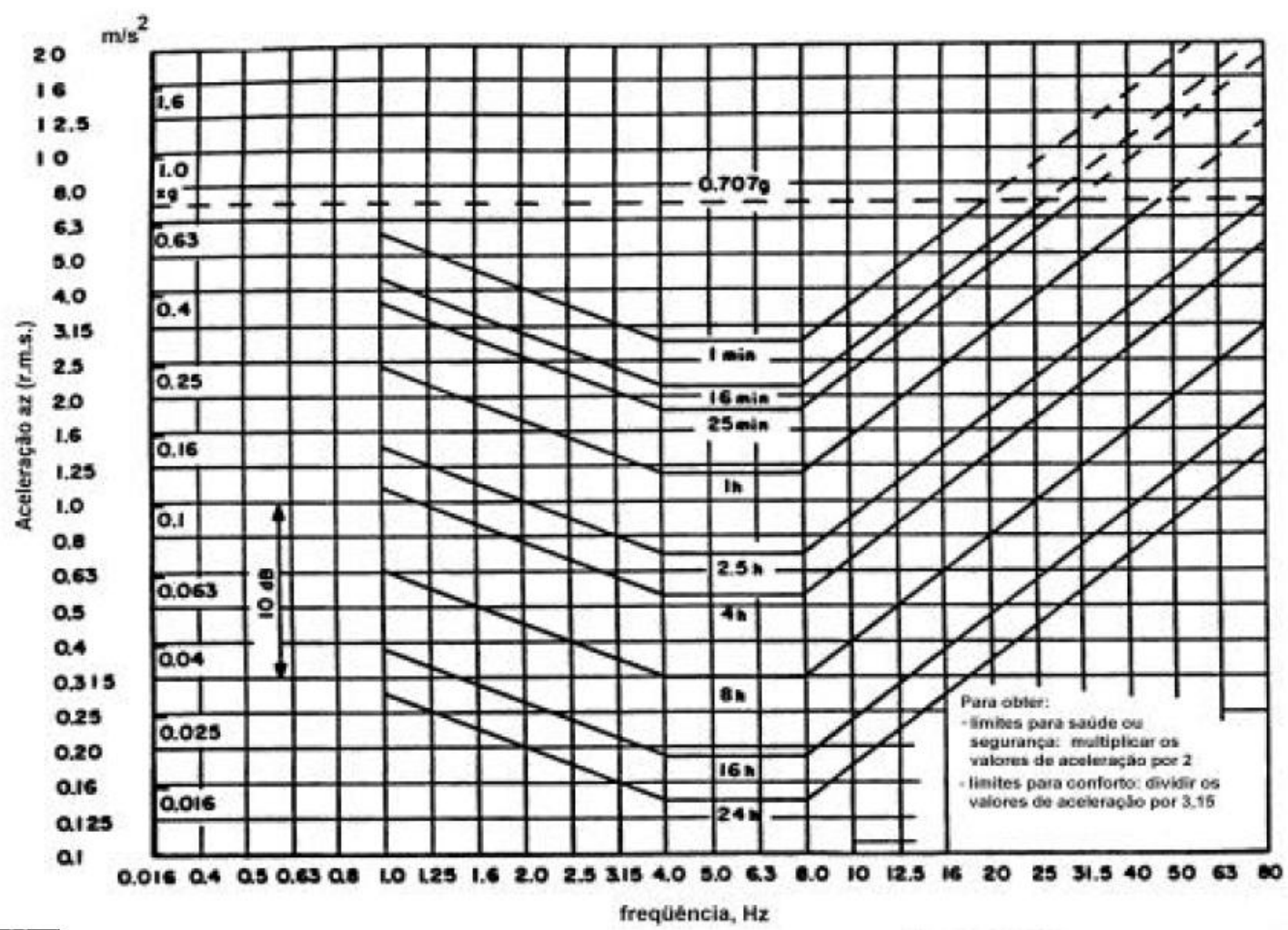

Figura 57 - Limites para conforto e fadiga em terço de oitava para eixo Z (ISO2631)

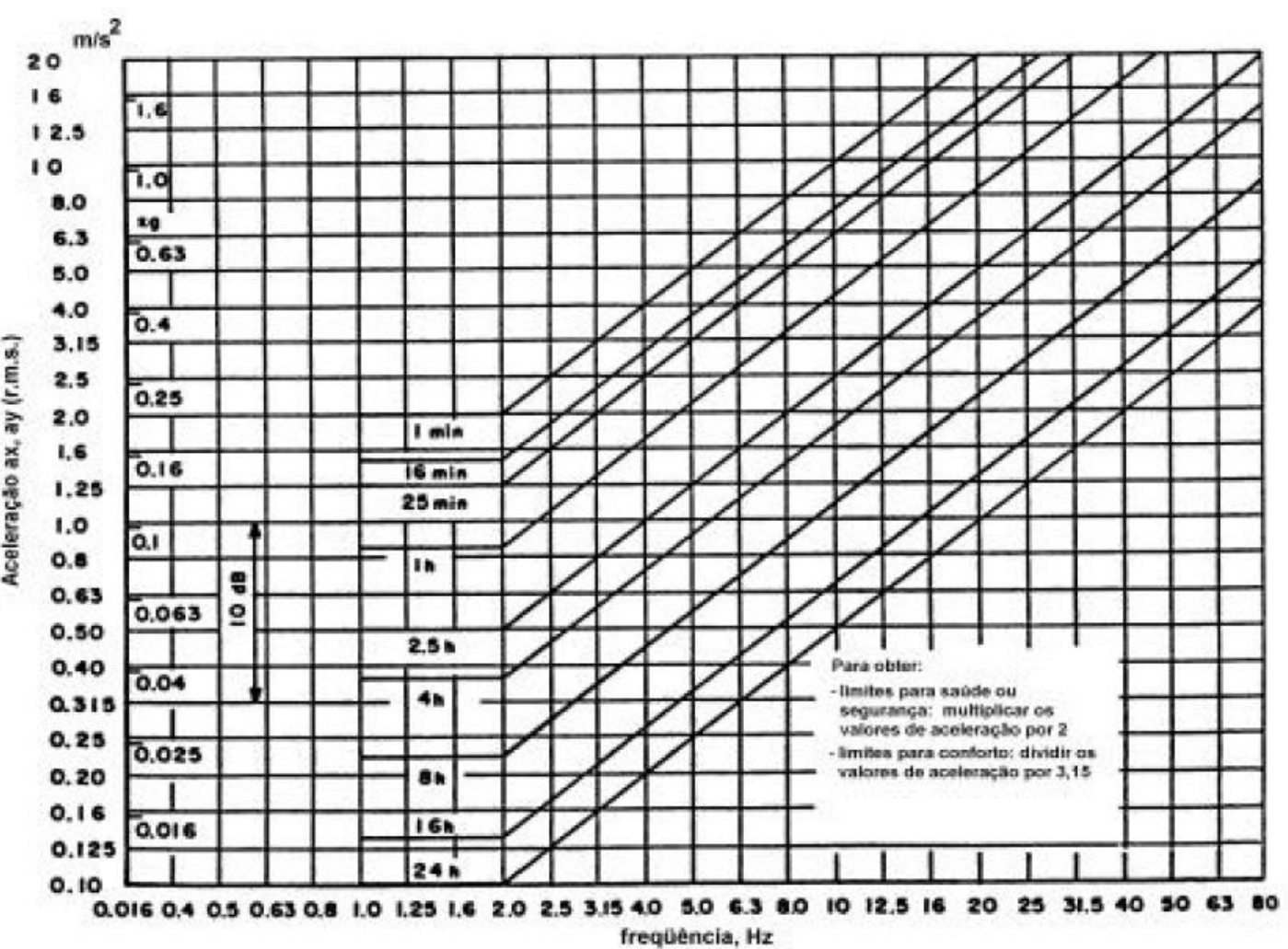

Figura 58 - Limites para conforto e fadiga em terço de oitava para eixo X e Y ISO2631) 
Como exemplo para o acelerômetro para assentos (figura 59) empregado na aquisição de dados para a verificação prática do conteúdo deste trabalho. O acelerômetro foi posicionado no assento do motorista e foram enquistados os dados de várias pistas necessárias para a caracterização de ride e controle necessários para os estudos. Novamente, nesta dissertação serão considerados somente os resultados para o eixo Z.

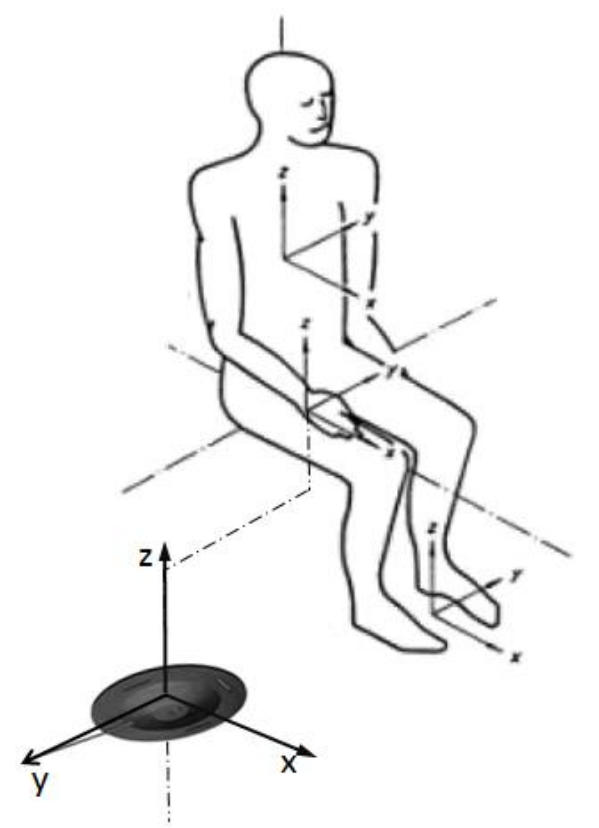

Figura 59 - Acelerômetro para o assento do banco

Como referência, as normas BS6841 e ISO2631-1(1997) apresentam os seguintes valores de aceleração R.M.S. para o conforto:

Tabela 2 - Referências para faixas de acelerações no corpo humano

\begin{tabular}{cl}
\hline Aceleração & Descrição da percepção durante a direção \\
\hline$<0,315 \mathrm{~m} / \mathrm{s}^{2}$ & $\rightarrow$ Confortável \\
\hline 0,315 a $0,630 \mathrm{~m} / \mathrm{s}^{2}$ & $\rightarrow$ Um pouco desconfortável \\
\hline 0,8 a $1,6 \mathrm{~m} / \mathrm{s}^{2}$ & $\rightarrow$ Desconfortável \\
\hline $1,25 \mathrm{a} 2,5 \mathrm{~m} / \mathrm{s}^{2}$ & $\rightarrow$ Muito desconfortável \\
\hline $2,0 \mathrm{~m} / \mathrm{s}^{2}$ & $\rightarrow$ Extremamente desconfortável \\
\hline &
\end{tabular}

Novamente ressaltando que são valores médios para os seres humanos e que dependendo do individuo, alguma variação pode ocorrer. 


\section{5 - Método da energia, as equações de Lagrange}

O movimento de partículas e corpos rígidos é governado pelas leis de Newton, porém conforme tem sido exposto nesta dissertação, o automóvel pode ser considerado um sistema de vários graus de liberdade com um sistema de coordenadas complexas, assim é interessante que as leis de Newton sejam consideradas em uma forma mais conveniente, deste modo o emprego do método da energia, as equações de Lagrange, pode conduzir a um melhor entendimento de como os vários sistemas que compõe um automóvel interagem entre si.

Para adicionar informação sobre o material de Lukowski apresentado neste trabalho, o seguinte pode ser colocado:

Derivação das equações de lagrange em coordenadas Cartesianas.Considerando as equações de conservação para um grande numero de partículas em um campo de forças conservadoras e coordenadas $x_{i}$. A energia cinética total é:

$$
T=\sum_{n=1}^{M} \frac{1}{2} m_{i} \dot{x}_{i}^{2}
$$

Onde Mé o numero dos graus de liberadde do sistema

Para partículas com um adireção apenas um $x_{i}$ é necessário para definir a posição de cada partícula, então $\mathrm{M}=\mathrm{N}$.

Para partículas viajando em três dimensões cada partícula requer $3 x_{i}$ então $\mathrm{M}=3 \mathrm{~N}$.

O momento de uma dada partícula em uma dada direção pode ser obtida diferenciando essa equação respeitando a coordenada $x_{i}$ apropriada.Fazendo assim o momento $p_{i}$ para essa partícula especifica nesta direção coordenada.

$$
\frac{\partial T}{\partial \dot{x}_{\imath}}=p_{i}
$$

A derivada em função do tempo do momento é:

$$
\frac{d}{d t}\left(\frac{\partial T}{\partial \dot{x}_{i}}\right)=m_{i} \ddot{x}_{i}
$$


Para um campo de forças conservadora, a força em uma partícula é dada pela derivada do potencial na posição da partícula da direção desejada.

$$
F_{i}=-\frac{\partial V}{\partial x_{i}}
$$

Da lei de Newton temos:

$$
F_{i}=\frac{d p_{i}}{d t}
$$

Equacionando as deduções acima em termos de potencial de um campo de forças podemos escrever:

$$
\frac{d}{d t}\left(\frac{\partial T}{\partial \dot{x}_{i}}\right)=\frac{\partial V}{\partial x_{i}}
$$

Então usamos o seguinte:

$$
\frac{\partial T}{\partial x_{i}}=0
$$

e

$$
\frac{\partial V}{\partial \dot{x}_{i}}=0
$$

Com isso podemos escrever a equação (3.48) como:

$$
\frac{d}{d t}\left(\frac{\partial(T-V)}{\partial \dot{x}_{i}}\right)-\frac{\partial(T-V)}{\partial x_{i}}=0
$$

Nós agora definimos $L=T$ - $V$ : L é chamado Lagrangiano. A equação (3.51) toma sua forma final como Equação de Lagrange em coordenadas cartesianas:

$$
\frac{d}{d t}\left(\frac{\partial L}{\partial \dot{x}_{i}}\right)-\frac{\partial L}{\partial x_{i}}=0
$$

Uma grande vantagem deste método de desenvolvimento de equações do movimento para sistemas complexos torna-se perceptível quando se muda do sistema cartesiano $x_{i}$ e move-se para um sistema de coordenadas geral. Como exemplo, podemos ter coordenadas polares $r$ e $\theta$, por exemplo, para uma partícula em uma posição bidimensional $x 1$ e $x 2$. As coordenadas polares $r$ e $\theta$ são as coordenadas generalizadas, um sistema com dois graus de 
liberdade permanece com dois graus de liberdade. Pode acontecer em alguns sistemas que o numero de coordenadas gerais é maior que o numero de graus de liberdade e isso pode ser limitado pela introdução de restrições ao sistema. É mais interessante não trabalhar nessas relações, mas sim trabalhar diretamente com numero de variáveis igual ao numero de graus de liberdade.

$$
x_{i}=x_{i}\left(q_{1}, \ldots q_{j}, \ldots q_{n}\right)
$$

O que é digno de nota desta formulação de Lagrange é que (3.52) permanece num sistema geral de coordenadas com $x_{i}$ substituído por $q_{i}$.

$$
\frac{d}{d t}\left(\frac{\partial L}{\partial \dot{q}_{i}}\right)-\frac{\partial L}{\partial q_{i}}=0
$$

Empregando as coodenadas gerais para derivar equação de lagrange a partir da lei de Newton:

$$
x_{i}=x_{i}\left(q_{1}, \ldots q_{j}, \ldots q_{n}\right)
$$

Para obter a velocidade $\dot{x}_{i}$, pegamos a derivada de (3.55) aplicando a regra da corrente:

$$
\dot{x}_{i}=\sum_{j=1}^{n} \frac{\partial x_{i}}{\partial q_{j}} \dot{q}_{j}
$$

Tomando a derivada parcial de (3.56) em $\dot{q}_{j}$ conseguimos a relação entre estas duas derivadas.

$$
\frac{\partial \dot{x}_{i}}{\partial \dot{q}_{\jmath}}=\frac{\partial x_{i}}{\partial q_{j}}
$$

Derivando a equação (3.57) temos a vantagem de que desde que as coordenadas $q_{i}$ são independentes, $\frac{\partial q_{i}}{\partial q_{j}}=0$ para $i \neq j$.

Seguindo a direção das equações $(3.44$ - 3.52) nos definimos um momento geral como

$$
p_{i}=\frac{\partial T}{\partial \dot{q}_{i}}
$$

Com

$$
T=\sum_{n=1}^{M} \frac{1}{2} m_{j} \dot{x}_{j}^{2}
$$


Dada pela equação (3.43).

Para o momento geral nos temos:

$$
p_{i}=\frac{\partial T}{\partial \dot{q}_{i}}=\sum_{j=1}^{n} m_{j} \dot{x}_{j} \frac{\partial \dot{x}_{j}}{\partial \dot{q}_{i}}=\sum_{j=1}^{n} m_{j} \dot{x}_{j} \frac{\partial x_{j}}{\partial q_{i}}
$$

Onde fizemos uso de (3.57)

Para um campo conservador de força, o trabalho feito durante um deslocamento $d x_{i}$ é dado por

$$
d W=\sum_{i=1}^{N} F_{i} d x_{i}=\sum_{j=1}^{N} \sum_{i=1}^{N} F_{i} \frac{\partial x_{i}}{\partial q_{j}} d q_{j}
$$

Nós identificamos:

$$
\sum_{i=1}^{N} F_{i} \frac{\partial x_{i}}{\partial q_{j}} d q_{j}
$$

Como o trabalho feito pelo deslocamento através de $d q_{j}$ e definimos uma força geral $Q_{j}$ como

$$
Q_{j}=\sum_{i=1}^{N} F_{i} \frac{\partial x_{i}}{\partial q_{j}}
$$

Então o trabalho é expresso por:

$$
d W=\sum_{j=1}^{N} Q_{j} d q_{j}
$$

Para um sistema conservador, o trabalho feito por um pequeno deslocamento $d q_{j}$ é:

$$
d W=-d V=-\frac{\partial V}{\partial q_{j}} d q_{j}
$$


Onde V é a função potencial expressa no sistema de coordenadas das coordenadas gerais e $\frac{\partial V}{\partial q_{j}}$ é a mudança em potencial devido a mudança na coordenada geral $q_{j}$. Então a força geral é:

$$
Q_{j}=-\frac{\partial V}{\partial q_{j}}
$$

Em analogia a 4 nos examinamos agora o tempo derivado do momento geral., $p_{i}$.

$$
\frac{d p_{i}}{d t}=\frac{d}{d t}\left(\frac{\partial T}{\partial q_{i}}\right)=\sum_{j=1}^{N}\left(m_{j} \ddot{x}_{j} \frac{\partial x_{j}}{\partial q_{i}}+m_{j} \dot{x}_{j} \frac{d}{d t} \frac{\partial x_{j}}{\partial q_{i}}\right)
$$

Desde que $\frac{\partial x_{j}}{\partial q_{i}}$ é a função do q que são funções do tempo, nos temos pela regra da corrente:

$$
\frac{d}{d t} \frac{\partial x_{j}}{\partial q_{i}}=\sum_{k=1}^{N} \frac{\partial^{2} x_{j}}{\partial q_{i} \partial q_{k}} \dot{q}_{k}
$$

Da lei de Newton, $m_{j} \ddot{x}_{j}=F_{j}$, então o primeiro termo em (3.67) é dado por:

$$
\sum_{j=1}^{N} m_{j} \ddot{x}_{j} \frac{\partial x_{j}}{\partial q_{i}}=Q_{i}
$$

Vamos considerar o segundo termo de (3.67). Considerar a expressão para $\frac{\partial T}{\partial q_{i}}$ e usar as equações $(3.56)-(3.57)$.

$$
\frac{\partial T}{\partial q_{i}}=m_{j} \dot{x}_{j} \frac{\partial \dot{x}_{j}}{\partial q_{i}}=m_{j} \dot{x}_{j} \frac{\partial}{\partial q_{i}} \sum_{k=1}^{N} \frac{\partial x_{i}}{\partial q_{k}} \dot{q}_{k}
$$

Esse é precisamente o segundo termo na equação (3.68). Nos temos identificado agora formas mais simples para as duas expressões na equação para o tempo derivado do momento geral. Devemos agora escrever:

$$
\frac{d p_{i}}{d t}=\frac{d}{d t}\left(\frac{\partial T}{\partial \dot{q}_{i}}\right)=Q_{i}+\frac{\partial T}{\partial q_{i}}=-\frac{\partial V}{\partial q_{i}}+\frac{\partial T}{\partial q_{i}}
$$

Desde que para um sistema conservador, o potencial é independente das velocidades, nos podemos colocar essa equação numa forma final definindo o Lagrangiano como L=T-V para obter a forma final da equação de lagrange como: 


$$
\frac{d}{d t}\left(\frac{\partial L}{\partial \dot{q}_{i}}\right)-\frac{\partial L}{\partial q_{i}}=0
$$

Concordando com (3.54), Equação (3.72) é a equação de Lagrange nas coordenadas gerais. O que é significante a respeito desta equação, aumentando sua força, é que cada equação contem apenas derivadas com respeito a aquele $q_{i} e \dot{q}_{i}$. 


\section{Capitulo 4 - Estudo de Caso}

Os direcionais citados e discorridos anteriormente podem ser consolidados com o seguinte exemplo prático, baseado em um veículo protótipo de uma montadora. Este veículo apresenta suspensão dianteira tipo McPherson e traseira tipo eixo de torção (twist beam). Este arranjo corresponde a quase todos os veículos atualmente no mercado nacional, sendo que as diferenças no comportamento dinâmico que são verificadas de marca a marca, de modelo a modelo, são devidas ao modo com que cada montadora direciona seus atributos de modo a possuir um comportamento característico para uma identidade própria.

\section{1 - Configuração}

O veículo considerado possui a seguinte configuração:

- Plataforma: B

- Entreeixos: 2446mm

- Bitola:

. Dianteira: $1450 \mathrm{~mm}$

. Traseira: $1400 \mathrm{~mm}$

- Altura do centro de rolagem

. Dianteiro: $75 \mathrm{~mm}$

.Traseiro: $175 \mathrm{~mm}$

- Pesos:

. Eixo dianteiro: $700 \mathrm{kf}$

. Eixo traseiro: $450 \mathrm{~kg}$

- Posição do CG:

.X: $942 \mathrm{~mm}$

.Y: $0 \mathrm{~mm}$

.Z: $575 \mathrm{~mm}$

De modo a manter uma configuração de carga intermediária e representativa, o veículo sempre é avaliado ou medido em configuração de duas pessoas, sendo elas, o motorista e o passageiro ao lado. 
É considerada aceleração lateral até $0,5 \mathrm{~g}$ e em condição estacionária, durante as curvas, dado que este trabalho é voltado a elementos de rigidez das suspensões automotivas, assim o amortecimento não fara parte das análises a seguir.

\section{2 - Modelo simplificado}

Uma das ideias deste trabalho e permitir, através de estudos para conceituação do produto, direcionar de modo mais correto as especificações de componentes para os programas veiculares. Deste modo o modelo simplificado pode ser empregado em fases iniciais de programa. Esse modelo foi montado em ambiente do software MSC/ADAMS View para facilitar o trabalho e processamento das informações assim como melhor interface para análises quanto à funcionalidade dos métodos descritos neste trabalho. Por se tratar de um modelo simplificado, o que se busca é analisar sua precisão em mostrar fenômenos que possam acontecer em um protótipo real. Não exibir, exatamente, os valores numéricos de todos os fenômenos, mas sim o comportamento e sensibilidade.

Partindo-se de um modelo de viga suspensa (Nowland, 2012) por quatro sistemas de massa (desprezível), mola/amortecedor em contato com o solo e sendo os pneus mais u m sistema mola/amortecedor associado em série aos quatro primeiros e com os centros de arfagem e rolagem definidos (figura 60), foram realizadas algumas simplificações conforme a seguir para endereça-lo ao foco dessa dissertação.

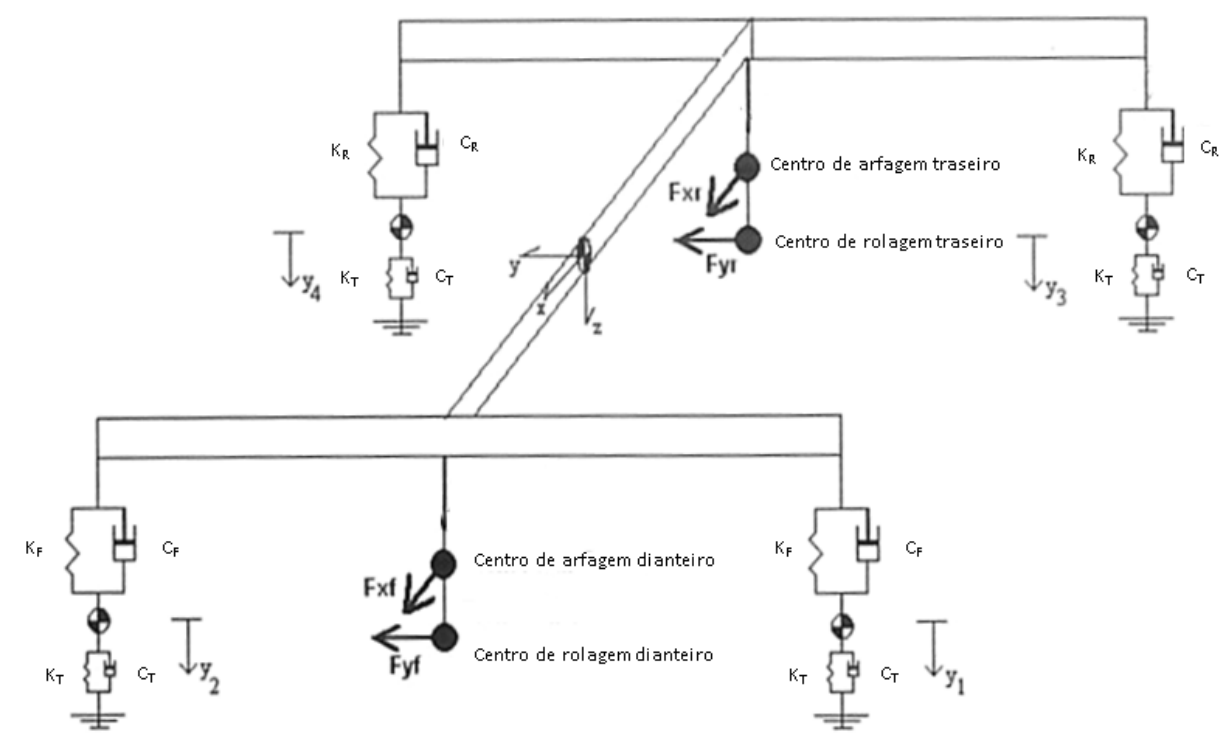

Figura 60 - Modelo em viga suspensa 
. Influencia dos pneus foi retirada, pois se tratando de análise em faixas lineares de direção, o comportamento quanto a escorregamento e aderência e sua consequente influenciam nas forças que irão ser gerenciadas no sistema de suspensão pode ser resumido como simplesmente uma reta.

. Por serem estudos conduzidos em estado estacionário, não é considerada a transição de um estado de equilíbrio a outro, assim a necessidade de representar amortecedores, para controlar as variações de energia do sistema devido à variação de velocidade, também é retirada (vide tópicos sobre método da energia equações de Lagrange).

. São considerados o movimento vertical e a arfagem da carroceria, tomando como referência os trabalhos de Rowell, Guest e Olley para a caracterização de ride.

A rolagem da carroceria é considerada de modo a complementar a caracterização de movimentos para ride e acrescentar a interação com o controle da carroceria (estabilidade) em curvas.

. A geometria dos sistemas de suspensão dianteira e traseira é resumida no eixo de rolagem e no centro de arfagem. Por se tratar de estudo em faixa linear e consequente pouco deslocamento das suspensões, o passeio desses pontos no espaço não é considerado, somente são consideradas suas posições iniciais.

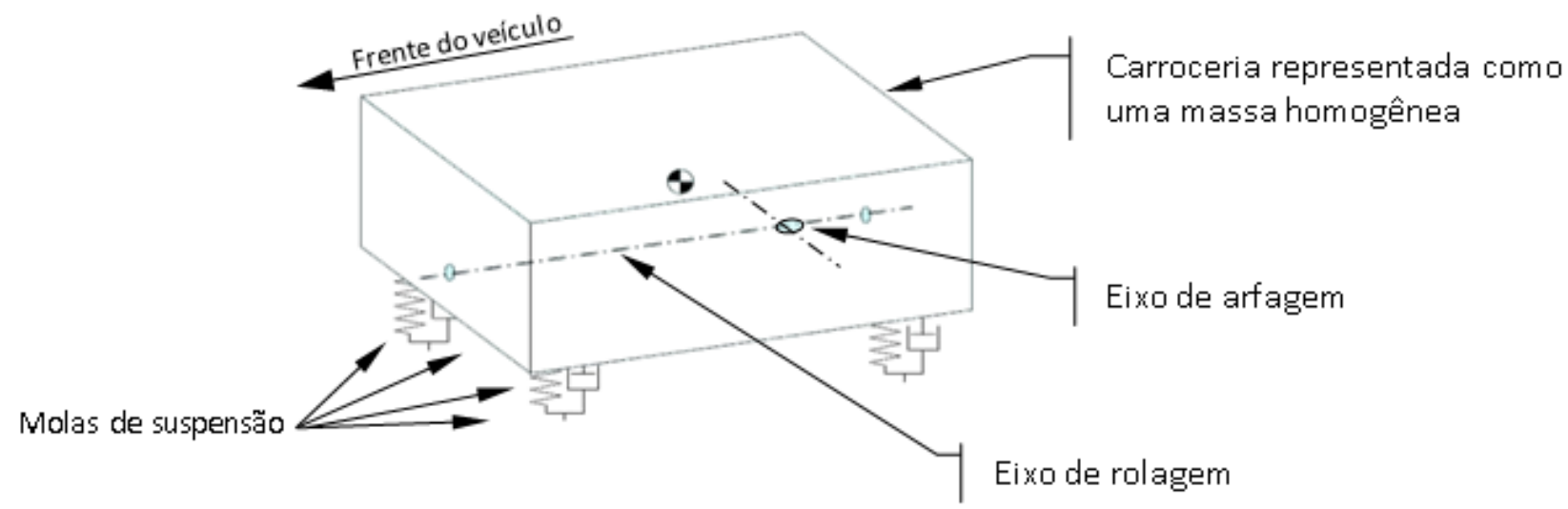

Figura 61 - Representação do modelo simplificado final 
. Como informação complementar, as molas e o CG da massa homogênea são posicionados de modo a representar o veiculo a ser estudado.

Assim resulta a imagem da figura 61.

A imagem da figura 62 representa esse modelo quando montado em MSC/ADAMS View.

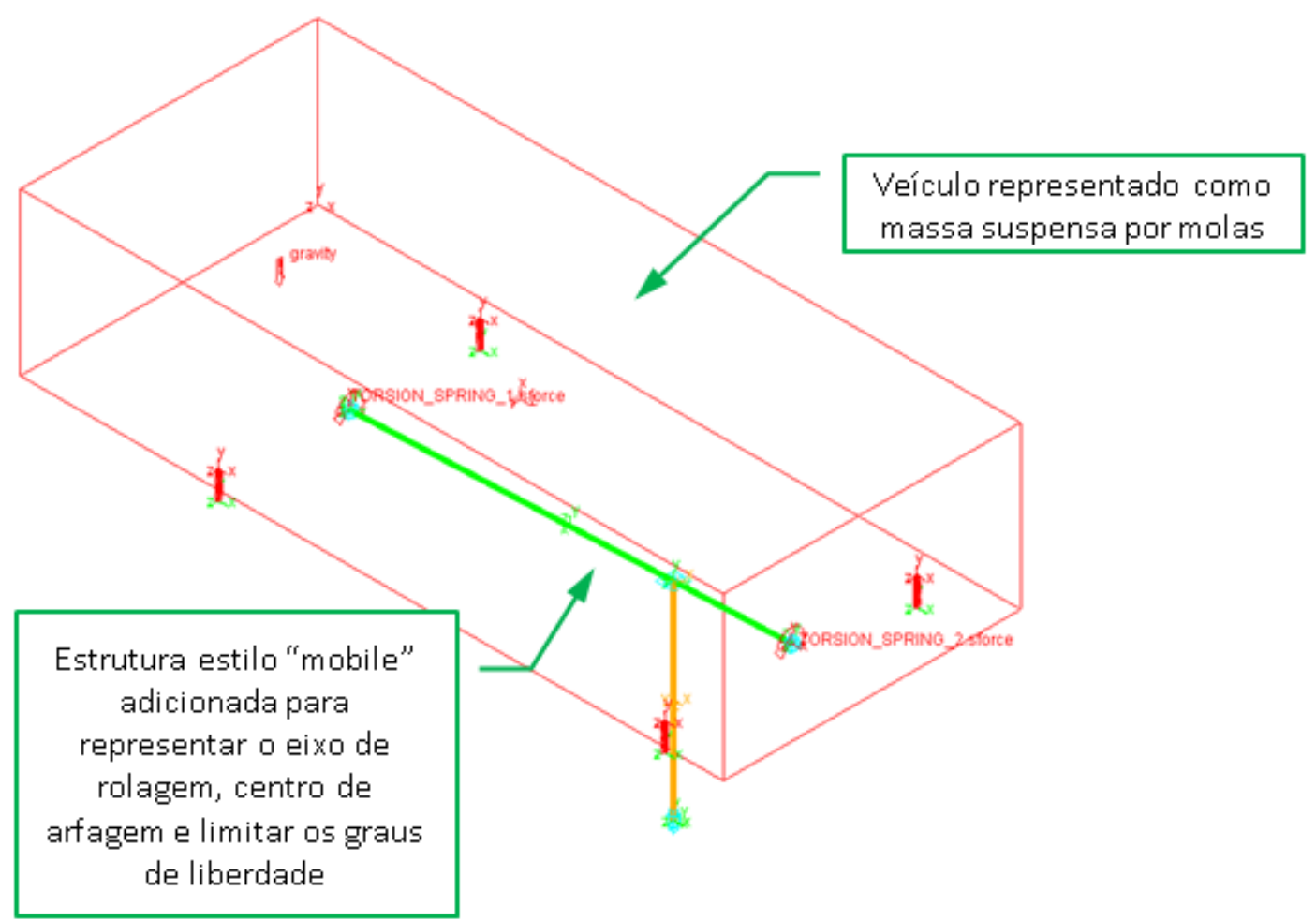

Figura 62 - Modelo simplificadoem MSC/ADAMS VIew

As molas possuem rigidezes definidas conforme o posicionamento e movimento do centro da roda. Elas estão fixas ao solo do modelo, pois assim pode-se estudar as suspensões propriamente. Eliminando a variável pneu, é possível reduzir a complexidade do modelo, porém manter adequada fidelidade às análises na faixa empregada.

A estrutura representativa para os movimentos de rolagem e arfagem que é adicionada ao modelo é posicionada conforme posições do eixo de rolagem e é fixado à massa por juntas esféricas para permitir movimento de rolagem. Uma junta de revolução é colocada na estrutura para simular o eixo de arfagem. E finalmente uma junta translacional para permitir 
movimentação vertical. Neste mecanismo é possível verificar-se também movimentação de rolagem em diagonal, a composição dos movimentos de rolagem e mergulho ou levante (figura 63).

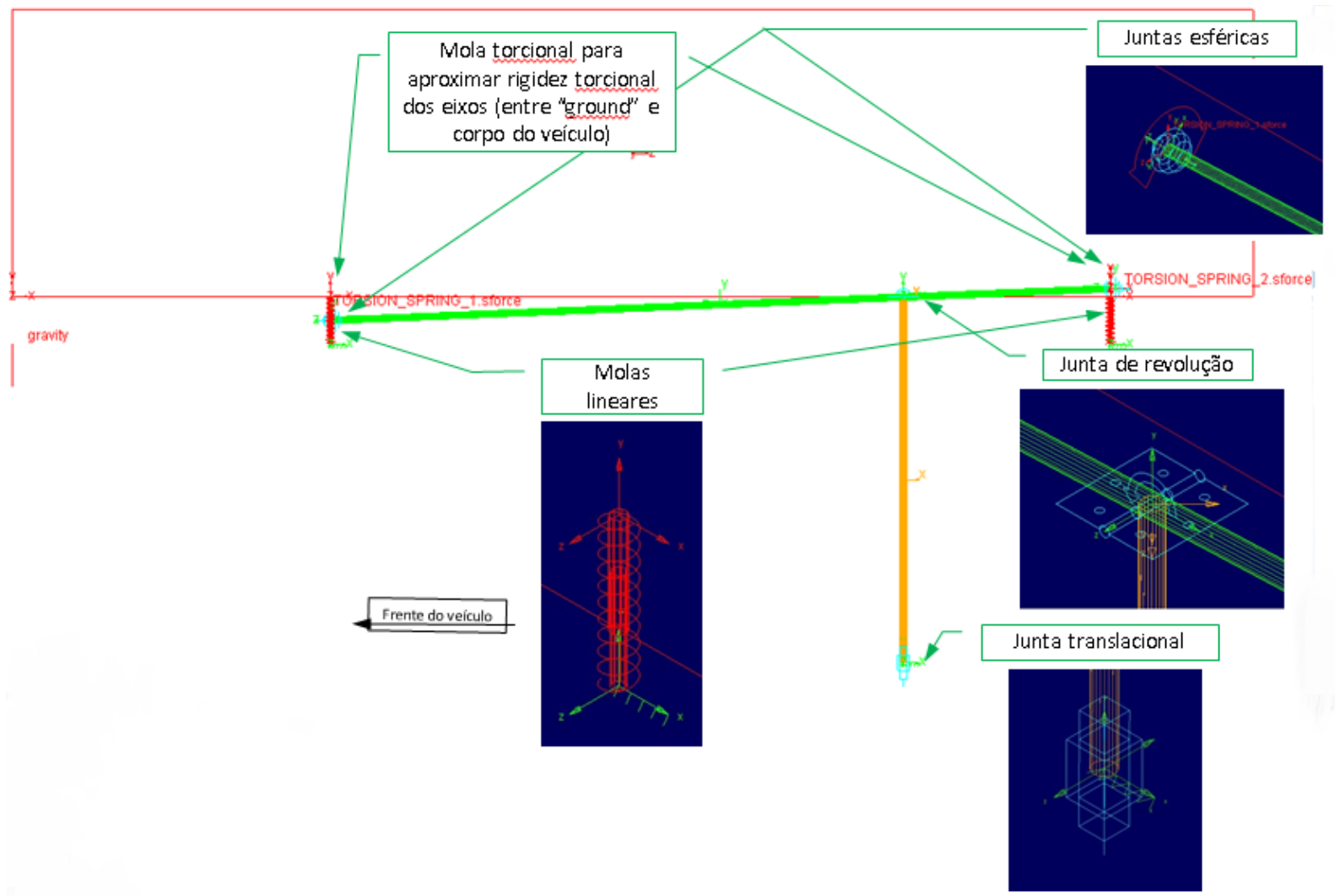

Figura 63 - Detalhes do modelo simplificado(vista lateral)

Como item adicional, uma mola de torção é acrescentada de modo a simular as barras estabilizadoras. Esse elemento de força é montado entre o ground (solo) do modelo e a massa, assim tem-se o movimento que é relativo à carroceria.

Considerando controle de rolagem podemos seguir as seguintes aproximações no que se refere à identificação da frequência natural para rolagem:

$$
f_{\text {roll }}=\frac{1}{2 \pi} \sqrt{\frac{k_{\text {roll }}}{\theta_{\text {roll }}}}
$$

$f_{\text {roll }}=$ frequência natural

$k_{\text {roll }}=$ constante elástica das molas quando em movimento de rolagem

$\theta_{\text {roll }}=$ inércia do veículo incidindo na suspensão 
Deve-se ressaltar que em termos de movimentação rotacional (torsional), o aspecto da estabilidade deve prevalecer, através de valores de frequência natural mais elevados, definidos de modo empírico também e em torno de $2,2 \mathrm{~Hz}$ a $2,3 \mathrm{~Hz}$. Isso valendo para veículos de passeio. É a mesma análise para a movimentação vertical do veículo, porém leva em conta a rigidez torcional, e o movimento de rolagem, assim a ideia é verificar o quão abrupto o veículo pode se apresentar. As figuras 64 e 65 apresentam graficosde rigidez torsionalpara o eixo dianteiro e traseiro para toda a faixa de deslocamento das suspensões, porém somente nas regiões circuladas corresponde a faixa linear.

Para a estabilidade, a métrica esta relacionada com a distribuição das rigidezes para a dianteira e para a traseira, para visualizar se o comportamento do veículo apresenta tendência de subesterço ou sobreesterço em condição estacionária. Esses cálculos podem fornecer uma ideia do quão atuante está uma barra estabilizadora, em outras palavras, se as proporções das rigidezes torcionam estão dentro de valores condizentes para o veículo. Novamente, valores aceitáveis e verificados empiricamente situam-se entre $60 \%$ e $55 \%$, ou seja, rigidez maior no eixo dianteiro. No caso apresentado, o veículo apresenta subesterço durante a faixa linear.

É verificado que em todas as manobras ditas de estabilidade, como por exemplo, as situações transitórias de entrada e saída de curva e movimentação resultante do esterço apresentam características de velocidade do movimento das suspensões próximas ao ride primário. Porém salientando que quando o veículo transita de um estado de movimento para outro, a variação de energia cinética da carroceria deve ser dissipada via amortecedores.

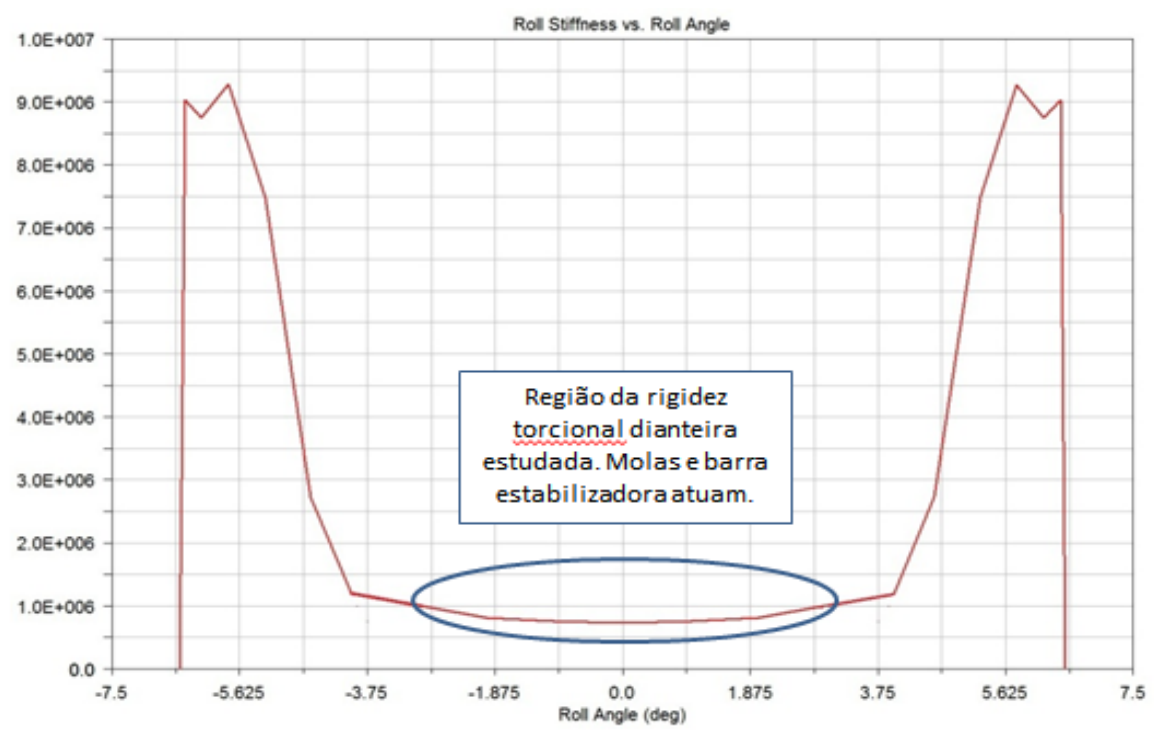

Figura 64 - rigidez de rolagem para eixo dianteiro 


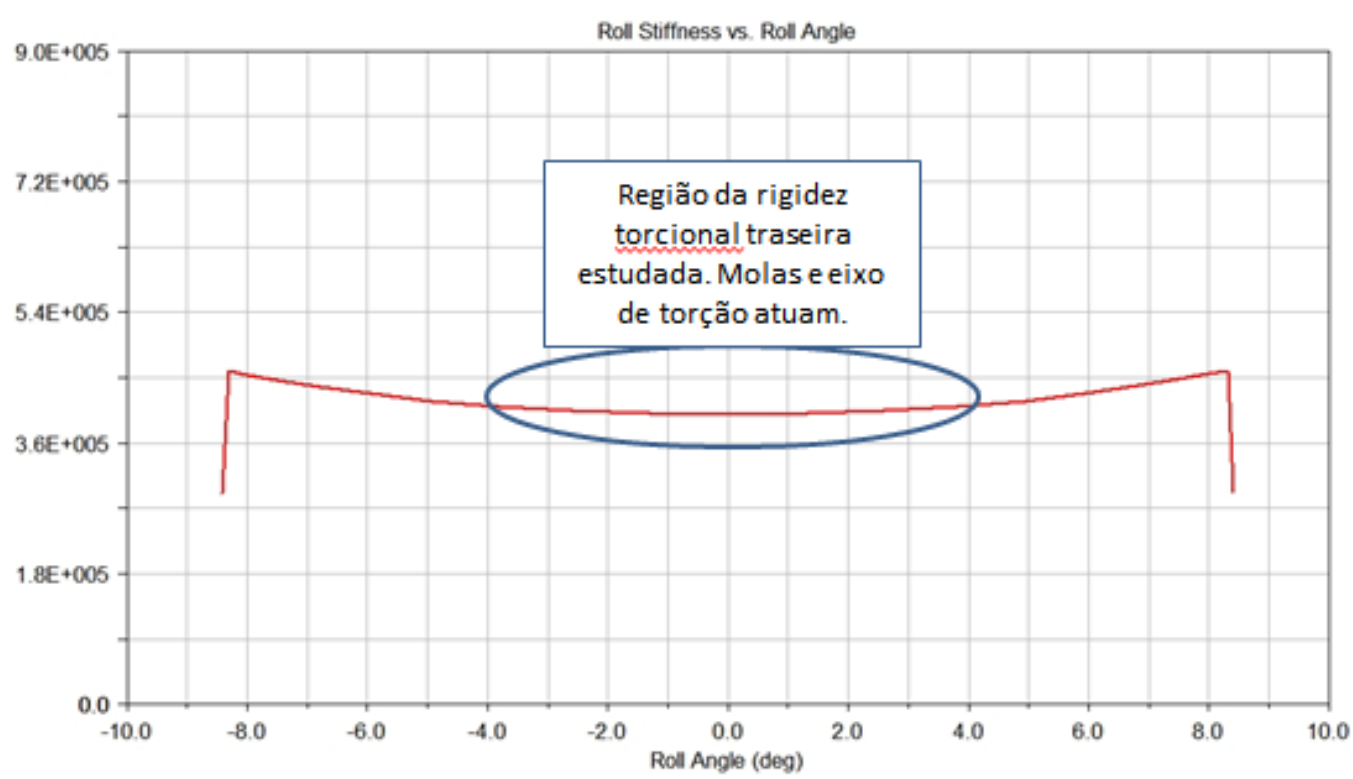

Figura 65 - Rigidez de rolagem para eixo traseiro

De acordo com o uso do modelo simplificado, chegou-se ao seguinte resultado de rigidezes para as molas:

Tabela 3 - Comparativo das frequências de ride avaliadas(eixo dianteiro)

\begin{tabular}{|c|c|c|}
\hline Configuração & $\begin{array}{l}\text { rigide } \mathrm{mola} \\
(\mathrm{N} / \mathrm{mm})\end{array}$ & $\begin{array}{l}\text { frequencia de } \\
\text { ride }(\mathrm{Hz})\end{array}$ \\
\hline 1 & 15 & 1,14 \\
\hline 2 & 17 & 1,18 \\
\hline 3 & 18 & 1,21 \\
\hline 4 & 20 & 1,23 \\
\hline 5 & 21 & 1,25 \\
\hline 6 & 23 & 1,30 \\
\hline 7 & 25 & 1,35 \\
\hline
\end{tabular}

Tabela 4 - Comparativo das frequências de ride avaliadas(eixo traseiro)

\begin{tabular}{ccc}
\hline Configuração & $\begin{array}{c}\text { rigidez mola frequencia de } \\
(\mathrm{N} / \mathrm{mm})\end{array}$ & $\begin{array}{c}\text { ride }(\mathrm{Hz}) \\
\text { ris }\end{array}$ \\
\hline 1 & 14 & 1,30 \\
\hline 2 & 15 & 1,34 \\
\hline 3 & 16 & 1,38 \\
\hline 4 & 17 & 1,42 \\
\hline 5 & 18 & 1,46 \\
\hline 6 & 19 & 1,50 \\
\hline 7 & 20 &
\end{tabular}


Esses valores foram calculados de modo a verificar qual a sensibilidade do veículo quando a variação de rigidezes das molas e as frequências naturais das suspensões e assim reduzir a complexidade da biblioteca de molas a ser testada fisicamente.

Conforme exposto por Dixon (figura17 desta dissertação) a percepção humana apresenta sensibilidade que se aproxima de uma escala logarítmica sendo assim as molas mais adequadas ao veículo devem se situar próximos a $1,3 \mathrm{~Hz}$ para a suspensão dianteira e $1,4 \mathrm{~Hz}$ para a suspensão traseira.

\section{3 - Conceitos iniciais e avaliações subjetivas}

Tomando como referência inicial os trabalhos de John C. Dixon, foi definido para a suspensão dianteira um intervalo de valores de molas que permitisse frequências de ride dentro dos intervalos de $1,15 \mathrm{~Hz}$ a $1,35 \mathrm{~Hz}$ para a dianteira e para a traseira de $1,25 \mathrm{~Hz}$ a $1,48 \mathrm{~Hz}$. Esse intervalo é bem mais abrangente do que se fixaria na prática, sendo o intuito mostrar como cada mola é percebida pelo ser humano. As avaliações são baseadas na norma SAEJ1441.

A ideia a seguir é a continuidade dos estudos para as definições numéricas e quanto a verbalização das definições dos resultados subjetivos, adotar as referências de Olley e Milliken. Assim como definir a proporção de frequências da dianteira para a traseira que permita melhor percepção de conforto durante a direção. Para as avaliações subjetivas, é empregada uma escala de notas variando de 1 a 10 para qualificar a percepção subjetiva.

Assim foram realizadas avaliações subjetivas em pistas de asfalto, terra e calçamento de paralelepípedos, sendo todas com superfícies não totalmente planas, porém com boa qualidade de piso, pois o intuito é avaliar como as variações de molas controlam a carroceria, no sentido de controle de movimentos propriamente dito no chamado ride primário, ou seja, eventos caracterizados por apresentar grande amplitude e baixa frequência.

Relembrando conceito de frequência natural inicial para o ride primário:

$$
f=\frac{1}{2 \pi} \sqrt{\frac{k}{m}}
$$




$$
\begin{aligned}
& f=\text { frequência natural } \\
& k=\text { constante elástica da mola } \\
& m=\text { massa do veículo incidida na suspensão }
\end{aligned}
$$

Assim:

Tabela 5 - Resultados subjetivos para o eixo dianteiro

\begin{tabular}{ccccc}
\hline Configuração & $\begin{array}{c}\text { rigidez mola } \\
(\mathrm{N} / \mathrm{mm})\end{array}$ & $\begin{array}{c}\text { fre quencia de } \\
\text { ride }(\mathrm{Hz})\end{array}$ & $\begin{array}{c}\text { avaliação subje tiva avaliação subjetiva } \\
\text { de controle }\end{array}$ & $\begin{array}{c}\text { de comforto } \\
\text { de }\end{array}$ \\
\hline 1 & 15 & 1,15 & 5,0 & 8,0 \\
\hline 2 & 17 & 1,19 & 5,6 & 8,0 \\
\hline 3 & 18 & 1,21 & 6,0 & 7,5 \\
\hline 4 & 20 & 1,24 & 6,5 & 7,5 \\
\hline 5 & 21 & 1,26 & 7,0 & 7,0 \\
\hline 6 & 23 & 1,29 & 7,6 & 7,0 \\
\hline 7 & 25 & 1,34 & 8,0 & 6,5 \\
\hline
\end{tabular}

Tabela 6 - Resultados subjetivos para o eixo traseiro

\begin{tabular}{ccccc}
\hline Configuração & $\begin{array}{c}\text { rigidez mola } \\
(\mathrm{N} / \mathrm{mm})\end{array}$ & $\begin{array}{c}\text { frequencia de } \\
\text { ride }(\mathrm{Hz})\end{array}$ & $\begin{array}{c}\text { avaliação subjetiva avaliação subjetiva } \\
\text { de controle }\end{array}$ & \begin{tabular}{c} 
de comforto \\
\hline 1
\end{tabular} \\
14 & 1,27 & 5,0 & 9,0 \\
\hline 2 & 15 & 1,31 & 6,0 & 8,5 \\
\hline 3 & 16 & 1,35 & 6,5 & 8,0 \\
\hline 4 & 17 & 1,39 & 7,0 & 7,5 \\
\hline 5 & 18 & 1,43 & 8,0 & 7,0 \\
\hline 6 & 19 & 1,46 & 8,5 & 6,0 \\
\hline 7 & 20 & 1,51 & 9,0 & 5,0 \\
\hline
\end{tabular}

Segundo os resultados subjetivos acima temos as seguintes observações:

- As configurações 5 e 6 foram as melhores para o eixo dianteiro considerando o balanço entre conforto e controle. A verbalização do fenômeno é que a suspensão assimila as entradas causadas pelos eventos da pista, porém mantendo o movimento vertical contido, com mínimo de deslocamento. Considerando movimentos laterais ou diagonais, a descrição do controle e conforto é a mesma.

- As configurações 4 e 5 foram as melhores para o eixo traseiro considerando o mesmo balanço de conforto e estabilidade. O que se observou é que a percepção de conforto 
significou uma finalização do movimento oscilatório de carroceria iniciado pela dianteira. Por se tratar de uma maior rigidez de mola, a percepção de controle é maior que a dianteira, assim subjetivamente mais estável pela finalização de movimentos.

- Quando o veículo estava montado com as configurações 6 dianteira e 2 traseira, o comportamento da carroceria foi de apenas transladar, a percepção foi de falta de controle pois o movimento não se "finalizou" como nas configurações com molas de maior rigidez.

- Nas demais configurações que apresentaram frequência de ride maior na suspensão dianteira que na traseira, a percepção é de pior conforto e instabilidade direcional.

- Para as configurações 6 dianteira e 4 traseira montadas, o veículo apresentou melhor compromisso de percepção para conforto e controle da carroceria. Então se tem para este exemplo:

. Rigidez das molas dianteiras: $23 \mathrm{~N} / \mathrm{mm}$

. Frequência de ride dianteira: $1,29 \mathrm{~Hz}$

. Rigidez das molas traseiras: $17 \mathrm{~N} / \mathrm{mm}$

. Frequência de ride traseira: $1,39 \mathrm{~N} / \mathrm{mm}$

. Proporção entre as frequências da dianteira para a traseira: 1:1,08

\section{4 - Avaliações}

As avaliações foram realizadas em duas frentes, subjetiva e objetiva. A avaliação subjetiva significa que o ser humano é o sensor para verificar o desempenho, através de sua percepção, do veículo e avaliação objetiva é a medição e verificação do desempenho através de números.

Para a avaliação subjetiva, somente o engenheiro responsável pelo desenvolvimento e integração de performance (dinâmica veicular) de atributos é empregado. Para a medição de acelerações para atributos do conforto, foi considerado somente o eixo $Z$ vertical e o acelerômetro posicionado no assento do banco do motorista (figura 66). 
O engenheiro responsável deve estar fluente com a norma SAE J1441 relativa às avaliações, assim como os conceitos de dinâmica veicular apresentados no capitulo 3 .

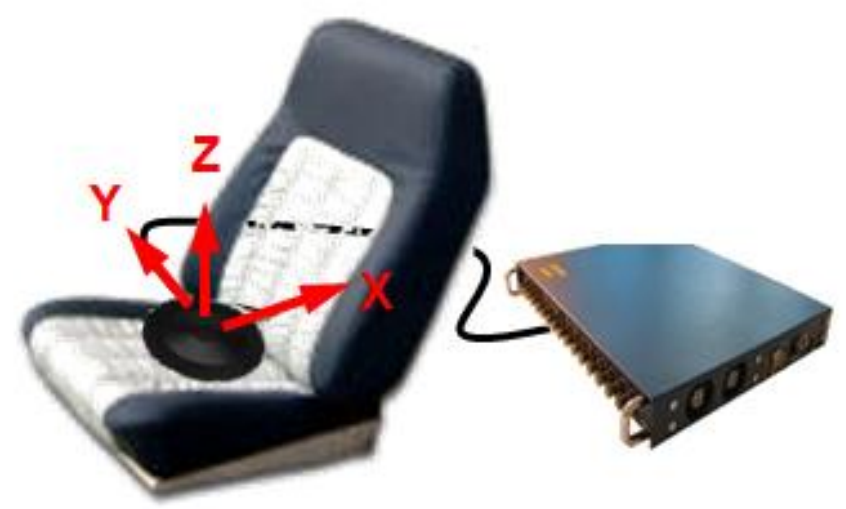

Figura 66 - Ilustração para instalação de acelerômetro de banco

Para mostrar as diferenças entre três configurações distintas de molas avaliadas no veículo e como elas afetam o conforto pode-se apresentar o seguinte:

Para essas medições foram definidas três configurações básicas conforme a tabela 7. Essas configurações foram definidas após análise dos valores com o modelo simplificado e com as avaliações subjetivas, deste modo, foi possível avaliar os componentes conforme a percepção humana e encontrar valores finais mais adequados ao veículo. E adição conforme a imagem que o veículo deve assumir para suas características uma configuração ou outra deve ser definida, mercado voltado a performance molas de maior rigidez (configuração 1 da tabela 7), para mercado voltado ao uso comum, as molas de melhor equilíbrio dianteira para traseira (configuração 2 da tabela 7).

Tabela 7 - Referência subjetiva para comparação com aquisição

\begin{tabular}{ccccc}
\hline configurações & $\begin{array}{c}\text { rigidez mola } \\
\text { dianteira (N/mm) }\end{array}$ & $\begin{array}{c}\text { rigidez mola } \\
\text { traseira (N/mm) }\end{array}$ & $\begin{array}{c}\text { avaliação } \\
\text { subjetiva de } \\
\text { controle }\end{array}$ & $\begin{array}{c}\text { avaliação } \\
\text { subjetiva de } \\
\text { comforto }\end{array}$ \\
\hline 1 & 23 & 18 & 8,0 & 7,0 \\
\hline 2 & 23 & 17 & 7,5 & 7,5 \\
\hline 3 & 21 & 17 & 7,0 & 7,5 \\
\hline
\end{tabular}

Assim, na aquisição de dados para ride primário podem-se verificar as seguintes situações (figura67): 


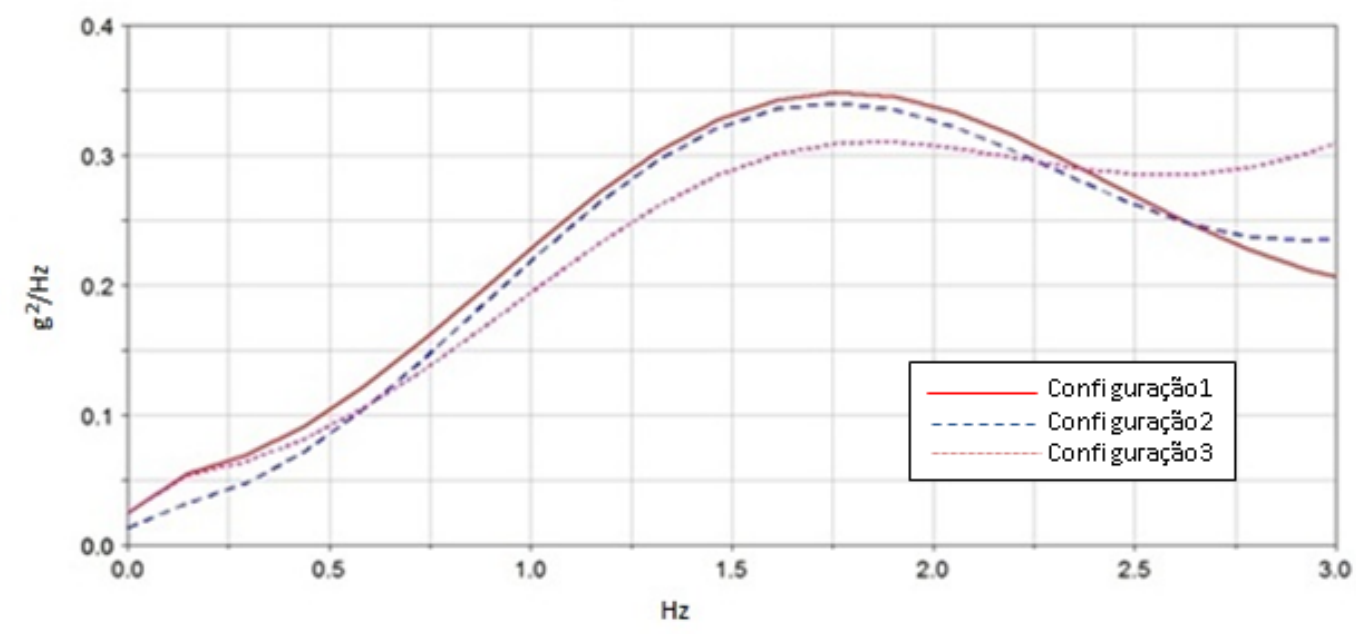

Figura 67 - PSD resultante de aquisição de energia de ride primário

Considerando os movimentos percebidos pelo avaliador durante as atividades em pista e os sinais medidos, temos os seguintes cenários:

I. Percepção de movimentação vertical

Pode ser verificada pelo sinal de deslocamento vertical do banco do motorista através do valor RMS da segunda integral do sinal de aceleração.

II. Percepção do movimento entre o eixo dianteiro e traseiro

Também encontrada através do sinal de deslocamento vertical do banco do motorista através do valor RMS da segunda integral do sinal de aceleração, porém trata-se da proporção entre o deslocamento do eixo dianteiro (RMS diant)e do eixo traseiro $\left(\mathrm{RMS}_{\text {tras }}\right)$, assim temos:

$$
M_{d \rightarrow t}=\frac{R M S_{\text {diant }}}{R M S_{\text {tras }}}
$$

III. Curva de raio constante (estado estacionário)

Pode ser melhor percebido através do gradiente de rolagem, sendo o número aquisitado por instrumentação específica.

Como resultado, a configuração de melhor percepção de ride foi a numero 2 apesar do valor do pico da densidade de energia não ter sido o mais baixo. Esse resultado condiz com as definições de Olley para melhor configuração de conforto e controle do veículo (figura68) 
citado nos capítulos de bibliografia e revisão teórica. Temos então o resultado das medições o nas tabelas 8 e 9:

Tabela 8 - Valores de referência para percepção de ride

\begin{tabular}{ccc}
\hline Configurações & $\begin{array}{l}\text { Deslocamento vertical } \\
\text { no motorista }(\mathrm{mm})\end{array}$ & $\begin{array}{l}\text { Percepção de } \\
\text { deslocamento entre o } \\
\text { eixo dianteiro e traseiro }\end{array}$ \\
\hline 1 & 29 & 0,90 \\
\hline 2 & 27 & 0,92 \\
\hline 3 & 22 & 0,86 \\
\hline
\end{tabular}

Tabela 9 - Valores de gradiente de rolagem

\begin{tabular}{cc}
\hline \multicolumn{2}{c}{ Tabela 9 - Valores de gradiente de rolagem } \\
\hline Configuraçồes & $\begin{array}{c}\text { Gradiente de } \\
\text { rolagem }(\%)\end{array}$ \\
\hline 1 & 5,1 \\
\hline 2 & 5,3 \\
\hline 3 & 6,0 \\
\hline
\end{tabular}

Apenas para ilustrar como ocorre o deslocamento percebido pelo motorista temos o gráfico abaixo (figura68).

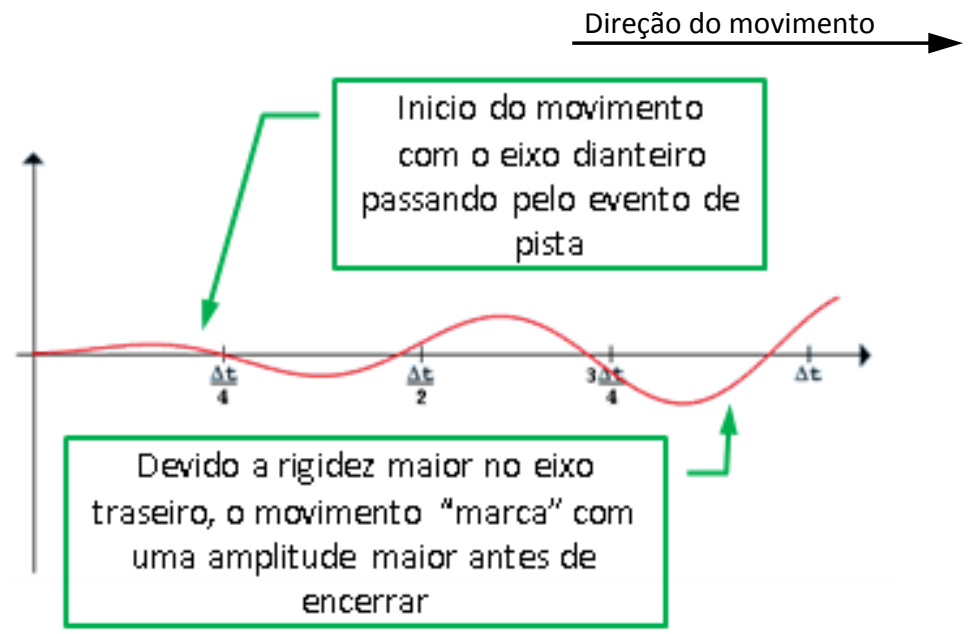

Figura 68 - Ilustração das oscilações das suspensões e suas descrições 


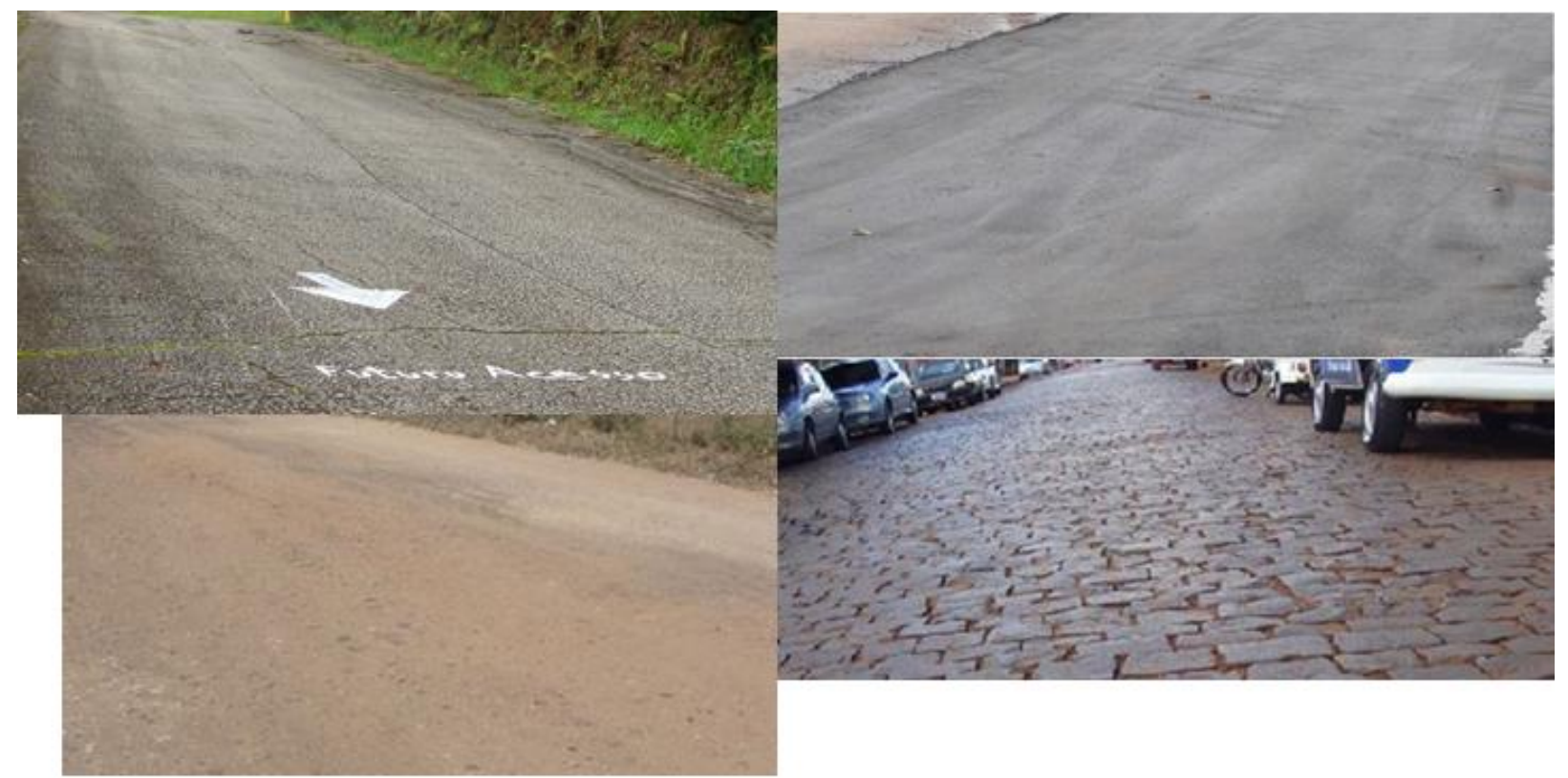

Figura 69 - Imagem de pistas empregadas (ride primário)

As imagens apresentadas na figura 69 correspondem a típicas pistas para avaliação de ride primário. A principal característica é a existência de eventos na topografia que não causem mudança de estado de movimento na carroceria. Apesar das pistas possuírem diferentes texturas devido aos diferentes tipos de material empregado em sua pavimentação, somente é considerado para essas análises as oscilações ou deformidades existentes na superfície, assim restringindo a análise para o ride primário.

\section{5 - Considerações}

Para ilustrar o comparativo do que foi percebido e medido em campo com o modelo simplificado, a figura70 e as tabelas 10 e 11 trazem os resultados simulados preliminares.

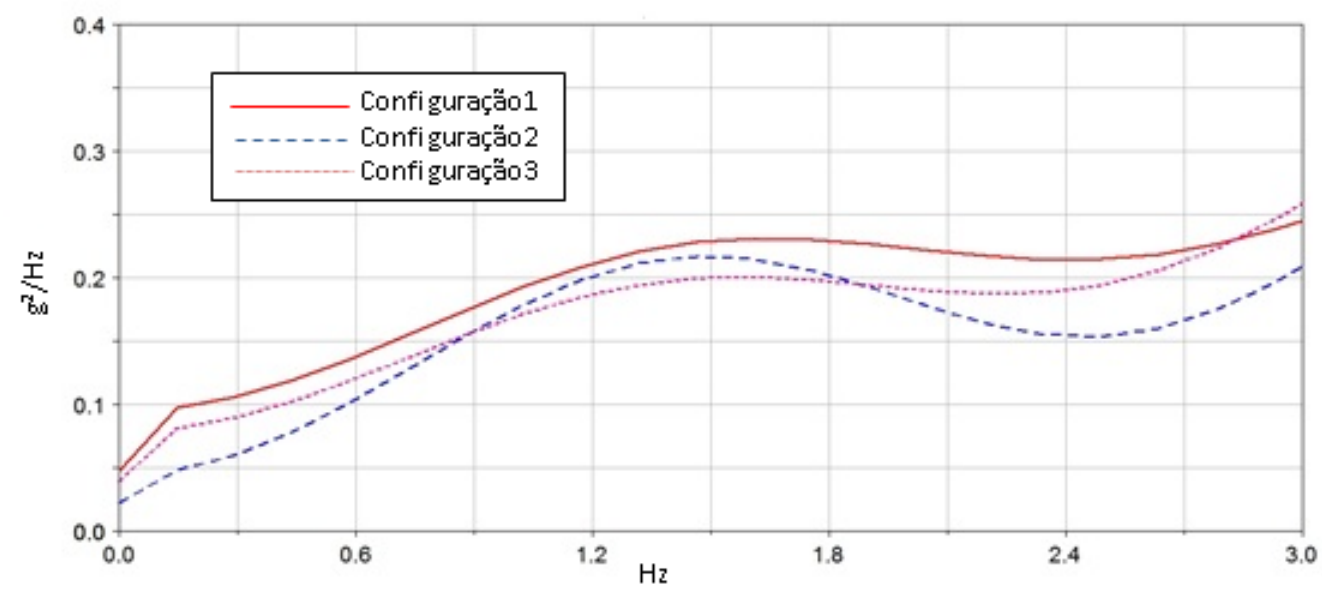

Figura 70 - PSD para ride primário simulada 
Tabela 10 - Valores simulados para referenciar o ride

\begin{tabular}{ccc}
\hline Configuraçồes & $\begin{array}{l}\text { Deslocamento vertical } \\
\text { no motorista }(\mathrm{mm})\end{array}$ & $\begin{array}{l}\text { Percepçắ de } \\
\text { deslocamento entre o } \\
\text { eixo dianteiro e traseiro }\end{array}$ \\
\hline 1 & 30 & 0,91 \\
\hline 2 & 29 & 0,92 \\
\hline 3 & 24 & 0,87 \\
\hline
\end{tabular}

Tabela 11 - Valores simulados de gradiente de rolagem

\begin{tabular}{cc}
\hline Configuraçồes & $\begin{array}{c}\text { Gradiente de } \\
\text { rolagem }(\%)\end{array}$ \\
\hline 1 & 5,4 \\
\hline 2 & 5,5 \\
\hline 3 & 6,3 \\
\hline
\end{tabular}

Considerando as medições, os valores mais baixos de aceleração não necessariamente corresponderam à melhor percepção de conforto para as avaliações. Podem ser verificadas as seguintes situações:

. A traseira deve apresentar frequência de ride superior à dianteira ou ocorrerá uma percepção de descontrole quando sendo dirigido.

. Quando ambas as frequências, dianteira e traseira estão iguais, a percepção é de indefinição no movimento (desconforto).

. Quando a frequência da traseira está mais que $10 \%$ superior à da dianteira, a percepção passa a ser de movimento abrupto, novamente degradando a percepção de conforto.

Assim, chega-se a molas dianteiras de rigidez $23 \mathrm{~N} / \mathrm{mm}$ para o veículo de plataforma B. Sendo a proporção do incremento da rigidez da dianteira para a da traseira, $8 \%$ resultando rigidez de $17 \mathrm{~N} / \mathrm{mm}$. 


\section{Capitulo 5 - Conclusões e trabalhos futuros}

\section{1 - Comentários iniciais devidos ao escopo da dissertação}

Conforme os resultados dos estudos do capítulo anterior pode-se apresentar os seguintes comentários:

Para veículos cuja função principal seja voltada ao transporte de passageiros como carros de passeio, esporte, utilitários esportivos, algumas caminhonetes, a referência para as métricas das frequências naturais da suspensão são totalmente válidas para direcionar o ajuste das suspensões, pois por se tratar de proporção entre massa veicular e rigidez das molas, apresenta sempre o mesmo comportamento quanto a atributos. A grandeza de interesse é a frequência natural e o valor praticado esteja em um intervalo de cerca de $1,25 \mathrm{~Hz}$ a $1,30 \mathrm{~Hz}$.

Esse valor é endereçado ao eixo dianteiro e para o eixo traseiro é necessário um incremento deste valor, na ordem de $8 \%$ a $10 \%$ numa condição usual e intermediária de carga (normalmente duas pessoas) de modo que a suspensão traseira oscile fora da fase da dianteira e "marque" o movimento da oscilação após a passagem por um evento. Em outras palavras, que o movimento mais "lento" inicie primeiro. Esse conceito do refinamento do ride se refere à percepção humana do movimento iniciando e acabando. Na figura 71, abaixo, apresenta a amplitude da oscilação percebida pelo motorista quando passando por um evento.

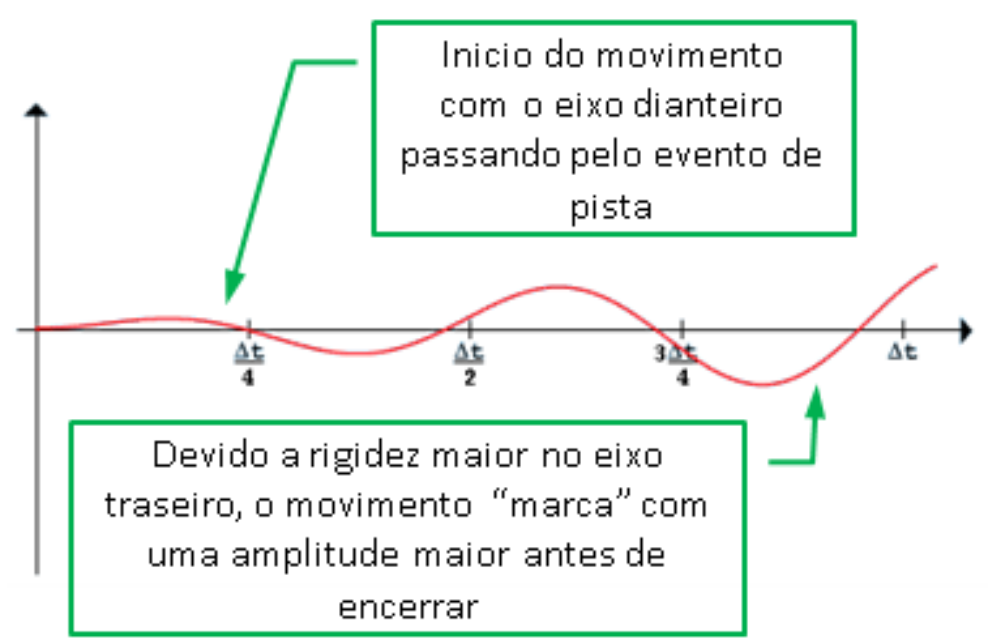

Figura 71 - Ilustração da oscilação resultante para ride 
Novamente citando, os valores de rigidez os quais este conceito converge, não são suficientes para controlar totalmente o veículo em todas as situações de curva que apresentem valores de aceleração lateral superior a $0,5 \mathrm{~g}$, ainda dentro da chamada faixa linear. Para essas situações é necessário instalar um componente que incremente a rigidez torcional das suspensões, como uma barra estabilizadora, de modo que este componente permita incrementar os valores de rigidez de rolagem até o valor objetivado pelo conceito do veículo.

Outro ponto a ser observado se refere às interações que ocorrem entre todos os componentes das suspensões. Após o acerto das molas/amortecedores, o controle, a estabilidade em condições de sublimite mostrou-se totalmente coerente com o calculado assim como o conforto na condição do chamado ride primário, com a carroceria do veículo se mantendo estabilizada durante todas as fases das curvas em que foi avaliado, e, sendo que os movimentos e as oscilações verticais se mantêm em fase próxima, minimizando qualquer perturbação. Quanto à análise de conforto, parte das vibrações, e também se somaram asperezas, apresentaram comportamento não esperado, pelo fato das mesmas não apresentarem total sensibilidade às variações de carga de amortecimento e/ou rigidez de molas fazendo com que em algumas situações de direção, existam vibrações sendo geradas e transmitidas/amplificadas de outras fontes e caminhos, como por exemplo, algumas que posteriormente foram identificadas como vindas do trem de força. Este comportamento pode ser verificado não somente no veículo estudado, mas em todos os demais existentes no mercado.

Após as análises de dados e avaliações veiculares, os comentários e direcionais podem ser acrescidos de mais detalhes, que são os pontos apresentados nos próximos tópicos.

\section{2 - Considerações adicionais}

O trem de força do veículo, por se tratar de uma massa suspensa em um sistema de coxins, apresenta vibrações características que são transferidas para os ocupantes. Estas vibrações se apresentam do mesmo modo que aquelas induzidas pelo pavimento (vibrações e asperezas) em que o veículo transita, sendo que por não serem originadas da pista, as suspensões tem pouca influência em seu comportamento. 
Várias asperezas que são percebidas pelos ocupantes e que têm origem na qualidade superficial do pavimento não podem ser isoladas pelo conjunto mola/amortecedor devido ao fato deles não possuírem sensibilidade, em sua operação, a esse tipo de entrada. Várias delas possuem amplitudes e frequências que só podem ser isoladas através de componentes confeccionados em elastômeros (borracha, poliuretano,...). E em adição, devido à sua construção e operação esses componentes apresentam não linearidades e consequentemente influem na resposta a manobras e no crescimento dos esforços sendo necessário acrescentar análise da elastocinemática para as suspensões.

As disciplinas atribuídas à área de NVH têm a ver com ruído, vibrações e asperezas, como o próprio nome indica (Noise, Vibration and Harshness). Apesar disso, existe uma faixa de frequências que possuem sensibilidade em componentes de suspensão e assim devem ser tratadas em conjunto com os atributos da dinâmica veicular já que o objetivo de eliminar as perturbações é comum para as duas áreas. Esta faixa em comum corresponde ao chamado ride secundário e se situa entre $8 \mathrm{~Hz}$ e $100 \mathrm{~Hz}$.

Estas considerações são devidas a fatores de grande influência nas percepções de conforto e estabilidade do veículo. Assim devem ser consideradas como ideias para novos trabalhos a serem realizados no âmbito da pós-graduação como dissertações ou teses.

Os próximos itens são necessários para reforçar vários comportamentos veiculares que inicialmente não faziam parte do escopo deste trabalho, porém no desenvolver dos estudos eles se demonstraram bastantes marcantes para o funcionamento das suspensões assim como da percepção humana destas perturbações.

\subsection{1 - Vibrações e asperezas do trem de força}

Apesar de não apresentar influência na estabilidade dentro da faixa estudada, os veículos equipados com motores de combustão interna apresentaram vibrações características que costumam ser confundidas com problemas de vibração das suspensões. Essas vibrações acabam ocorrendo em várias situações de uso desde o veículo parado e motor em marcha lenta até quando atinge a velocidade máxima. 
Como foi citado anteriormente, mudanças nas suspensões veiculares não induziram a uma redução representativa na percepção das vibrações. Num segundo momento, foram instalados coxins de trem de força com desenho e rigidez modificados de modo a evitar a condição de ressonância da massa suspensa (o trem de força) com os movimentos da carroceria e também a transmissibilidade das asperezas devidas ao funcionamento do motor para a carroceria (e consequentemente para os ocupantes). A figura 72 apresenta um modelo simplificado da instalação do trem de força num veículo. Pode ser visto como uma massa suspensa na massa suspensa.

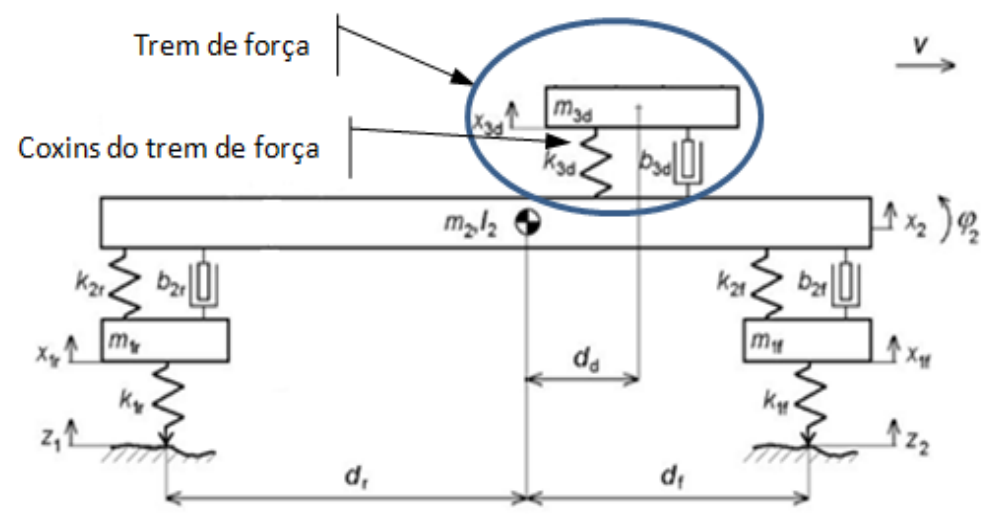

Figura 72 - Representação de modelo simplificado para análise de vibrações e trem de força

A figura73, a seguir, apresenta o gráfico de PSD para o eixo Z vertical do veículo, de modo a demonstrar as diferenças de vibrações antes (NP) e depois (Prop) da troca dos coxins. Nela pode-se verificar que o pico a $12 \mathrm{hz}$ foi reduzido, este pico corresponde à ressonância do trem de força com a carroceria.

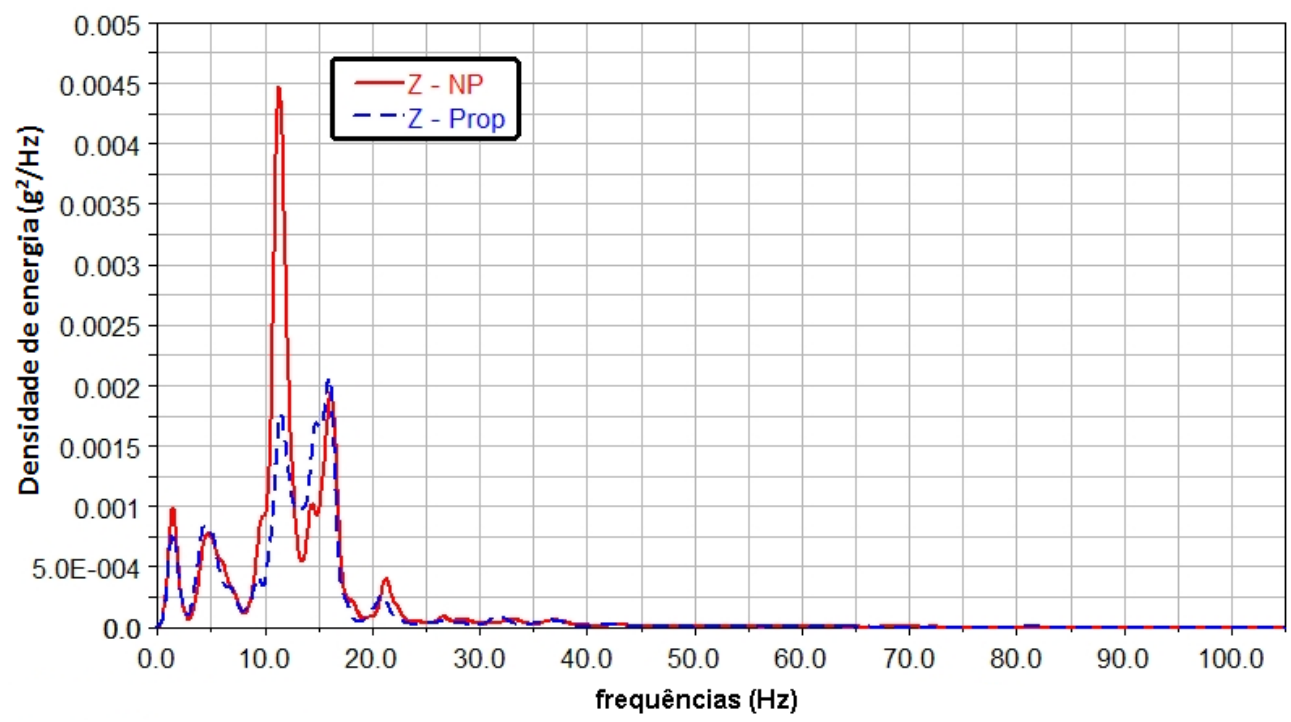

Figura 73 - PSD gerada a partir de valores de aceleração no bando do motorista 
Não foi possível medir dados referentes a redução das asperezas do funcionamento do motor de modo a comparar as propostas assim como realizar em profundidade um estudo de sensibilidades. Vale ressaltar que esta frente também é merecedora de uma análise em maior profundidade.

A ideia de aprofundar estudos nos temas ligados ao trem de força e sua interação com o veículo é atingir um melhor entendimento dos fenômenos e permitir maior refinamento durante o desenvolvimento dos atributos veiculares de modo a aumentar a satisfação dos clientes. Um possível direcional seria entender o trem de força como massa suspensa da massa suspensa e os coxins dele como suspensões. Deve-se adicionar também a transmissibilidade das vibrações que o próprio conjunto motriz gera quando em seu funcionamento para a carroceria.

\subsection{2 - Buchas do sistema de suspensão}

Adicionando mais um fator que exerce influência na percepção de conforto veicular, as buchas aplicadas às fixações dos braços de suspensão são mais um item que apresenta influência à percepção de conforto. Neste caso, como já comentado anteriormente, sua influência é sentida em frequências mais altas, o chamado ride secundário, pois a ideia do uso de elastômeros nas suspensões e direção é empregar suas características mecânicas não lineares para filtrar entradas de pequeno deslocamento e frequências mais altas, as quais o conjunto molas/amortecedores não possui sensibilidade para controlá-los.

Durante o desenvolvimento deste material, foi necessária a análise desses componentes, pois novamente, as molas/amortecedores não haviam apresentado sensibilidade para uma parcela dos problemas de aspereza durante a condução do veículo.

O entendimento do fenômeno foi possível devido à análise das vibrações e asperezas conforme a norma ISO-2631. Nela são discorridas as análises e métodos para se caracterizar o que e como as entradas da pista chegam aos ocupantes. Os três gráficos a seguir (figuras 74, $75,76)$ apresentam os sinais prós processados das vibrações para os eixos $\mathrm{X}$, Y e Z do assento do motorista. 


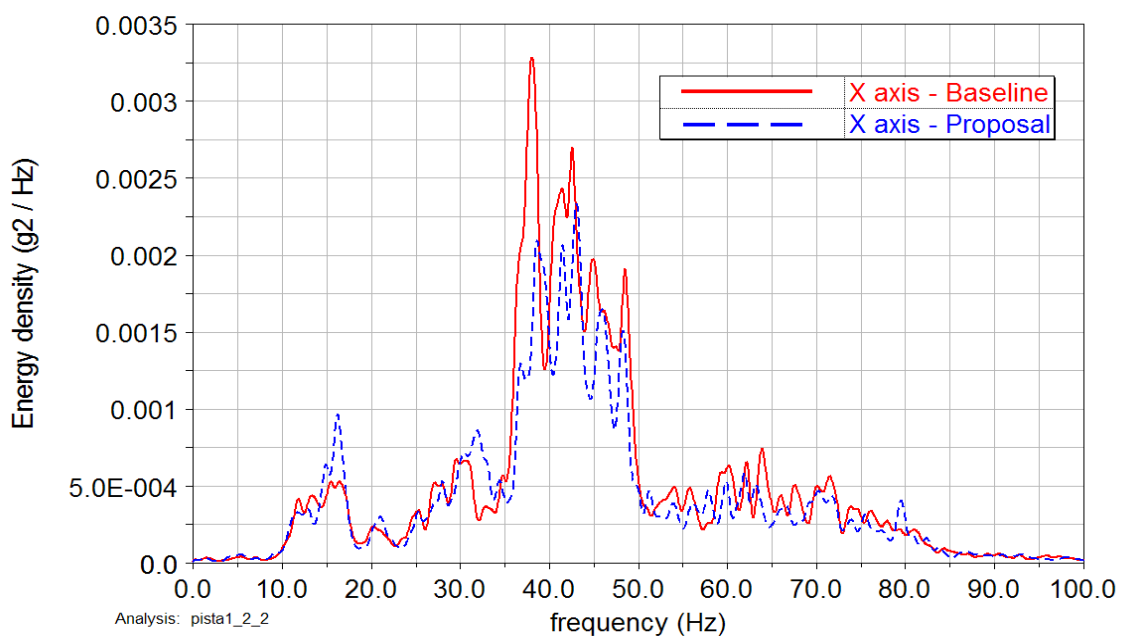

Figura 74 - PSD para eixo X

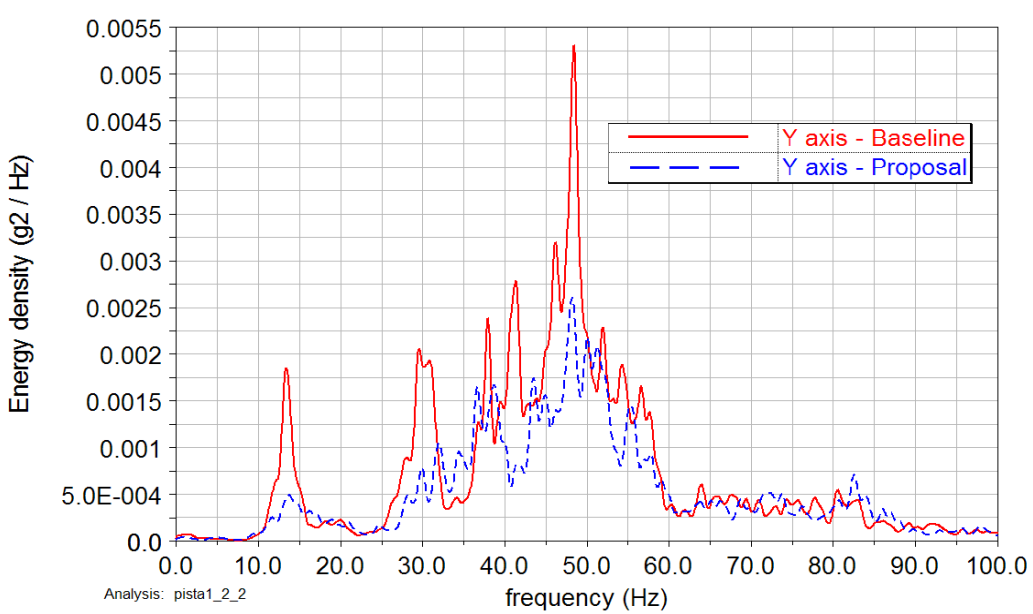

Figura 75 - PSD para eixo Y

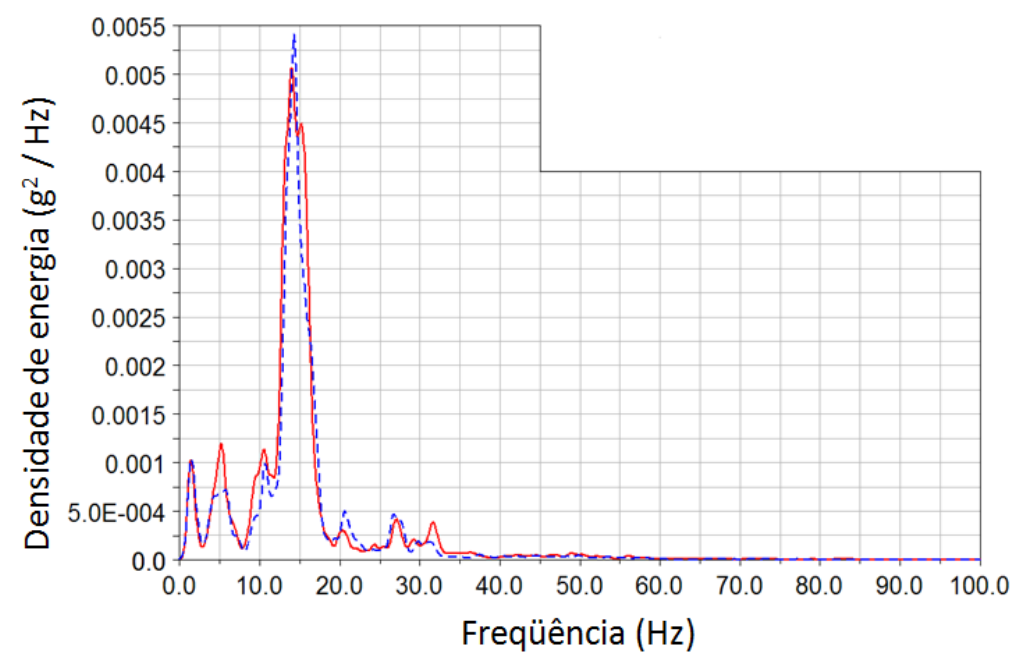

Figura 76 - PSD para eixo $Z$ 
Devido às buchas corresponderem aos pontos de ancoragem das suspensões é necessário realizar uma análise referente à influência destas melhorias de conforto na dirigibilidade. Foram empregadas as manobras de resposta em frequência e centro de esterço (frequency response e on-center) para aquisitar e analisar informações e demonstrar as diferenças.

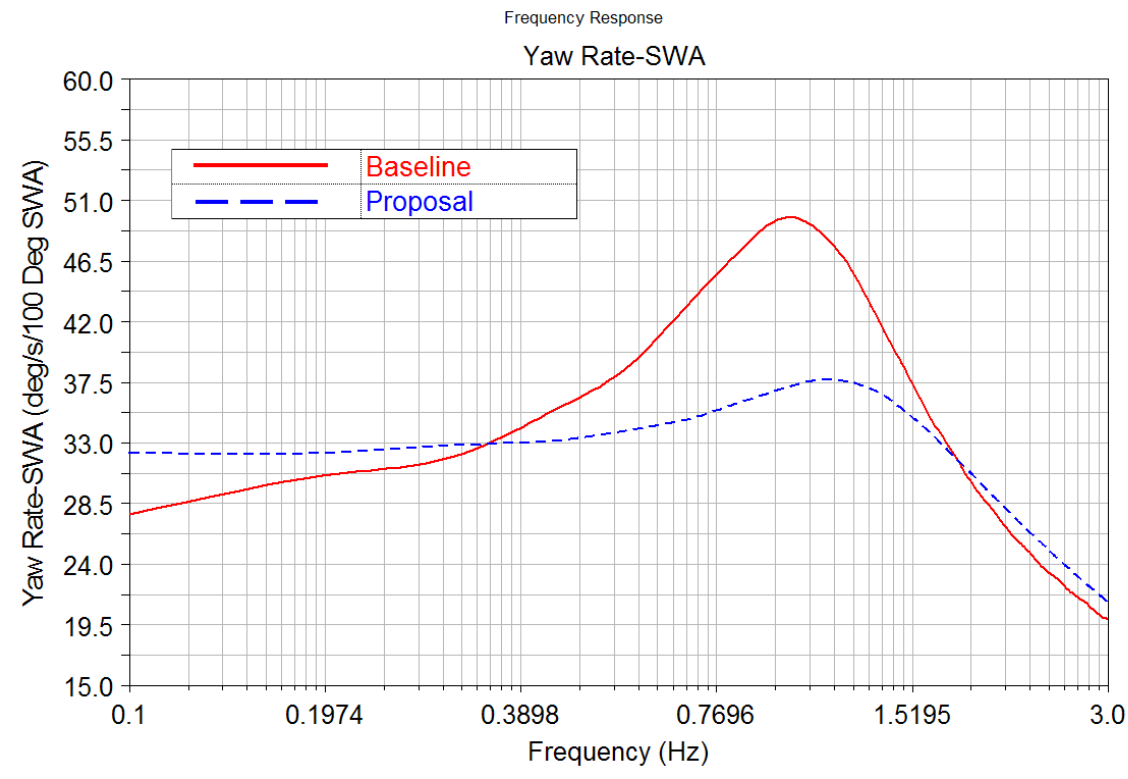

Figura 77 - Exemplo de resposta em frequencia

A figura 77 corresponde a uma análise de resposta em frequência onde o métrico adotado é a rotação em torno do eixo $\mathrm{Z}$ que o veículo apresenta à medida que o volante é esterçado em velocidades angulares crescentes. O eixo das ordenadas do gráfico apresenta valores em Hertz, pois a entrada corresponde a um determinado deslocamento linear do sistema de direção em determinadas frequência de acionamento. Com base nas curvas geradas, pode-se concluir que o veículo apresenta uma maior linearidade de resposta em várias velocidades de acionamento do volante, sendo que isso pode ser traduzido num comportamento mais linear nas respostas do veículo em função das entradas geradas pelo motorista. Ou seja, um veículo mais previsível durante a direção. 


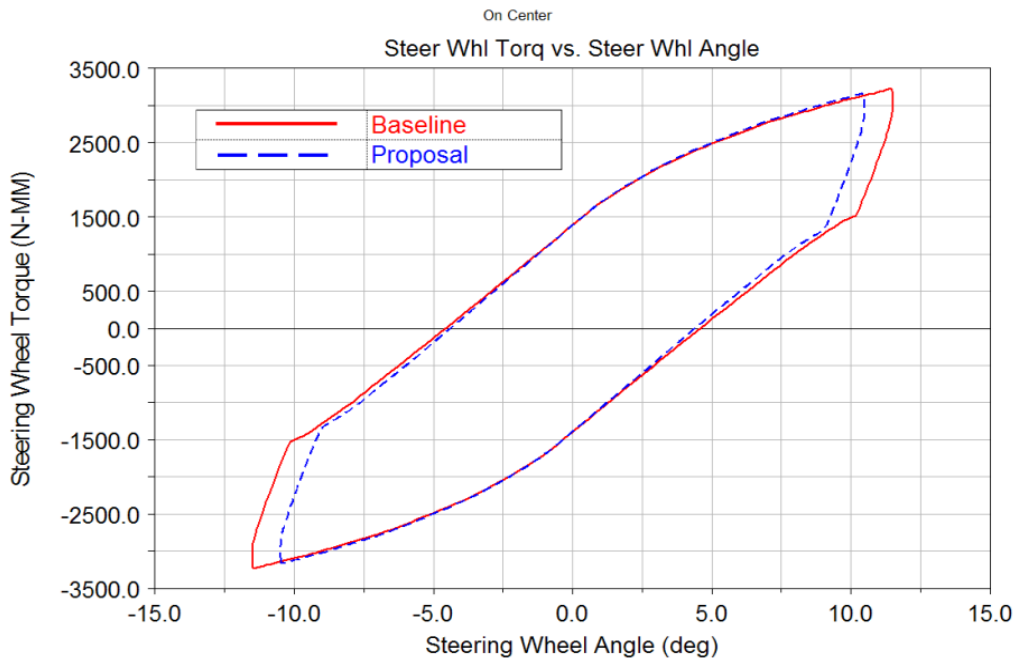

Figura 78 - Exemplo de resposta em centro

Considerando a resposta em centro (figura 78), o que se percebe é que o aumento de esforço no volante durante o esterço considerando o ângulo empregado no volante é um pouco mais notório, para o mesmo ângulo de entrada no volante, o esforço cresce mais rápido. Em outras palavras a percepção de "borracha" e imprecisão no esterço é reduzida.

Como já foi exposto, é necessário o uso de elastômeros para permitir melhor isolamento das suspensões. Sendo assim, seria necessário um estudo para investigar de modo mais profundo como é a função de transferência das buchas e isoladores de borracha das entradas da pista para o monobloco, pois existe sensibilidade de rigidez de estruturas do chassi, dos pontos de fixação dos componentes e também das buchas de suspensão. Como regra geral, quanto maior a rigidez da estrutura, e dos pontos de fixação, melhor serão os resultados para isolamento da propagação de vibrações e asperezas assim como permitindo menor rigidez para as buchas quando se pensa em estabilidade e controle. E também como dependendo do desenho dos braços de controle é necessário segregar funções específicas para cada bucha, as chamadas buchas de estabilidade e conforto. 


\subsection{3 - Interface com NVH}

Complementando a ideia do lugar comum entre NVH e Dinâmica Veicular, as percepções a seguir são dedicadas a NVH, porém sofreram também influência dos componentes de suspensão.

Durante as avaliações foi verificado que a qualidade e pressão sonora também sofreram influencia com o refinamento das asperezas via rigidez das buchas de suspensão. Esta influência surgiu em pavimentos de asfalto de grossa rugosidade e pedriscos. O gráfico a seguir apresenta um comparativo da densidade de pressão sonora em função das frequências das vibrações enquistadas. O valor médio de redução de pressão sonora ficou em cerca de 1 dB, sendo que em frequências específicas a redução se aproxima de $5 \mathrm{~dB}$. Vide a figura 79.

Como ferramenta adicional para se analisar as mudanças de conforto de direção para estas situações, quando se realiza a integra da função do gráfico de densidade de energia se gera a totalização da energia da perturbação que chega aos ocupantes. Assim podemos ter os totais apresentados nas colunas abaixo (gráfico80).

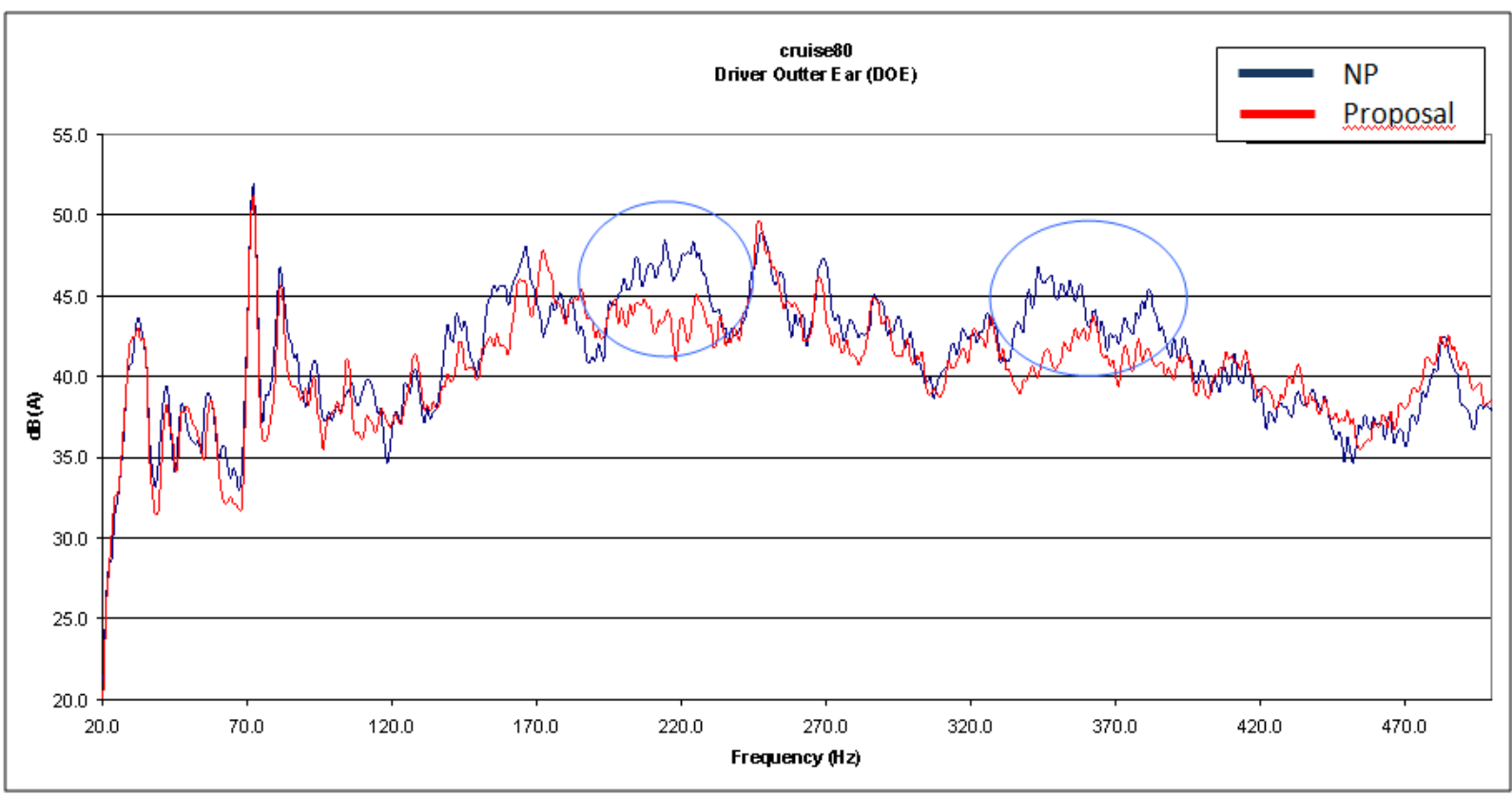

Figura 79 - PSD para análise de ruidos 


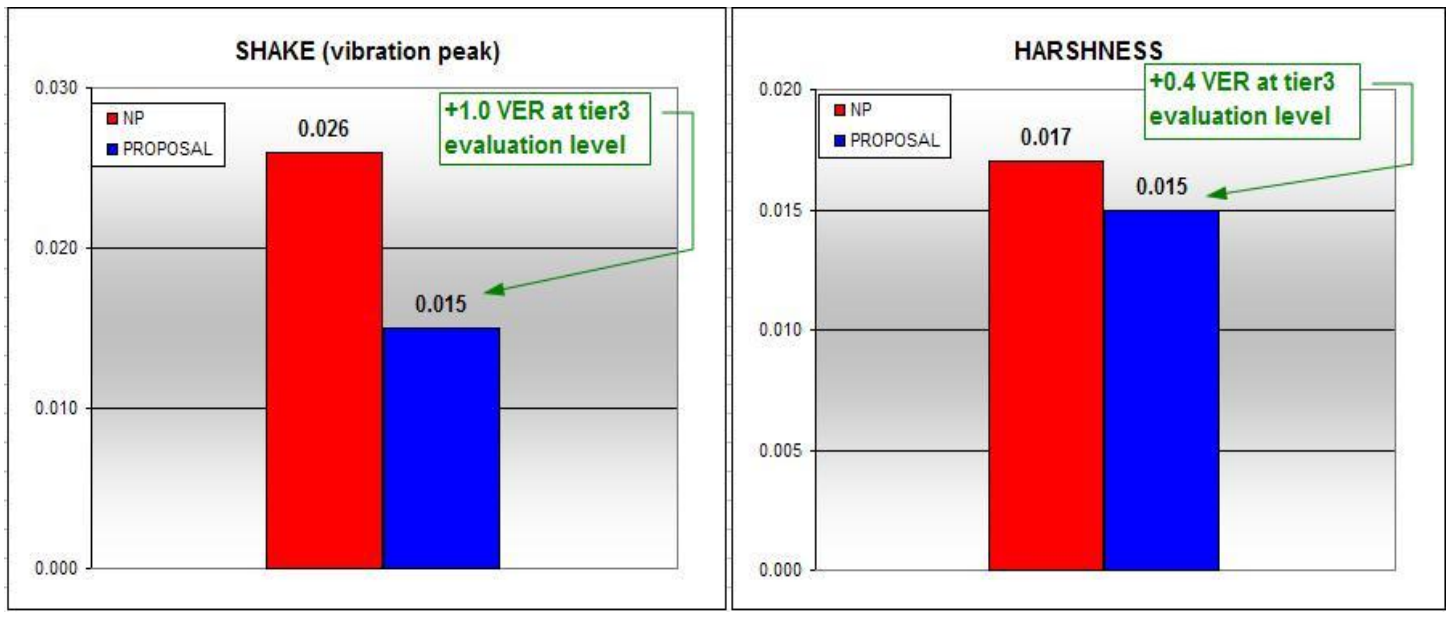

Figura 80 - Quantia de energia em faixa de ride secundário

\section{3 - Direcionais para novas frentes de estudos}

O próximo item é necessário para reforçar vários comportamentos veiculares que inicialmente não faziam parte do escopo deste trabalho, porém no desenvolver dos estudos eles se demonstraram bastantes marcantes para o funcionamento das suspensões assim como da percepção humana destas perturbações. A ideia de reforçar esses pontos como passíveis de maiores estudos tem como base a necessidade de se ter maior conhecimento no comportamento veicular de modo a permitir maior refinamento dos atributos que o veículo apresente e assim torná-lo mais agradável e dedicado ao uso das pessoas.

\subsection{1 - Amortecedores}

O aprofundamento de estudos em seu funcionamento é necessário, pois do mesmo modo que ele permite melhor controle das oscilações da carroceria, o chamado ride primário, ele apresenta influência sobre várias situações do ride secundário. Apesar disso, é recomendado que sua operação não passasse de frequências de cerca de $14 \mathrm{~Hz}$ e para todas as frequências que sejam superiores, sejam empregados isoladores e buchas de elastômeros. Outros pontos são as várias solicitações que podem surgir dependendo da qualidade das pistas e que apresentem grande velocidade de deslocamento assim como amplitudes do próprio deslocamento. Mais um adendo (já citado no texto desta dissertação) é referente à quais situações o amortecedor deve apresentar maior ação, pois ele por si só pode ser fonte de vibrações. 


\section{Capítulo 6 - Referências bibliográficas}

ARRUDA, J. R. de F., HUALLPA, B. N., Análise Espectral de Sinais e sistemas mecânicos Lineares, Universidade Estadual de Campinas Faculdade de Engenharia Mecânica, Campinas, 2005 .

BALBINOT, A., Caracterização dos níveis de vibração em motoristas de ônibus: Um enfoque no conforto e na saúde. Tese (2001). Universidade Federal do Rio Grande do Sul.

BUTLER, B. P., ALEM N. M., Apache Helicopter Seat Cushion Evaluation, Aircrew Protection Division, USAARL Report No. 94-32, July 1994.

COOPER, G.E., and HARPER, R.P., "The Use of Pilot Rating in the Evaluation of Aircraft Handling Qualities," NASA TN D5153, April 1969.

COVENTRY UNIVERSITY, Researchnet CUCV, Damian Harty, site disponível em http://wwwm.coventry.ac.uk/researchnet/cucv/Pages/Profile.aspx?profileID=764, visitado em 10 de agosto de 2012.

DIXON, J. C., Shock absorber handbook, (495p) SAE R-176, ISBM0-7680-0050-51999.

DVORAK R., FREISTETTER F., Chaos and stability in planetary systems. [S.1.]: Birkhäuser, 2005. p. 24. ISBN 3540282084

FERNANDES C. G., Método probabilístico para estudo de sistemas dinâmicos não lineares, Universidade de São Paulo, Escola Politécnica, programa de pós-graduação em engenharia naval e oceânica, 2009.

FÓRMULA 1, Renault R26 - Mass damper system, julho 2006, disponível em $<$ http://www.formula1.com/teams_and_drivers/teams/6/technical/2006/311.html>, acesso em 16 de julho 2011. 
FREEMAN, T. E., Reduction of Vehicle Chassis vibration using the powertrain system as a multi degree-of-freedom dynamics absorber, Tese (2004), Escola de engenharia mecânica, Universidade de Purdue.

GANZAROLLI, F., Otimização das buchas do braço inferior de controle da suspensão dianteira, SAE 2010 (paper), 210-36-0248I.

GOLDSTEIN H., Classical Mechanics, Addison-Wesley Addison Wesley; 3 edition, 2001, ISBN-13: 978-0201657029

GRECCO P., Class notes (USP EESC MSc course), 2009.

LEMOS, N. A., Mecânica Analítica, Livraria da Física, 2a ed., editora livraria da física, 388p, 2007, ISBN 9788588325241

LU, J., FILEV, D., JOHNSON, L., "Real-time Tire Imbalance Detection Using ABS Wheel Speed Sensors," SAE Int. J. Mater. Manuf. 4(1):1036-1047, 2011, doi:10.4271/2011-01-0981.

LUKOWSKI S., MOMOT M., KRAEMER D., KUNZ D., Teoria linear básica de dirigibilidade e estabilidade dos automóveis.(2008) Departamento de engenharia mecânica da universidade de Wisconsin, Platteville, DOI: 10.1243/09544070JAUTO899.

MAIA, N. M: Introdução à Mecânica Analítica, IST Press

MCBEATH S., Equação da Regressão. Revista Racecar Engineering, IPC Media, Londres, Outubro 2009.

MILliKEN W. F. \& MILlIKEN D. L., Race Car Vehicle Dynamics, (890p) SAE R-146, ISBN: 978-0-7680-1127-2.

MILLIKEN W. F. \& MILLIKEN D. L., Chassis design - Principles and analysis, (638p) SAE R-206, ISBN: 978-0-7680-0826-5.

NEUREDER U. Dr. Ing., Internal material, Ford of Europe 2005, 2008. 
NOWLAND D., Simulating the Deltawing, Racecar Engineering magazine, june 2012 ISSN: 0961-1096.

NOWLAND D., Dynamics of the racecar, Racecar Engineering magazine, april 2011 ISSN: 0961-1096.

ORTIZ, M., To roll or not to Roll, RaceCar Engineering Magazine, december 2010, ISSN0961-1096.

PARRY-JONES R., Internal material, Ford of Europe 2005.

RYU, J., MOSCHUCK, N. K., CHEN, S., Vehicle State Estimation for Roll Control System, Proceedings of the 2007 American Control Conference Marriott Marquis Hotel at times Square New York City, USA, July 11-13, 2007

RAHNEJAT, H., Multi body dynamics vehicles, machines and mechanisms, (356p), SAE ISBN 0-7680-0269-9.

REIMPELL, J., STOLL, H., BETZLER J. W., The Automotive Chassis, SAE ISBN: 978-07680-0657-5.

RILL, G., Road Vehicle Dynamics fundamentals and modeling, CRC Press, 2012, ISBM: 978-1-4398-3898-3

SOCIETY OF AUTOMOTIVE ENGINEERS, Subjective rating scale for vehicle handling, J1441, SAE, 1998

SOCIETY OF AUTOMOTIVE ENGINEERS, Vehicle Dynamics terminology, J670e, SAE, 1952, last revised 1976.

SODRÉ, U., Transformadas de Fourier, Curso de ciências da computação 2003. 
WEISSTEIN, E. W., "Fourier Matrix." do MathWorld - A Wolfram Web Resource, site disponível em <http://mathworld.wolfram.com/FourierMatrix.html〉, acesso em 20 de julho de 2011.

WIDNALL, S., Energy Methods: Lagrange's Equations, MIT OpenCourseWare: Massachusetts Institute of Technology, MIT16_07F09_Lec20, 2009 Versão 3.0, site disponível em <http://ocw.mit.edu/courses/aeronautics-and-astronautics/16-07-dynamics-fall2009/lecture-notes/>, accesso em 13 de julho de 2012. Licença: Creative commons BY-NCAS. 


\section{Apêndice A - Vibrações do trem de força e a Dinâmica veicular}

Os amortecedores inerciais são empregados contra vibrações devidas a movimentos harmônicos. Grosso modo, eles são ajustados para que se movam fora de fase de uma frequência problemática de um sistema ou então amortecer uma frequência ressonante quais seriam inviáveis de se amortecer diretamente.

Traçando um paralelo com a automobilística, deve-se adicionar massa a um sistema que apresenta vibrações harmônicas como, por exemplo, um semieixo de transmissão ou uma árvore de transmissão. Essa massa extra faz com que a percepção da vibração devida à operação do componente seja minimizada. Outro ponto de vista é a adição de massa de modo a causar amortecimento ao sistema, como por exemplo, o amortecedor torcional do virabrequim de motores de ciclo alterando.

Como analogia elétrica, existe o circuito ressonante (circuitos LCR) cuja função é operar em uma única frequência determinada como, por exemplo, o circuito de um relógio de quartzo. Como ilustração, a figura81 a seguir representa um circuito RLC em série.

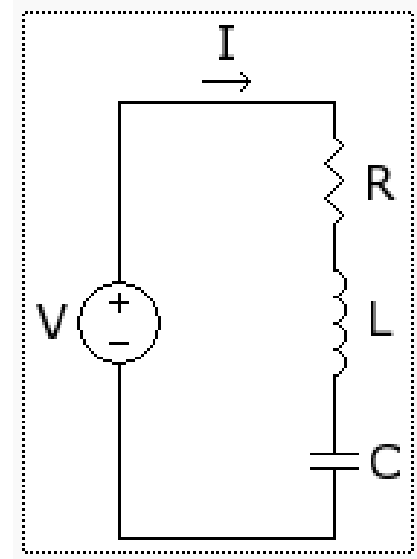

Figura 81 - Circuito RLC em série

\section{Onde:}

$\begin{array}{ll}\text { V } & \text { Tensão da fonte de força } \\ \text { I } & \text { Corrente da fonte de força } \\ \text { R } & \text { Resistência do resistor } \\ \text { L } & \text { Indutância do indutor } \\ \text { C } & \text { Capacitância do capacitor }\end{array}$


Fazendo uso desta analogia elétrica, pode-se apresentar o seguinte:

Equação diferencial que governa o movimento:

$$
F(t)=k \cdot x+c \cdot \dot{x}+m \cdot \ddot{x}
$$

Para o circuito elétrico emprega-se R,L,C:

$$
\vartheta(t)=\vartheta_{R}+\vartheta_{L}+\vartheta_{C}
$$

O conceito do fenômeno pode ser descrito da seguinte forma:

Dado um motor de massa $\mathrm{m}_{1}$ fixo ao solo através de seus coxins, ele vibra à medida que opera. Os coxins operam como molas paralelas e amortecedores $\mathrm{k}_{1} \mathrm{e}_{1}$. A força do motor nos coxins é F0. Uma massa menor $\mathrm{m}_{2}$ é adicionada através de coxins com $\mathrm{k}_{2} \mathrm{e} \mathrm{c}_{2}$, de modo a diminuir $\mathrm{F}_{0}$. Assim $\mathrm{F}_{1}$ é a resultante através da operação deste sistema (figura82).

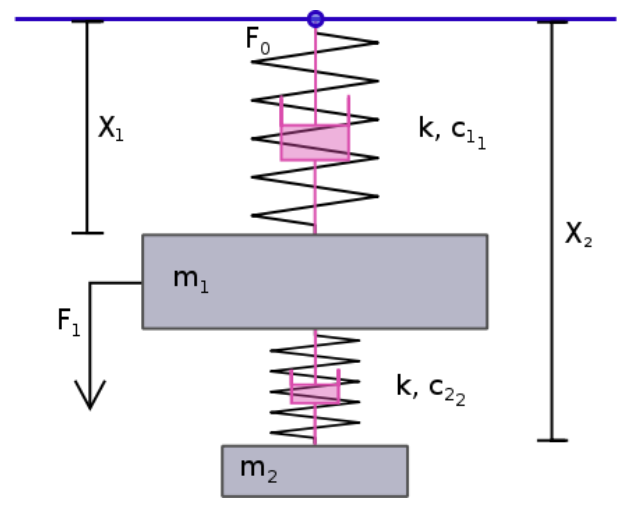

Figura 82 - Modelo simplificado

A resposta do sistema pode ser observada nas curvas das figuras 83 e 84 , sendo em vermelho com a massa e em azul sem a massa. O pico da resposta é bastante reduzido na frequência em que ocorre ressonância, porém existe incremento em outras frequências. Estes dois outros picos podem ser minimizados alterando-se a rigidez da mola/amortecedor $\left(k, c_{2} 2\right)$ ou então a distância entre eles através da massa $\left(\mathrm{m}_{2}\right)$.

Analisando os dois gráficos a seguir, temos a fase e a amplitude das massas no sistema. Sendo:

. Linha negra - massa m1 sem o amortecedor inercial.

. Linha azul - o movimento da massa para amortecimento.

. Linha vermelha - o movimento da massa primária. 


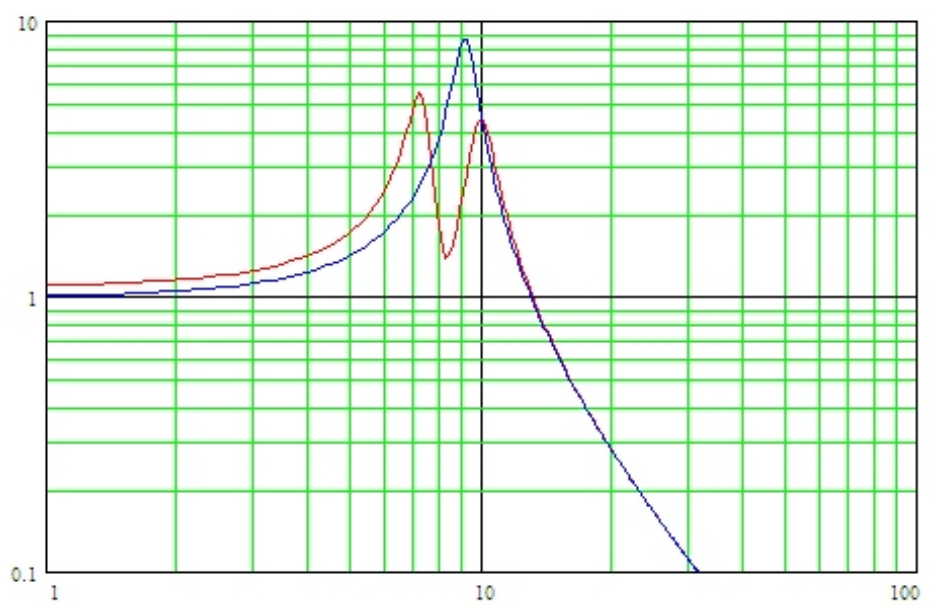

Figura 83 - Efeito do DMS num modelo simplificado de motor
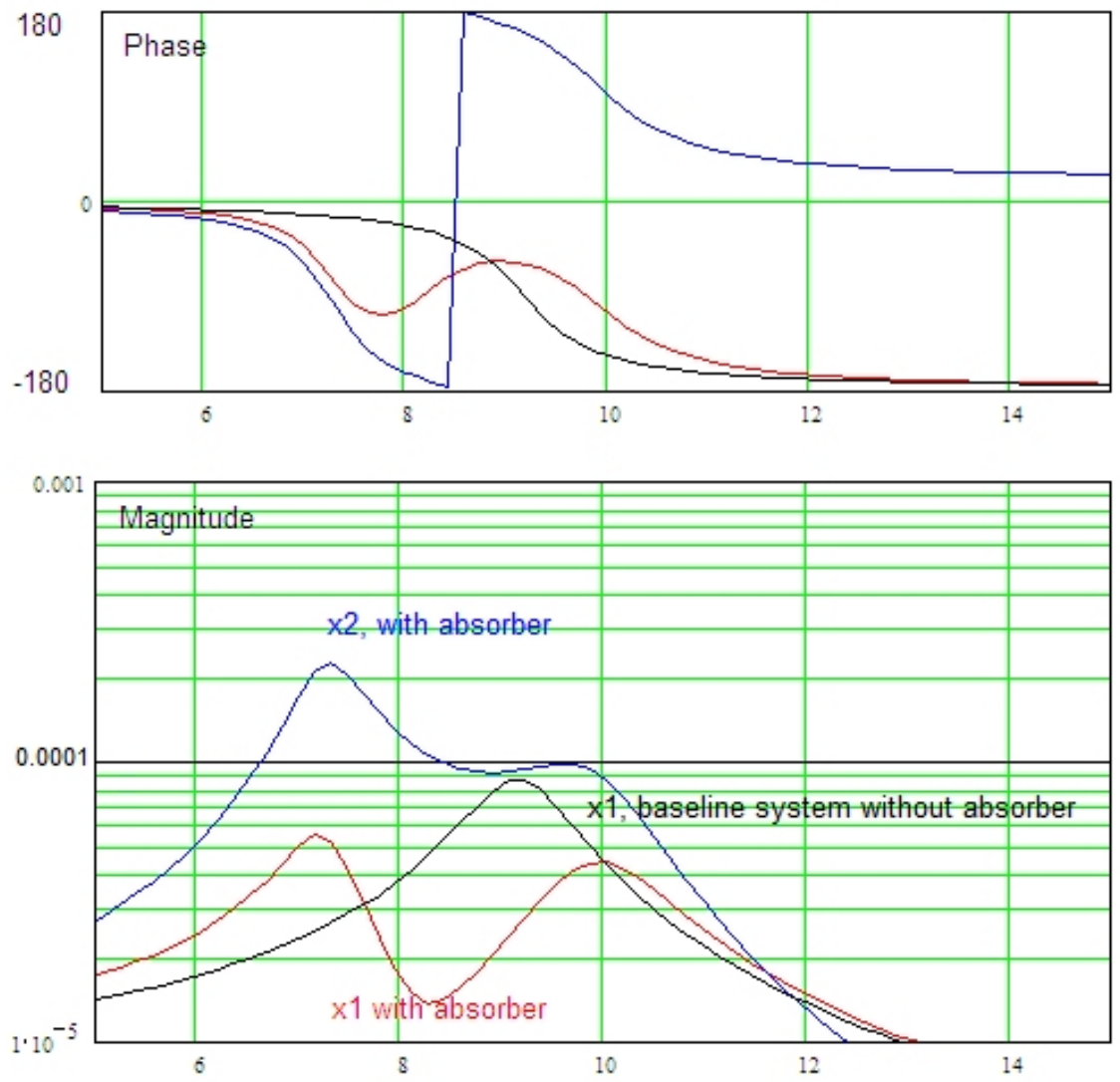

Figura 84 - Fase e magnitude do sistema de massas

No gráfico de amplitude, a massa $m_{2}$ apresenta ressonância muito maior que $m_{1}$. Para o gráfico de fases, em frequências baixas as massas estão em fase, à medida que as frequências de excitação aumentam, as massas fogem de fase até que ficam a $180^{\circ}$ uma fase da outra, neste ponto se observa o maior controle da vibração. 
Considerando um veículo automotor, a analogia se faz com a carroceria, a chamada massa suspensa e o trem de força que grosso modo pode ser chamado de massa suspensa na massa suspensa. Assim os coxins que sustentam o trem de força devem ser ajustados de modo que durante o uso do veículo, sua massa opere em fase oposta a alguma vibração mais significativa na carroceria, sendo essa vibração devida a alguma irregularidade de pista. Em adição, o próprio motor é fonte de vibrações devido ao seu funcionamento, estas vibrações também devem ser consideradas quando da especificação das rigidezes estáticas e dinâmicas e amortecimentos dos coxins.

Como citado anteriormente, na Formula1 um dispositivo de DMS foi empregado há algum tempo no bico de um dos protótipos para que apresentasse melhoria nas vibrações verticais, o dispositivo era ajustado para que em determinados eventos de pista o sistema massa / mola entrasse em contra fase com a vibração do eixo dianteiro e assim amortecesse a vibração dele, fazendo com que a força normal nas rodas permanecesse mais tempo constante e deste modo se aproveitar melhor a aderência potencial que o veículo poderia permitir se não tivesse a vibração.

No caso do veículo de Formula 1, o dispositivo pode ser visualizado conforme as ilustrações da figura 85 :

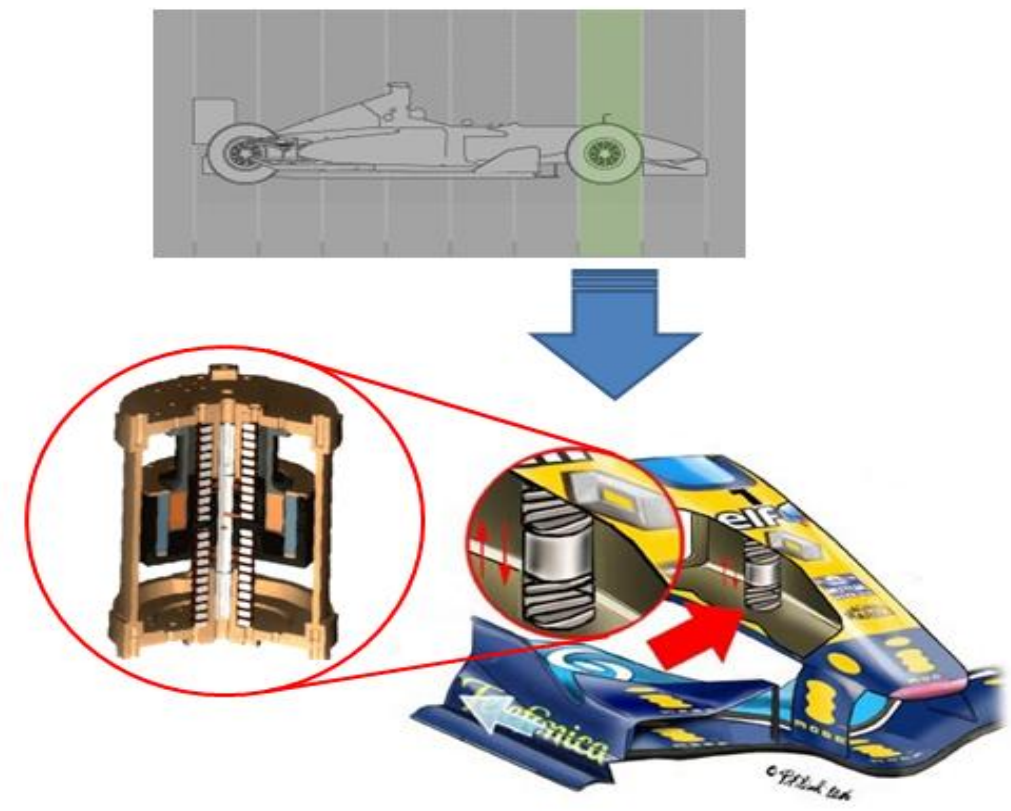

Figura 85 - Instalação de DMS em bico de carro de Formula1 


\section{Apêndice B - Amortecedores da suspensão}

Relembrando os direcionais dos estudos de Olley sobre conforto e estabilidade veiculares, à medida que se reduzia a rigidez da suspensão, tornava-se perceptível a necessidade de minimizar as oscilações da carroceria através de amortecimento e a melhor quantia desse amortecimento é o mínimo necessário para realizar o controle do veículo.

De acordo com Dixon, o propósito dos amortecedores é dissipar qualquer energia do movimento da carroceria e/ou rodas de modo a otimizar o controle para o comportamento dinâmico desejado.

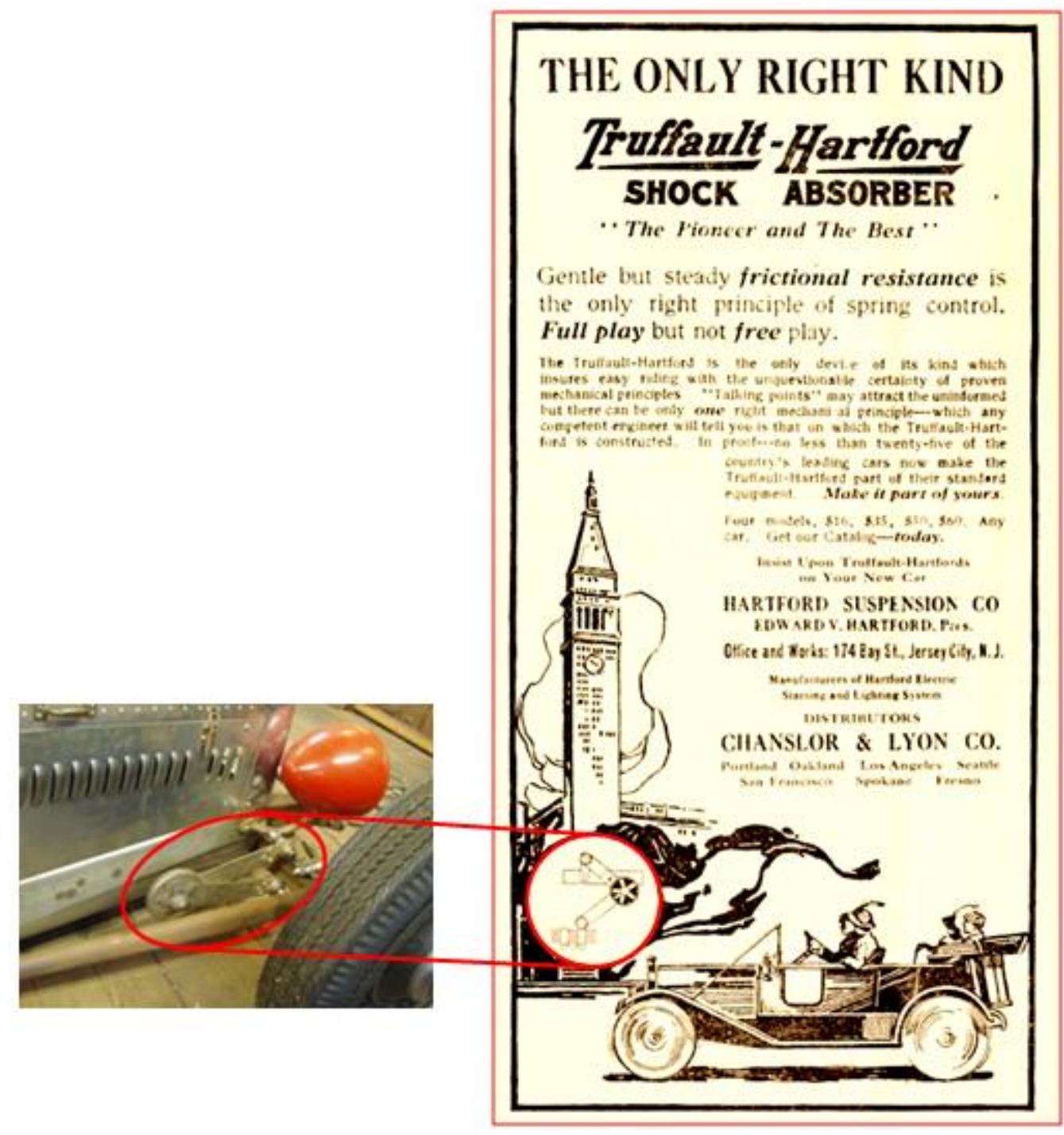

Figura 86 - Um dos primeiros sistemas de amortecedores a ser empregado em veículo 
A figura 86 acima apresenta um dos primeiros sistemas de amortecimentos a serem adaptados às suspensões automotivas de modo a incrementar a estabilidade assim como propiciar melhor controle das movimentações da carroceria.

Da equação diferencial da energia temos:

$$
F(t)=k \cdot x+c \cdot \dot{x}+m \cdot \ddot{x}
$$

Partindo de um modelo de quarto de carro, temos o seguinte modelo simplificado (figura 87):

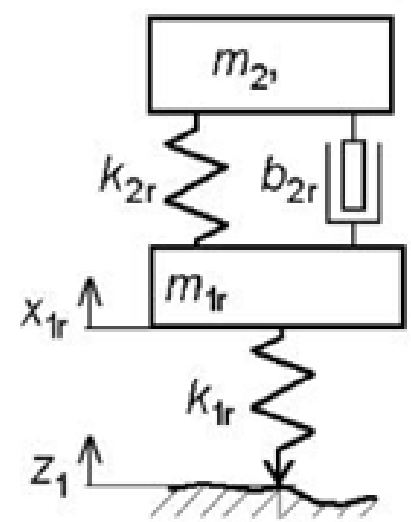

Figura 87 - Exemplo de modelo de quarto de carro

Assim temos as seguintes premissas para o amortecedor:

. Controlar movimentos de carroceria

. Controlar modos verticais das rodas

Do mesmo modo deve-se lembrar de que para todas as outras situações específicas existe um equilíbrio adequado de carga de amortecimento (compressão e tração), não permitindo que outras vibrações e asperezas surjam durante a direção.

A figura 88 apresenta uma típica curva de cargas de amortecimento, também conhecida como gráfico bolha, sendo o eixo horizontal correspondente ao deslocamento da haste, para movimentos de compressão e distensão, no eixo vertical as cargas de amortecimento para a compressão (positivas) e distensão (negativas) (figura89). Essa referência pode variar conforme a fonte de informações. 


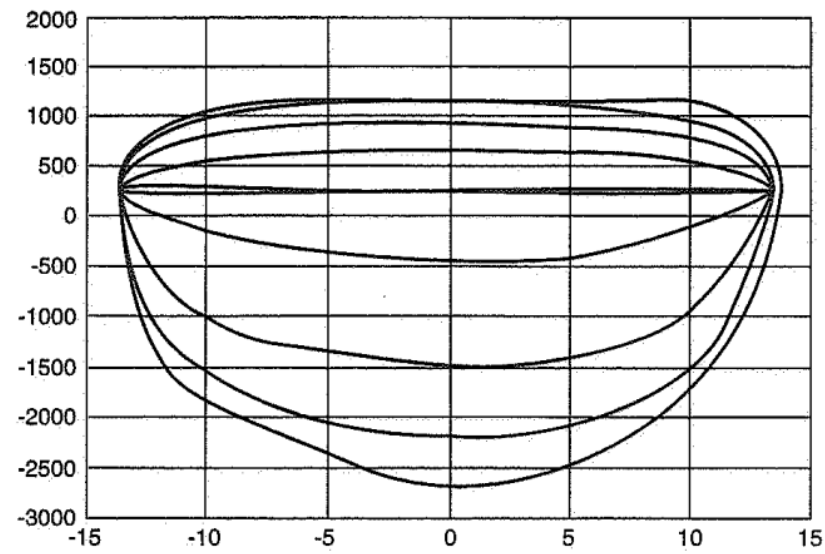

Figura 88 - Típico gráfico de forças de amortecimento

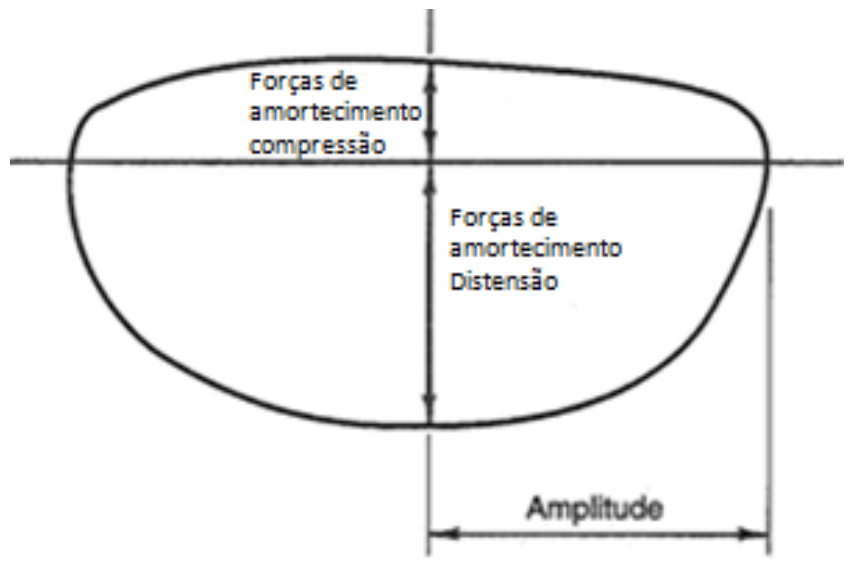

Figura 89 - Referências para a curva da figura 86

Essas curvas são apenas referências para a especificação das cargas necessárias em um veículo. O resultado final a ser homologado deve ser baseado em avaliações subjetivas dos atributos de ride assim como medições, tendo como exemplo as baseadas na norma ISO2361.

Tomando a figura abaixo como referência para o serviço de desenvolvimento, o seguinte pode ser verificado:

- Condições que implicam na necessidade de controle de carroceria apresentam frequências de operação baixas assim como as velocidades dos deslocamentos.

. Evitar situações que gerem movimentos abruptos de carroceria.

. Controlar modos verticais das suspensões, as vibrações livres entre as massas suspensas e não suspensas. 
Para a primeira condição é necessário grandes valores de amortecimento, para a segunda, pouco amortecimento e a terceira, novamente, maiores valores de amortecimento.

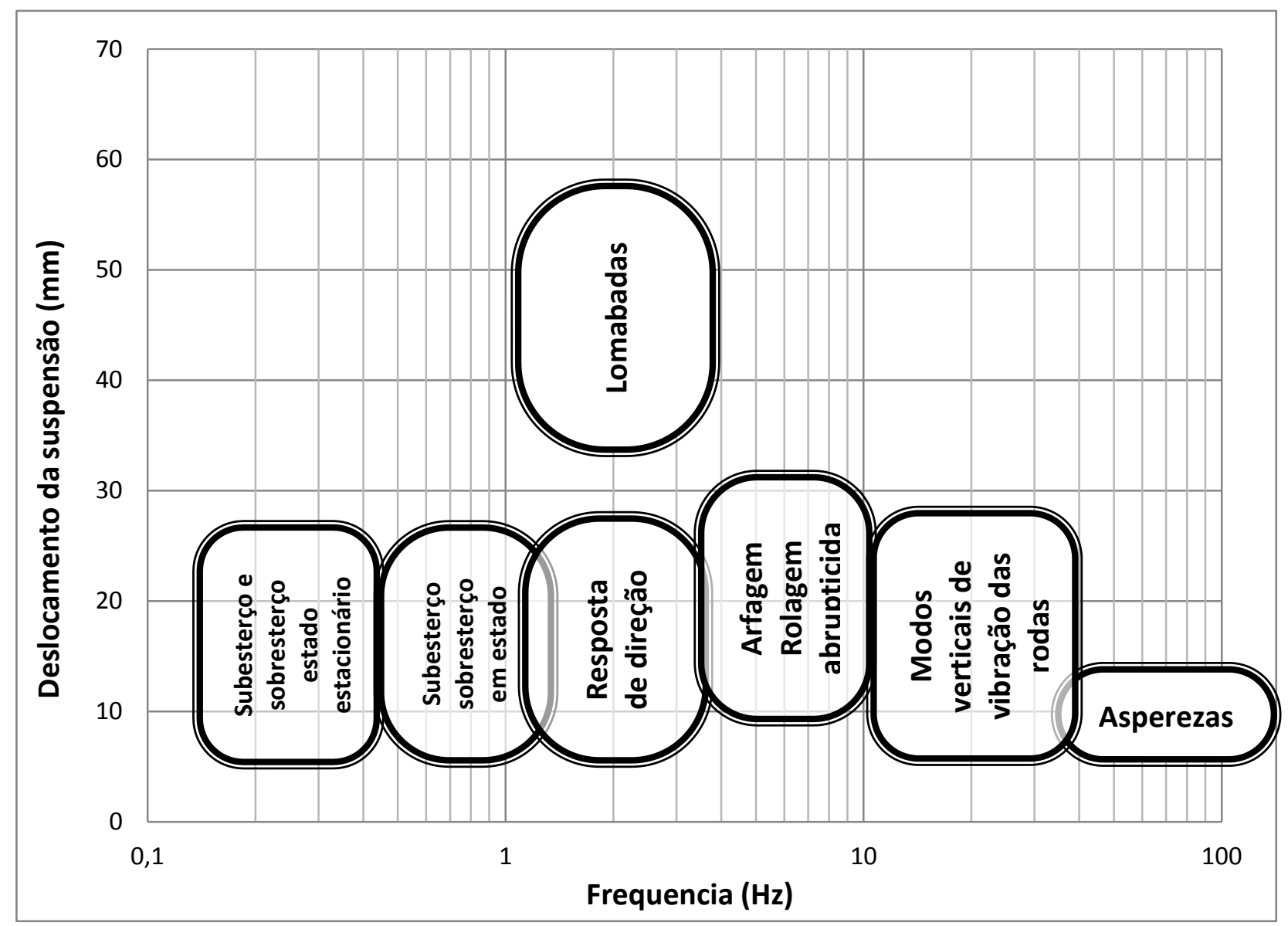

Figura 90 - Referência de manobras e entradas para a suspensão veicular

A figura 90 apresenta uma visão geral das características de deslocamento (curso) das suspensões e suas frequências de ride mais comuns. Quando se fala em asperezas, existe uma consideração relativa à operação dos amortecedores, eles são sensíveis a velocidade $(c \cdot \dot{x}$ da parcela do amortecimento na equação diferencial da energia). Deste modo para situações de asperezas que apresentem pequenos deslocamentos, deve-se trabalhar com isolamento elastomérico, ou seja, buchas e isoladores.

A figura 91 se refere a um sinal de vibração, considerando o ride, em harmônicas. Apenas como nota, o veículo apresenta um problema de modo de suspensão em cerca de 12hz. Mas para a situação de análise dos amortecedores, o seguinte pode ser citado: 
- Mesmo que o amortecedor apresente maiores forças de amortecimento, as harmônicas resultantes são mais baixas, resultando em menos vibrações e consequente melhoria no conforto.

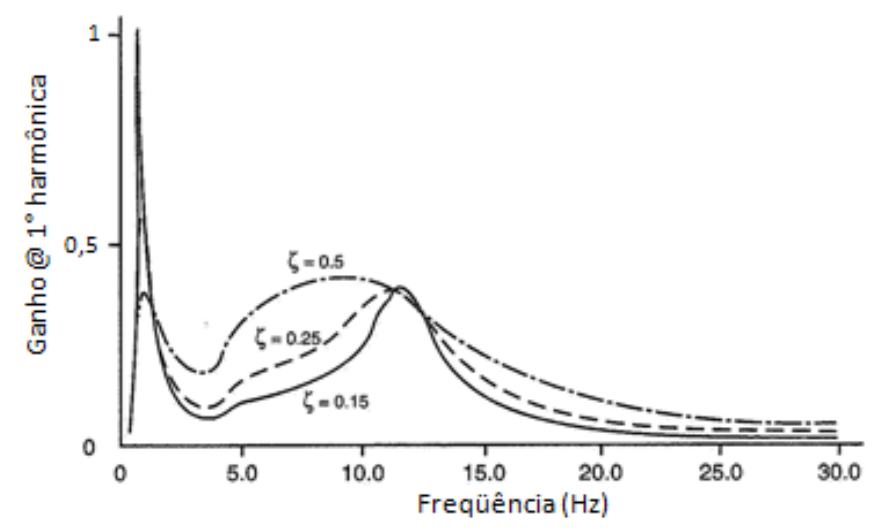

Figura 91 - Exemplo de PSD das harmônicas em uma suspensão

- Existe um valor de amortecimento adequado que maximiza o conforto para cada tipo de entrada de perturbação que a suspensão receba, sendo este valor de carga de amortecimento não muito alto, para que a energia do movimento seja dissipada gerando o mínimo de reação nas massas suspensas do veículo. Valores baixos significam a manutenção da perturbação e valores excessivamente altos significam que o amortecedor por si só torna-se uma fonte de perturbações. 